\section{2}

12

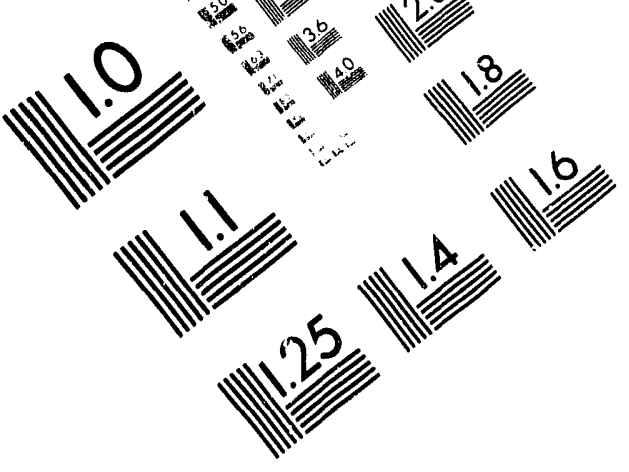

AlIM

Association for Information and Image Management

1100 Wayne Avenue, Suite 1100

Silver Spring, Maryland 20910

301/587-8202

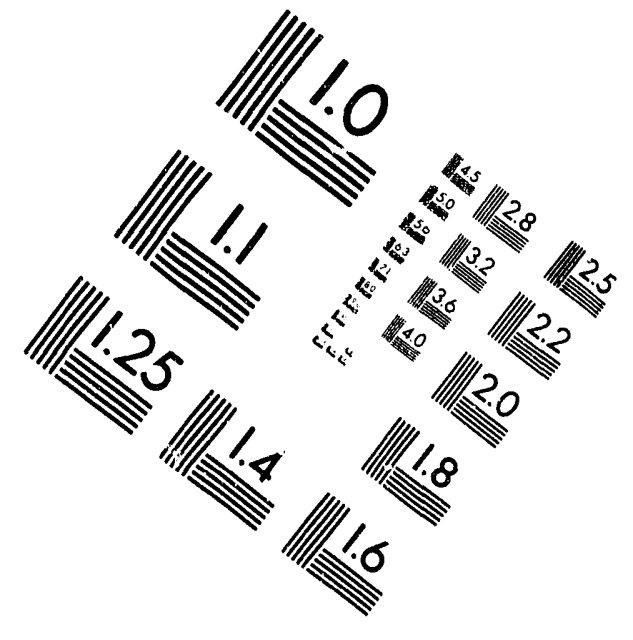

Centimeter

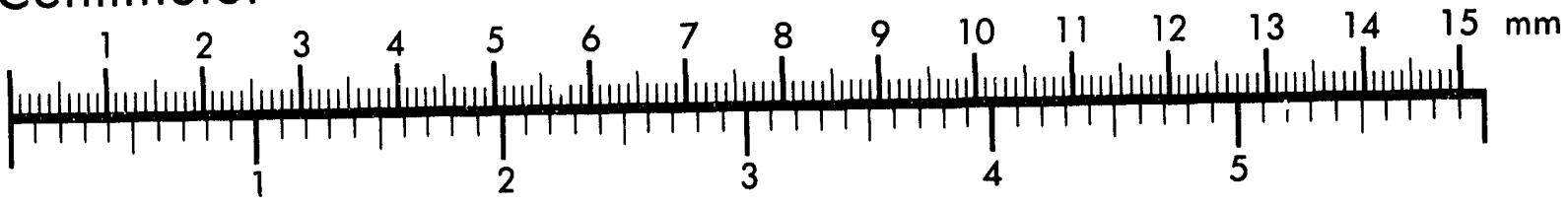
Inches
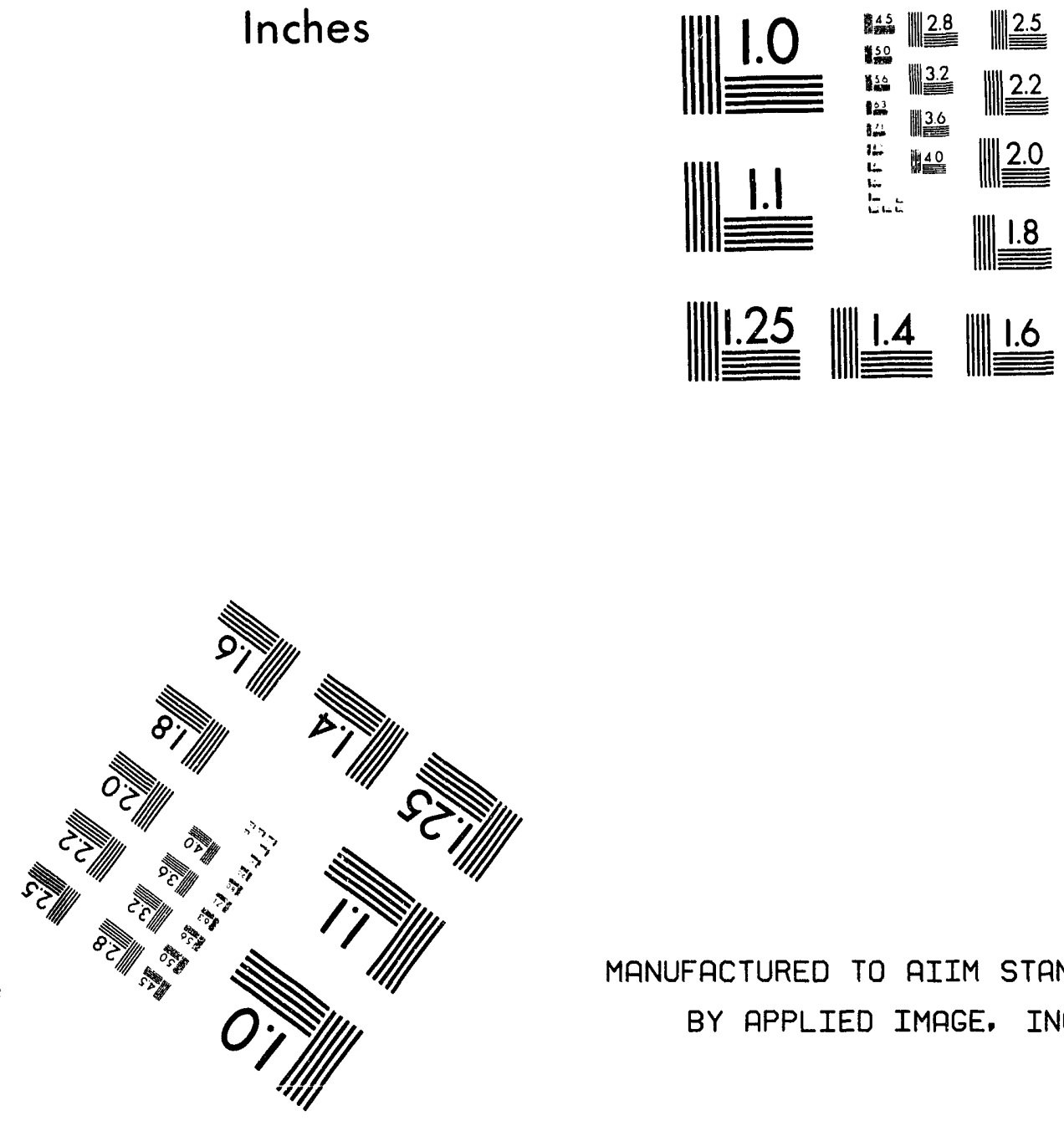

MANUFACTURED TO AIIM STANDARDS

BY APPLIED IMAGE, INC.

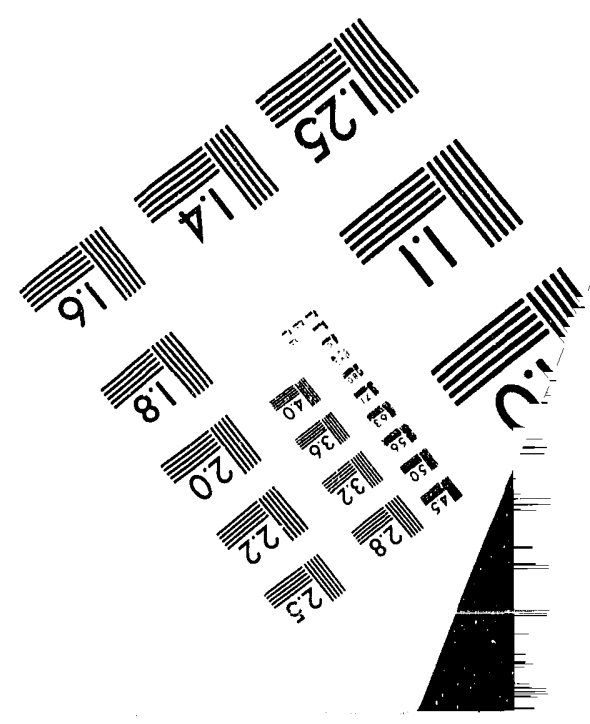



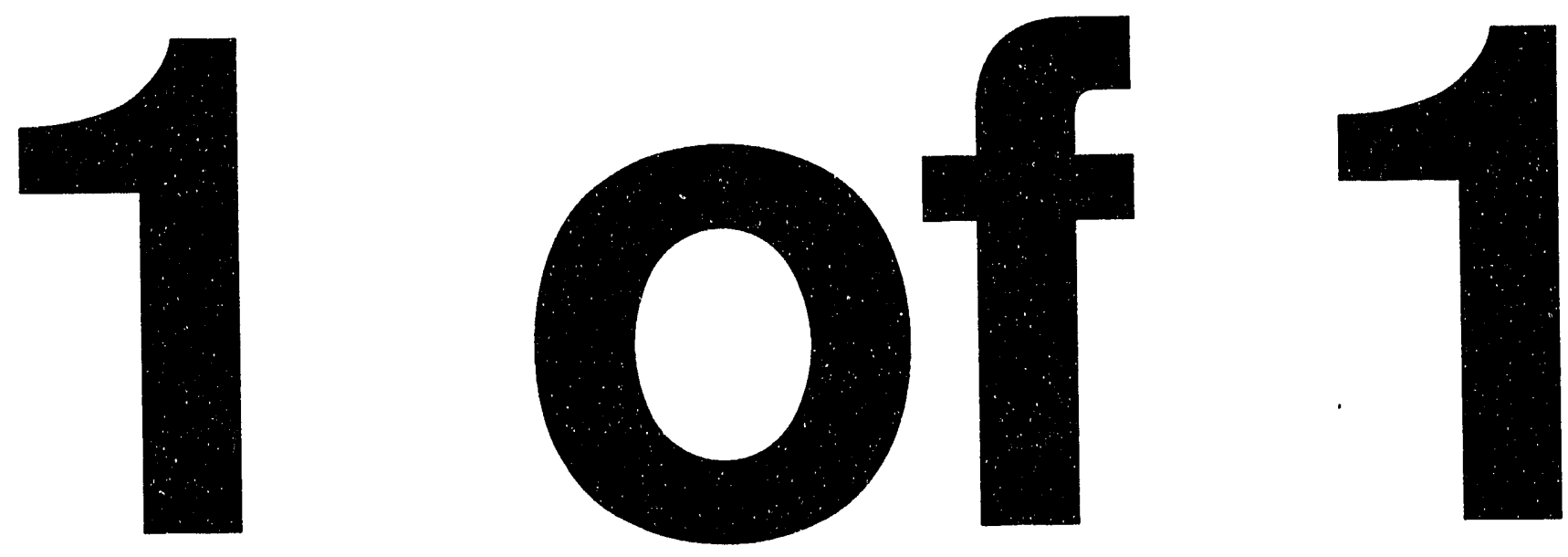
EGG-NRE-10722

WSRC-TR-93-187

Revision 0

Appendix SET-TMP-PT of the

Experiment Operating Specification for the Savannah River

One-Fourth Linear Scale, One-Sixth Sector,

Tank/Muff/Pump (TMP) Separate Effects Tests (SET)

Experiment Series

T. J. Boucher and J. L. Anderson (INEL)

J. S. Bollinger (WSRC)

J. D. Sterrett (Recce Engr. Assoc.)

Authors:

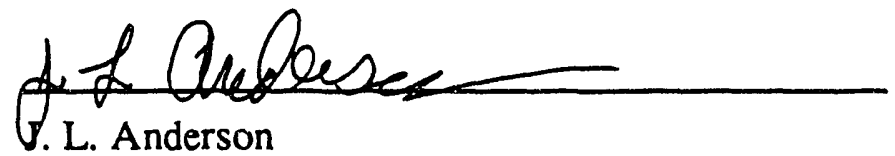

$\frac{5-21 \cdot 93}{\text { Date }}$

Authors: Inf. Boucher for f. S, Bollingen

$\frac{5-25-93}{\text { Date }}$

Authors: T. f. Boucher

$5 / 21 / 93$

T. J. Boucher

Date

Reviewed:

K. G. Condie, INEL SET Project Manager

$5 / 25 / 93$

Date

Approved:

CHechen

D. C. Mecham, Exp. Programs Unit Manager

$5 / 2193$

Date

MASTS: 
EGG-NRE-10722

WSRC-TR-93-187

Revision 0

\title{
Appendix SET-TMP-PT of the Experiment Operating Specification for the Savannah River One-Fourth Linear Scale, One-Sixth Sector, Tank/Muff/Pump (TMP) Separate Effects Tests (SET) \\ Experiment Series
}

by

\author{
J. S. Bollinger \\ (Westinghouse Savannah River Company) \\ J. D. Sterrett \\ (Reece Engineering Associates) \\ J. L. Anderson \\ T. J. Boucher \\ (Idaho National Engineering Laboratory)
}

May, 1993

\author{
Prepared for the \\ U.S. Department of Energy \\ Idaho Operations Office \\ Under DOE Contract No. DE-AC07-76ID01570 \\ and \\ Westinghouse Savannah River Company
}




\section{CONTENTS}

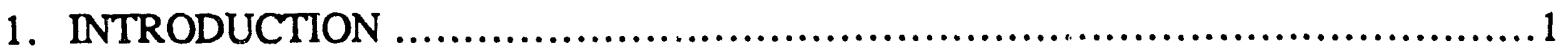

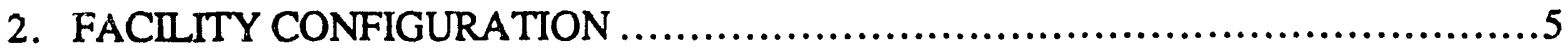

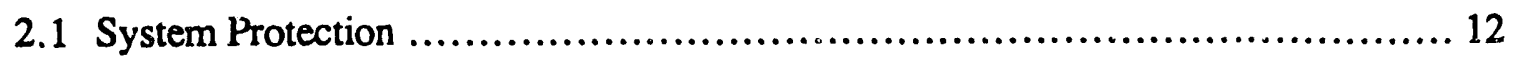

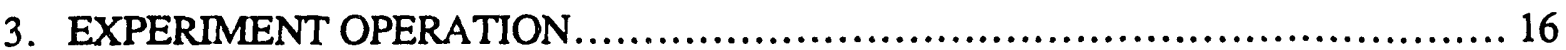

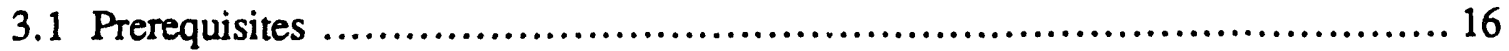

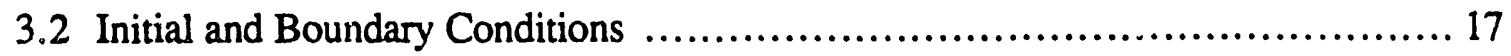

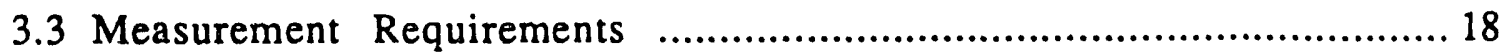

3.4 Measured or Computed Parameter Requirements ............................ 42

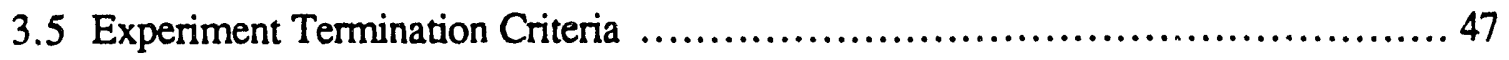

3.6 Post Testing Operational Checks.............................................. 47

3.7 Experiment Acceptance Criteria ............................................. 48

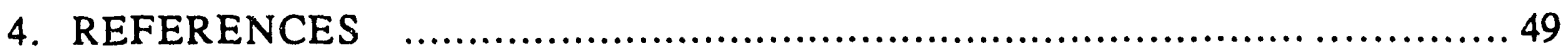

Appendix A - General Guidance for SET 1/4 Linear Scale Bingham Pump Single-Phase and Two-Phase, 'rwo-Component Complete Characterization Tests

Appendix B - Test Matrix Tables for SET Phase III Tests From NES-CDG-920181 . B-1

Appendix C - Test Matrix Tables for SET Phase III Tests From NES-CDG-920241, Revision 1 


\section{FIGURES}

1. SET Facility in the Tank/Muff/Pump Short Dischärge Configuration (Mod-TMPSD) for Pump/System Forward Flow Tests

2. SET Facility in the Tank Bypass Short Discharge Configuration (Mod-TBSD)

for Pump/Pump Suction Forward Flow Tests.

3. SET Facility in the Bingham Pump Reverse Flow Configuration (Mod-BPRF)

for Pump Reverse Flow Tests...................................................8

4. Piping and Instrumentation Drawing (PID) for INEL SET Facility in the

Tank/Muff/Pump Short Discharge (Mod-TMPSD) Configuration

5. Piping and Instrumentation Drawing (PID) for INEL SET Facility in the

Tank Bypass Short Discharge (Mod-TBSD) Configuration

6. Piping and Instrumentation Drawing (PID) for INEL SET Facility in the Bingham Pump Reverse Flow (Mod-BPRF) Configuration.

A-1. Complete Pump Characteristics for a Typical Double-Suction Centrifugal Pump

as Reported by A. J. Stepanoff

A-2. Example Pump Characteristic Curves Showing Relationship Between

Homologous Parameters and Stepanoff Curve (Figure A-1) Zones

A-3. Example Pump Homologous Heàd Curves Showing Relationship Between

Homologous Head Parameters and Stepanoff Curve (Figure A-1) Zones

A-4. Example Pump Homologous Torque Curves Showing Relationship Between

Homologous Torque Parameters and Stepanoff Curve (Figure A-1) Zones...

A-5. Skeleton Test Matrix for the Four Pump Characteristic Curve Quadrants. A-8

\section{TABLES}

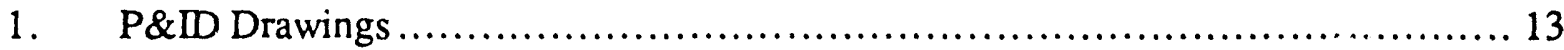

2. General System Configuration ........................................... 13

3. General Control System Configuration....................................... 14

4. General Configuration Drawings........................................... 14

5. Hydraulic Resistance Compensating Orifices for the SET Mod-TMPSD

Configuration .............................................................. 15

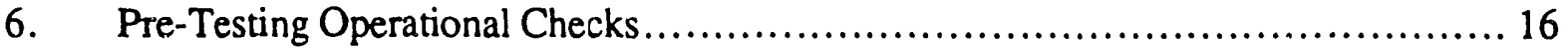

7. SET Tank/Muff/Pump Short Discharge (Mod-TMPSD) Experiment Instrumentation Grouped by Subsystem ..................................................... 19 


\section{TABLES}

8. SET Tank Bypass Short Discharge (Mod-TBSD) Experiment Instrumentation

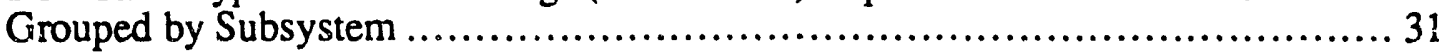

9. SET Bingham Pump Reverse Flow (Mod-BPRF) Experiment Instrumentation Grouped by Subsystem ..................................................... 37

10. Critical Parameters for SET-TMP-PT Single-Phase Bingham Pump Tests Grouped by Subsystem

11. Critical Parameters for SET-TMP-PT Two-Phase Bingham Puinp Tests

Grouped by Subsystem

12. Possible Methods of Obtaining Critical Parameters............................... 45

13. Post-Testing Operational Checks............................................. 47

A-1. Explanation of Stepanoff Curve Zones in Terms of Normalized Pump Homologous Parameters

A-2. Repeat Two-Phase Integral System Characterization with Pump Suction Air Injection Tests.

B-3. Single-Phase Liquid 1/4 Scale Formal Bingham Pump Quadrant One, Speed-to-Flow Ratio $\leq 1$ Tests.

B-5. Single-Phase Liquid 1/4 Scale Formal Bingham Purnp Free Rotor Hydraulic Characterization Tests....

C-1. Two-Phase Air-Water 1/4 Scale Formal Integral Tests - Pump Discharge Break with and without Simulated AC Pump Motor Trip.....................................

C-2. Controlled Drain Pump Discharge Break Formal Iritegral Tests..........................-4

C-3. Hold Point Pump Discharge Break Formal Integral Tests .........................

C-4. Controlled Drain Pump Discharge Break with De-energized Pump Motor Formal Integral Tests .

C-5. Hold Point Pump Discharge Break with De-energized Pump Motor Formal Integral Tests 


\section{INTRODUCTION}

This document is Appendix SET-TMP-PT of the Experiment Operating Specification (EOS) for the third set of experiments in the Savannah River One-Fourth Linear Scale, One-Sixth Sector, Separate Effects Tests (SET) experiment series. It contains information on experiment operation and facility configuration necessary to meet the key objectives stated in the tank-muff-pump onefourth linear scale Bingham pump formal test matrix definition letter[1]. In addition, general guidance is included to meet expanded objectives of providing complete characterization of the pump for all modes of operation (partially defined in a letter defining pump suction and maximum flow rate characterization tests[2]). Finally, information necessary to complete testing initiated as part of Phase II testing is also included[3 thru 6].

The Savannah River One-Fourth Linear Scale, One-Sixth Sector, Tank-Muff-Pump (TMP) Separate Effects Tests (SET) are being conducted by the Idaho National Engineering Laboratory (INEL) to investigate Savannah River Site (SRS) production reactor tank, muff, pump suction, and pump hydraulic response phenomena for large break loss-of-coolant accident (LBLOCA) scenarios. The test series consists of experiments representing a range of hydraulic conditions and geometries which bound those anticipated for LBLOCAs in SRS reactors. Data from these experiments will be examined to identify important hydraulic phenomena with the objective of providing data for benchmarking code calculations. Information obtained from the SET series will also expand the SRS data base on reactor LBLOCA events. Due to inherent scaling distortions and facility limitations, the results of experiments in the SET series will not be precise replications of full-scale Savannah River Site production reactor (SRSPR) response. The experiments will, however, provide hydraulic behavior sufficiently representative of full-scale SRSPR behavior to preserve important hydraulic phenomena and satisfy test objectives. Subsequent references in this document to simulating a full-scale SRSPR are restricted to the design of the experiment rather than the quantitative results expected.

The one-fourth linear scale Bingham pump will be characterized over a broad range of singlephase liquid and two-phase, two-component, air-water flow conditions in the SET-TMP-PT tests. Initial definition of Phase III testing needs focused primarily on pump characterization for SRS reactor prototypic conditions[1]. However, further consideration has resulted in a change in emphasis which puts greater focus on pump characterization for all modes of operation. Such testing will satisfy the requirements for SRS reactor prototypic condition pump characterization as well as provide a significant data base on scaled two-phase, two-component pump performance for all modes of operation. This data base will prove very beneficial for a wide range of applications 
including general thermal-hydraulic computer code pump modeling as well as SRS production reactor pump modeling.

The various modes of pump operation can be described in several manners. However, for Phase III pump testing, the typical centrifugal pump characteristics discussed by Stepanoff[7] will be utilized. Appendix A provides a brief description of the pump characteristics discussed by Stepanoff along with a brief discussion on the correlation of the Stepanoff curves to the general homologous pump curves and the homologous head and torque curves. As shown in Figure A-1, the various modes of operation have been identified by zone and lettered $A$ thru $\mathrm{H}$. The intent of Phase III pump testing will be to provide single and two-phase pump characterization for all modes of operation identified in the figure for a range of pump speeds, pump suction pressures and pump inlet volumetric flow qualities $(\beta)$. Based on the nomenclature identified in Appendix A, the following Bingham pump tests will be conducted as part of the SET-TMP-PT test series:

- Forward rotation, forward flow, normal pump (Zone A - positive head and torque) twophase pump characterization and formal tests. (This zone was well characterized for singlephase conditions during Phase II testing).

- Forward rotation, reverse flow, energy dissipation (Zone B - positive head and torque) single and two-phase pump characterization and formal tests.

- Reverse rotation, reverse flow, normal turbine (Zone C - positive head and torque) single and two-phase pump characterization and formal tests.

- Reverse rotation, reverse flow, energy dissipation (Zone D - positive head and negative torque) single and two-phase pump characterization and formal tests.

- Reverse rotation, forward flow, reverse rotation pump (Zone E - positive head and negative torque) single and two-phase pump characterization and formal tests.

- Reverse rotation, forward flow, energy dissipation (Zone F - negative head and negative torque) single and two-phase pump characterization and formal tests.

- Forward rotation, forward flow, reverse flow turbine (Zone G - negative head and negative torque) single and two-phase pump characterization and formal tests.

- Forward rotation, forward flow, energy dissipation (Zone $\mathrm{H}$ - negative head and positive torque) single and two-phase pump characterization and formal tests.

- Dead-head, forward rotation, no flow (boundary between zones A and B) and reverse rotation, no flow (boundary between zones $\mathrm{D}$ and $\mathrm{E}$ ) single-phase pump tests. 
- Locked-rotor, no rotation, forward flow (boundary between zones $F$ and $G$ ) and no rotation, reverse flow (boundary between zones B and C) single and two-phase pump tests.

- Zero head, forward rotation, forward flow (boundary between zones $A$ and $\mathrm{H}$ ) and reverse rotation, forward flow (boundary between zones $E$ and $F$ ) single and two-phase pump tests.

- Zero torque, forward rotation, forward flow (boundary between zones $\mathrm{G}$ and $\mathrm{H}$ ) and reverse rotation, reverse flow (boundary between zones $C$ and $D$ ) single and two-phase pump tests.

- Free-rotor (de-energized motor), forward flow single-phase pump formal tests.

- Simulated pump discharge break draindown formal tests with and without AC motor trip.

- Simulated pump discharge break draindown formal tests with pump motor de-energized (free rotor).

- Simulated pump discharge break single and two-phase hold point formal tests.

- Simulated pump discharge break single and two-phase hold point formal tests with pump motor de-energized (free rotor).

- Two-phase air-water pump suction pressure sensitivity characterization and formal tests.

As noted above, pump characterization and formal tests will be performed to determine whether the pump suction absolute pressure has a significant impact on pump performance. Tests conducted by Babcock and Wilcox Company (B\&W) for the Electric Power Research Institute (EPRI) for a 1/3-scale Bingham pump with air-water flow conditions incorporated extensive redundant tests at several pump suction pressures $[8,9]$. Suction side pressures in the B\&W tests ranged from 5 to 95 psig although most of the tests were performed at pressures exceeding 30 psig. B\&W test results indicated suction side pressure to have only second order impacts on twophase pump performance. This may not be the case, however with the 1/4-scale SET Bingham pump, which is a radial flow pump with a specific speed of $1176 \mathrm{rpm}(\mathrm{US} \mathrm{gpm})^{1 / 2} / \mathrm{ft}^{3 / 4}$ whereas the specific speed of the $1 / 3$-scale $B \& W$ pump was $4317 \mathrm{rpm}(\mathrm{US} \mathrm{gpm})^{1 / 2} / \mathrm{ft}^{3 / 4}$, characteristic of a mixed flow machine. Comparisons of EPRI pump test data at high specific speeds with the Semiscale test data (specific speed of $926 \mathrm{rpm}$ (US gpm) ${ }^{1 / 2} / \mathrm{ft}^{3 / 4}$ ) indicate that both single and twophase pump performance is significantly impacted by the specific speed of the pump[10]. Pump suction pressure characterization testing is therefore being performed in the SET-TMP-PT test program to provide adequate characterization of pressure sensitivities.

The SET-TMP-PT tests will be performed to thoroughly map pump performance as a function of the normalized total (air and liquid) flow rate, the normalized pump speed, and the volumetric 
quality of the suction-side flow in all four operating quadrants with the emphasis on quadrant one. The testing will include multiple homologous variable data points with the individual points being generated at different pump speed and flow rate conditions. These data will be used to determine whether two-phase pump performance follows the single-phase pump performance affinity relationships. Test points will be concentrated at values of the suction side volumetric quality at which pump head degradation and recovery are expected to occur. The volumetric quality of these tests points will be shifted as dictated by the results of the tests. Extensive tests have already been performed to characterize single-phase liquid pump performance for quadrant one. However, additional single phase tests will be performed in the remaining three quadrants to provide the complete single-phase homologous curves for utilization in analyzing the two-phase results.

An important objective of the tests will be to determine the flow regimes present in the entrance to the Bingham pump over the range of conditions tested since the two-phase air-water pump performance may change dramatically in transitioning from one flow regime to another.

A number of Phase II two-phase steady-state hold point tests will be repeated with the tank bypass, short pump discharge geometry (Mod-TBSD) and pump suction air injection. Data from these counterpart tests will be compared to the Phase II test results to investigate the sensitivity of the pump response to the method of air introduction and the pump suction and discharge geometries.

Tests will be performed with the pump rotor locked in place to characterize the single and twophase losses across the pump with flow in the normal direction. The pump geometry is such that the locked rotor resistance will be somewhat sensitive to the impeller position. Hence, the sensitivity to impeller position will be investigated by performing similar single-phase tests for several impeller positions. Also, the position of the rotor shaft (and therefore the impeller) will be noted for the locked rotor tests. Similar tests will involve de-energizing the Bingham pump motor and performing tests with the impeller free to rotate with single and two-phase normal pump flow. This data will be used to quantify the hydraulic resistance through the Bingham pump for both single and two-phase flow with the pump impeller free to rotate. The resulting data will be used to determine the pump hydraulic resistance so that ECS LOCA scenarios for the pump discharge break may be simulated in which both the $A C$ and DC pump drive motors have been shut down.

Second quadrant single-phase liquid test results will also be useful for analyzing the SRSPR pump suction break ECS LOCA scenario. The pump suction break ECS LOCA scenario involves a postulated pipe break at the pump suction flange such that the pump suction sees an atmospheric 
pressure boundary condition. The scenario would initially begin with the Bingham pump in $\mathrm{K}$ Reactor running at rated speed (AC motor operation). Following the pipe rupture, the system would rapidly depressurize and the moderator tank would drain. The discharge side of the pump on the ruptured pipe would see a time varying pressure boundary condition as the accident progressed. At some point in the scenario, the AC pump motor would be tripped off-line and the pump speed would decrease to approximately $1 / 3$ of the rated speed (DC motor operation). In simulating the pump suction break accident, it is critically important to accurately predict the break flow rates. This requires having homologous pump curves for the quadrant two energy dissipation (positive pump rotation with back flow through the pump) region which are currently unavailable for the Bingham pumps used in K-Reactor. Single-phase pump data will be taken for four normalized pump speeds $(\alpha)$ ranging from about 0.3 to about 1.0 and at normalized flow rates $(v)$ ranging from 0.05 to about 1.0 .

The remainder of this appendix is divided into two major sections. Section 2, "Facility Configuration," defines the required SET system configurations for the various SET-TMP-PT tests. The final section, "Experiment Operation," details system operational requirements for each set of SET-TMP-PT tests.

\section{FACILITY CONFIGURATION}

The facility configuration required for the pump characterization tests (SET-TMP-PT) is the One-Fourth Linear Scale, One-Sixth Sector Separate Effects Tests (SET) system in the Tank/Muff/Pump Short Discharge (SET Mod-TMPSD), Tank Bypass Short Discharge (SET ModTBSD) and Bingham Pump Reverse Flow (SET Mod-BPRF) configurations, as shown in Figures 1 thru 6. The SET facility is capable of simulating: a sector (one-sixth) of the L-Reactor moderator tank (including assemblies); an L-Reactor tank muff; an L-Reactor tank exit nozzle; LReactor pump suction piping (Systems 1, 5 or 6); an L-Reactor Bingham pump; and, L-Reactor pump discharge piping (System 5). With the exception of the Bingham pump all key components are constructed primarily from transparent materials which allow flow visualization. In the SET Mod-TMPSD configuration, the L-Reactor moderator tank, L-Reactor tank muff, L-Reactor tank exit nozzle, L-Reactor System 5 pump suction geometry, an L-Reactor Bingham pump and a portion of the first vertical section of the L-Reactor System 5 pump discharge geometry are simulated. A flow control valve is installed between the $1 / 4$ scale pump discharge vertical section termination point and the liquid storage tank. In the SET Mod-TBSD configuration, a portion of the L-Reactor System 5 pump suction geometry, an L-Reactor Bingham pump and a portion of the first vertical section of the L-Reactor System 5 pump discharge geometry are simulated. A flow 


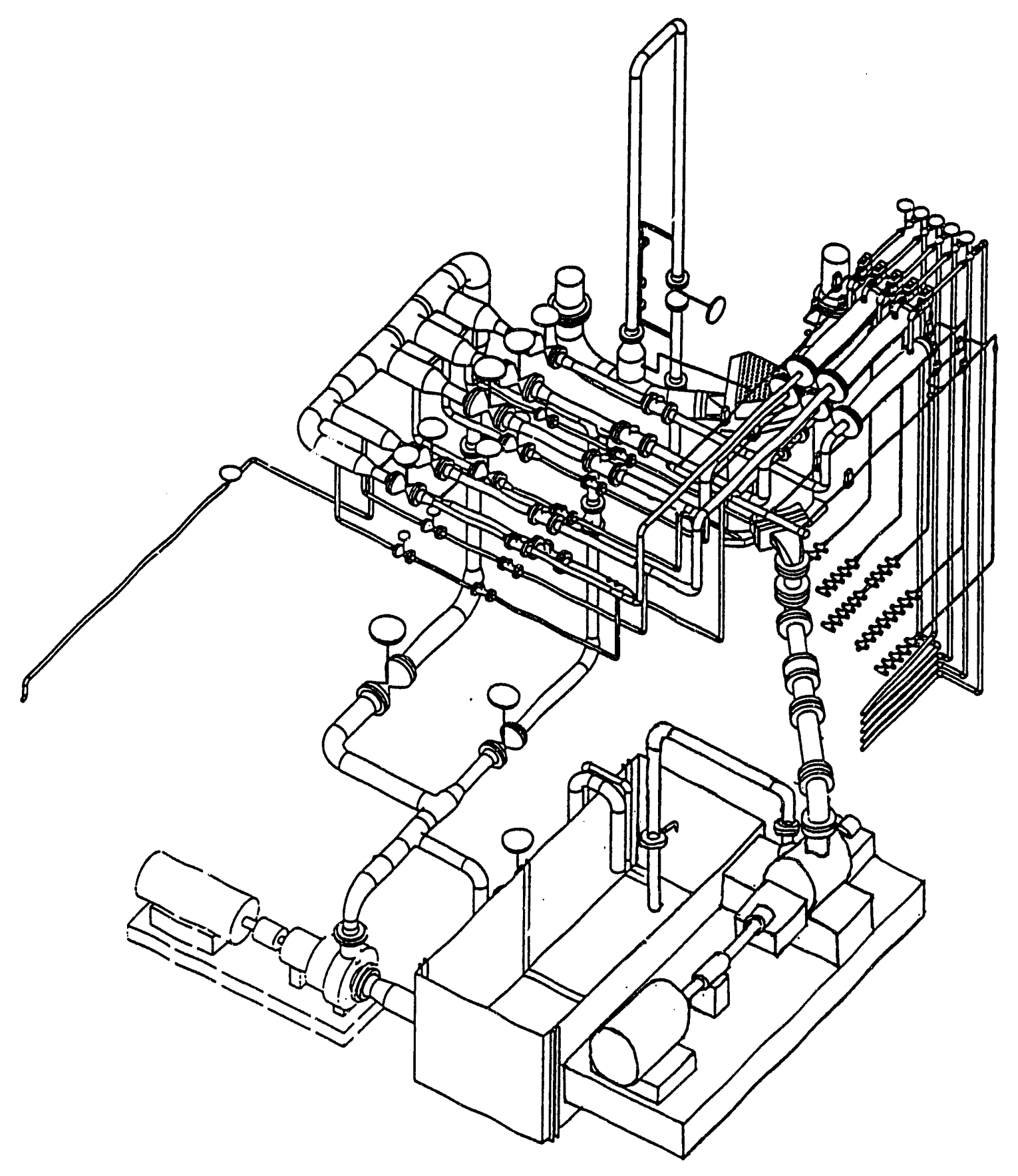

Figure 1. SET Facility in the Tank/Muff/Pump Short Discharge Configuration (Mod-TMPSD) for Pump/System Forward Flow Tests. 


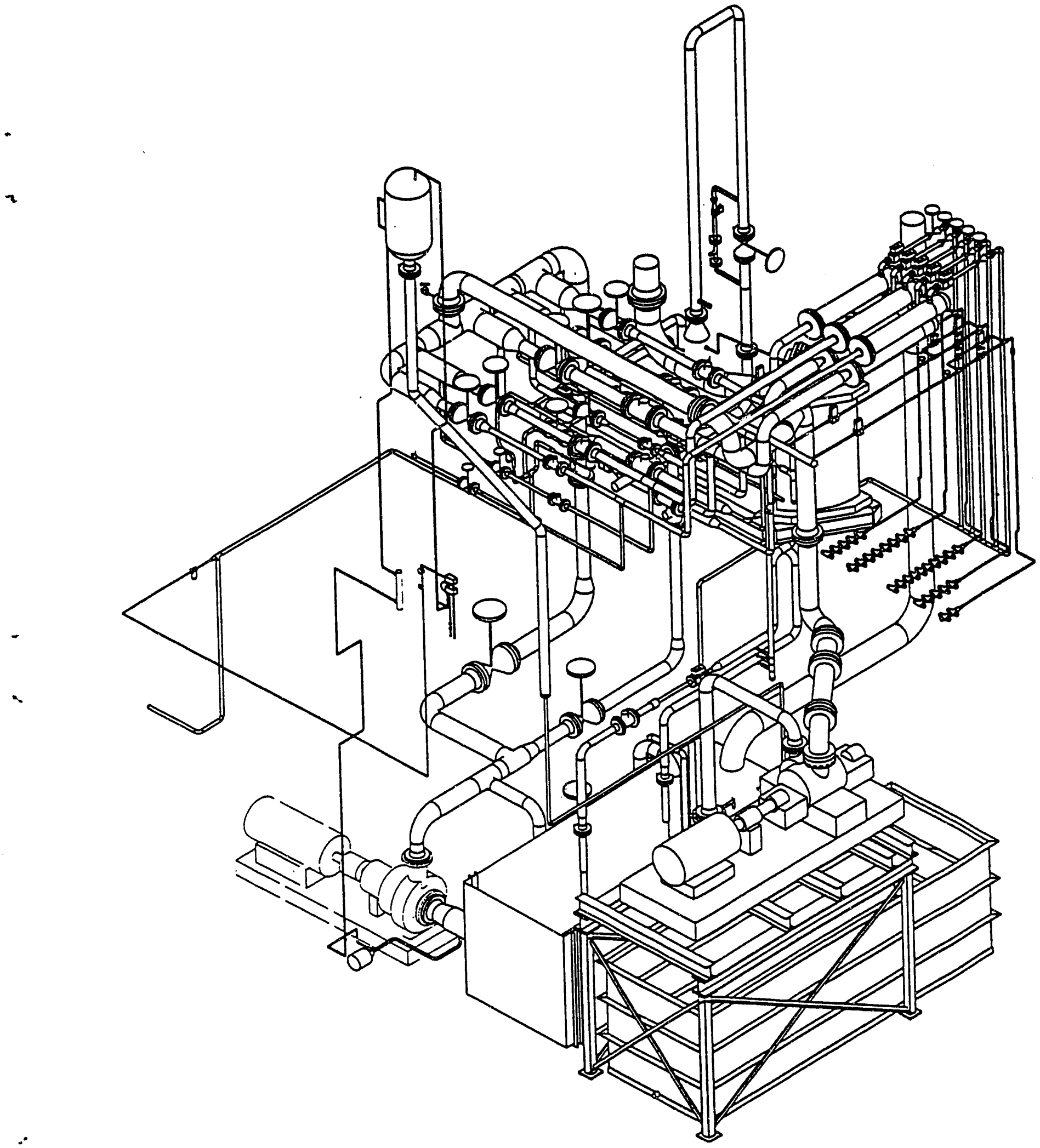

Figure 2. SET Facility in the Tank Bypass Short Discharge Configuration (Mod-TBSD) for Pump/Pump Suction Forward Flow Tests. 


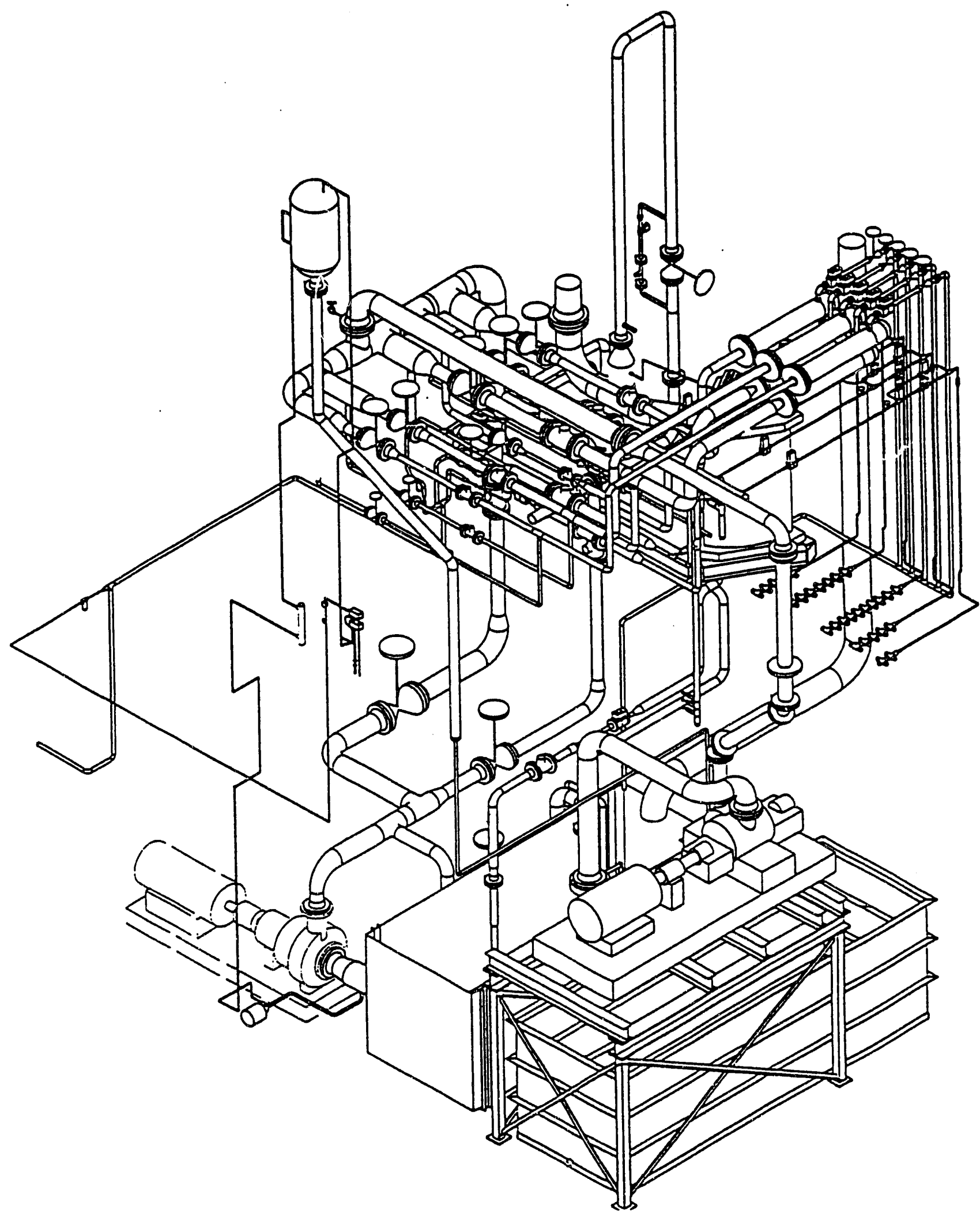

Figure 3. SET Facility in the Bingham Pump Reverse Flow Configuration (Mod-BPRF) for Pump Reverse Flow Tests. 


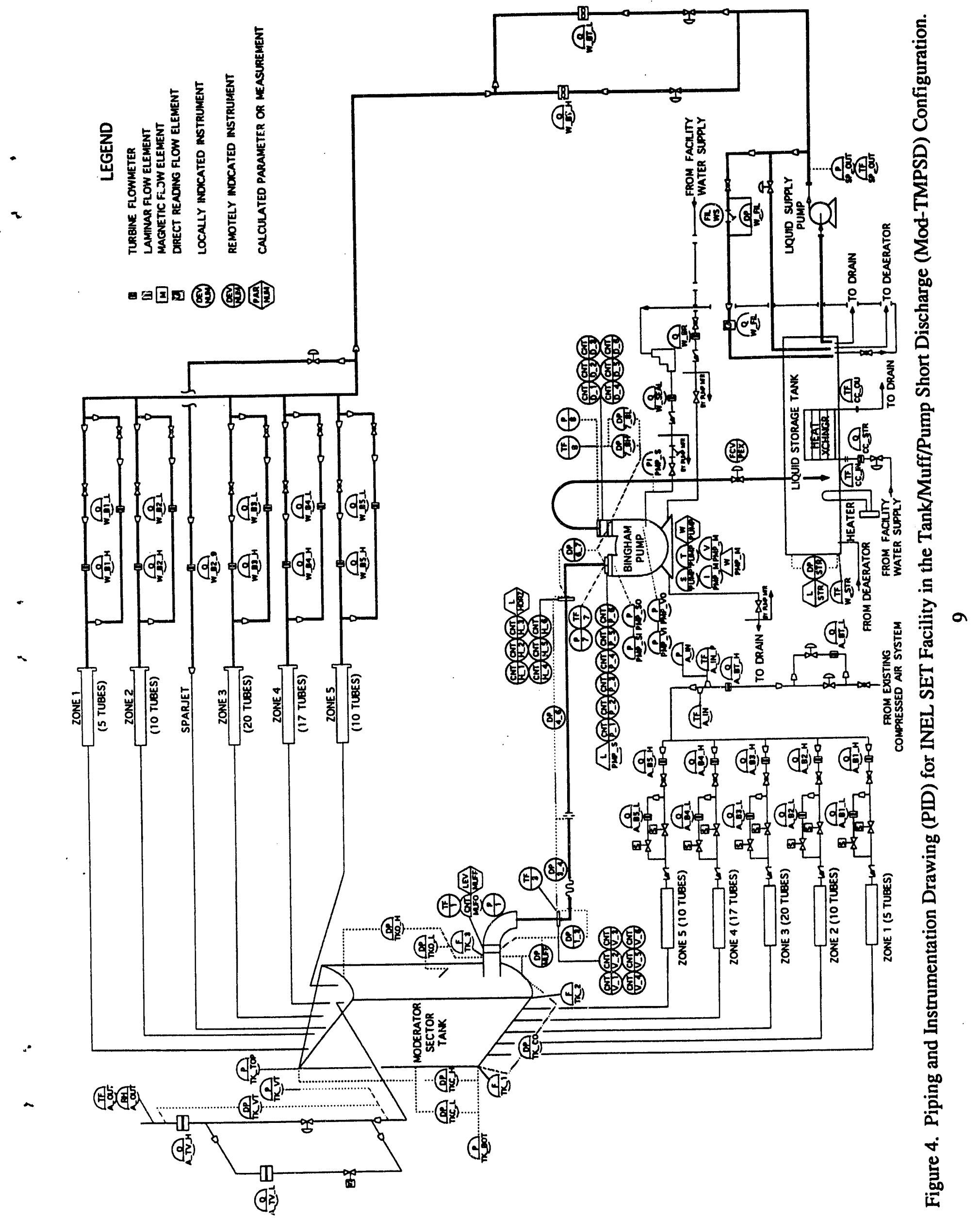




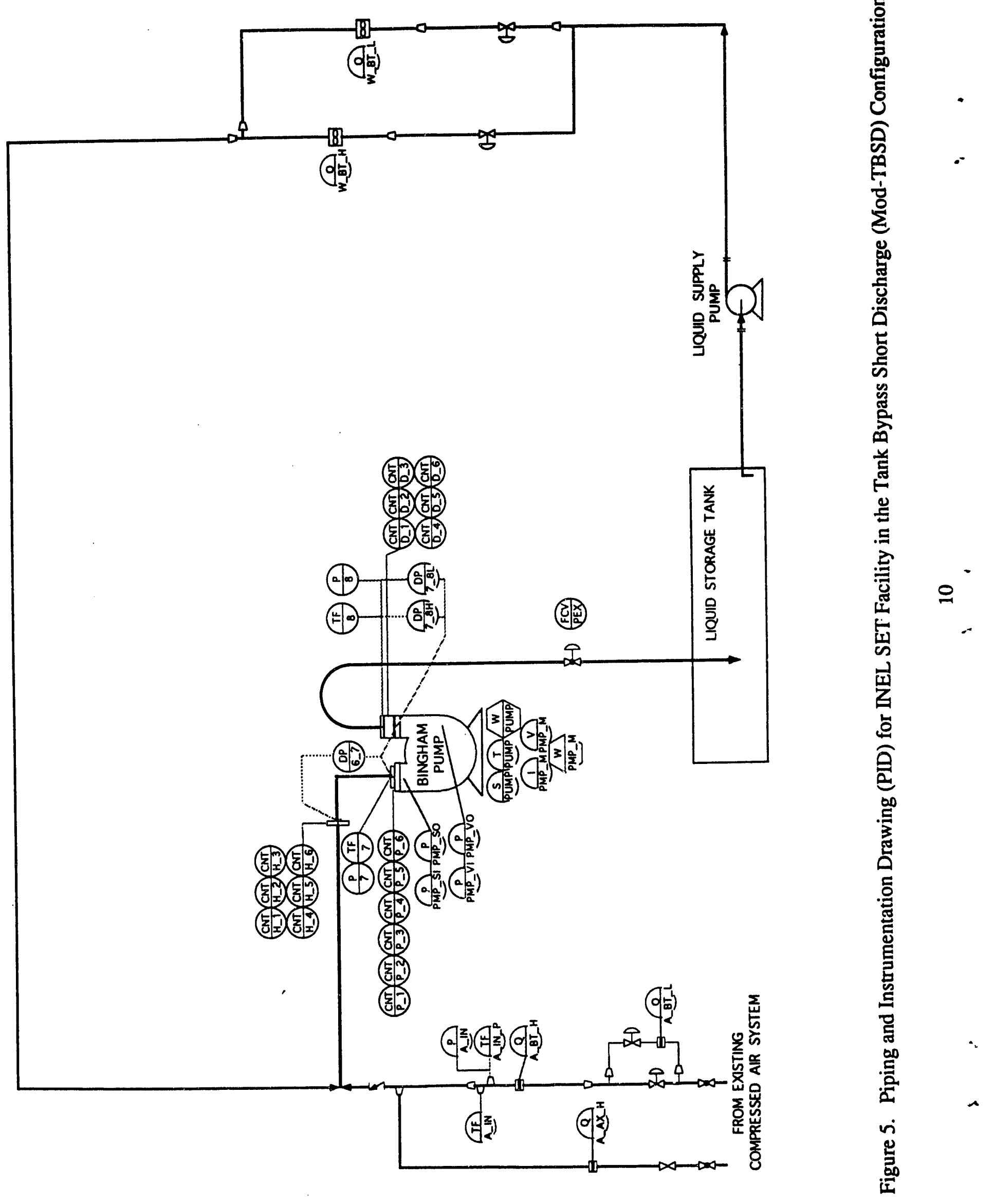




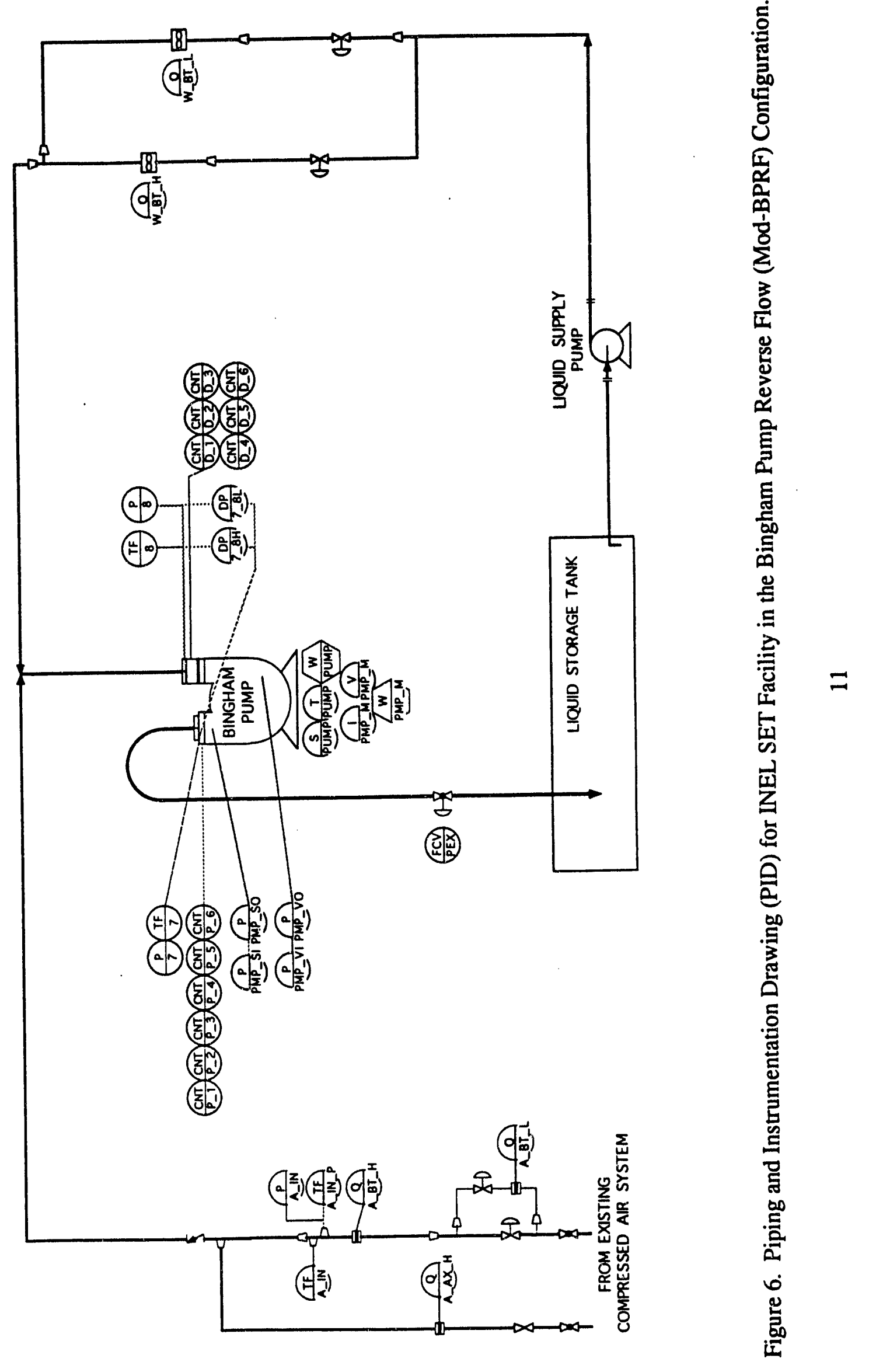


control valve is installed between the $1 / 4$ scale pump discharge termination point and the liquid storage tank. In the SET Mod-BPRF configuration the supply pump is connected to the scaled Bingham pump discharge in order to produce reverse flow through the pump. A flow control valve is installed between the $1 / 4$ scale pump suction termination point and the liquid storage tank. Basically, the SET facility consists of fluid systems (pipes, pumps, tanks, heat exchanger, heater, etc.), control systems (pumps, valves, and instrument air), and an experimental measurement system (transducers, amplifiers, digital data system). Further details of these subsystems may be found in Reference 11.

Table 1 lists the P\&ID drawings applicable to the SET-TMP-PT tests. The general system configuration for the SET-TMP-PT tests is outlined in Table 2. The configuration for the general control system is outlined in Table 3 and Table 4 lists the general configuration drawings for the SET-TMP-PT test configurations. Hydraulic resistance compensating orifices used for the tests are outlined in Table 5.

Additional system configuration requirements for certain pump modes of operation are:

- Pump motor wiring must be re-configured ( 2 of 3 phases reversed) for reverse rotation tests.

- A speed control device must replace the motor for pump turbining mode operations.

- A lever arm must be attached to the shaft to prevent rotation for pump locked rotor tests.

\subsection{System Protection}

The integrity of the SET facility for Phase III tests in the SET Mod-TMPSD configuration is preserved with rupture disks. The two rupture disks connected to the moderator sector tank provides sufficient pressure and vacuum relief capacity to protect the system. A drain is located in the test cell floor and all equipment in the test cell are located at an elevation above the floor and sufficiently remote from the moderator sector tank rupture disk piping to protect against water damage due to failure of moderator tank rupture disks.

The integrity of the SET facility for Phase III tests in the SET Mod-TBSD and Mod-BPRF configurations is preserved without rupture disks or relief valves. All three of these configurations are limited to test loop, scaled Bingham pump and supply system piping and do not include the moderator tank or transition elbow. Since the design pressures for the test loop, scaled Bingham pump and supply system piping are well above the dead head pressure of the liquid supply and $1 / 4$ linear scale Bingham pumps, no pressure protection is required. 
Table 1. P\&ID Drawings

Drawing Number Drawing Title 438994 1/4 Scale Separate Effects Test Piping and Instrumentation Diagram (Subset of Piping and Instrumentation shown on P\&ID)

\begin{tabular}{|l|l|}
\hline \multicolumn{2}{|l|}{ Table 2. General System Configuration } \\
\hline Basic Fluid System Configuration & $\begin{array}{l}\text { SET Mod-TMPSD, SET Mod-TBSD, } \\
\text { SET Mod-BPRF }\end{array}$ \\
\hline Major fluid systems used & $\begin{array}{l}\text { Test loop; liquid supply system; liquid injection } \\
\text { system; air supply system; air injection system }\end{array}$ \\
\hline Simulated Pump Suction Geometry & $\begin{array}{l}\text { System 5 (EG\&G Drawing 438933) for SET } \\
\text { Mod-TMPSD. Second horizontal and second } \\
\text { vertical sections of System 5 (EG\&G Drawing } \\
\text { 438933) for SET Mod-TBSD. Second vertical } \\
\text { section of System 5 (EG\&G Drawing 438933) } \\
\text { for SET Mod-BPRF. }\end{array}$ \\
\hline Simulated Pump & \begin{tabular}{l} 
1/4 linear scale Bingham pump for all tests. \\
\hline Simulated Pump Discharge Geometry
\end{tabular} \\
$\begin{array}{l}\text { First vertical section up to expansion joint of } \\
\text { System 5 (EG\&G Drawing 442955) for SET } \\
\text { Mod-TMPSD and SET Mod-TBSD. All } \\
\text { vertical and 45 sections up to entrance to } \\
\text { horizontal section of System 5 (EG\&G } \\
\text { Drawing 442955) for SET Mod-BPRF. }\end{array}$ \\
\hline
\end{tabular}




\section{Table 3. General Control System Configuration}

\begin{tabular}{l|l} 
General Control System Configuration & SET Mod-TMPSD, SET Mod-TBSD, SET
\end{tabular} Mod-BPRF

Major control systems used Liquid storage tank heater, liquid storage tank heat exchanger, liquid supply pump speed; liquid supply bypass flow; air supply system flow; $1 / 4$ scale Bingham pump speed; $1 / 4$ scale pump discharge exit flow.

\begin{tabular}{|c|l|l|}
\hline \multicolumn{3}{|c|}{ Table 4. General Configuration Drawings } \\
\hline $\begin{array}{c}\text { Drawing } \\
\text { Number }\end{array}$ & Revision & \\
\hline 438042 & & Moderator Tank Front Panel Assembly \\
\hline 438046 & & Moderator Tank Side Panel Assemblies \\
\hline 437726 & & Moderator Tank Tube Assembly and Detail \\
\hline 438918 & & Moderator Tank Angle Assemblies and Details \\
\hline 438919 & & Moderator Tank Angle Assembly and Details \\
\hline 438929 & & Pipe Spool Assemblies \\
\hline 438933 & & Loop 5 with Pump Piping Installation \\
\hline 438936 & & Transition Elbow Assembly \\
\hline 436299 & & Muff Assembly \\
\hline 438928 & & Elbow Assemblies \\
\hline 439003 & & Air Manifold Assemblies \\
\hline 439031 & & Water Manifold Assemblies \\
\hline 439032 & & Water Manifold Assemblies \\
\hline 438907 & & Water Storage Tank Assembly \\
\hline 438938 & & Muff Storage Cask and Source Holder Assemblies and Details \\
\hline 432982 & & Muff Densitometer Wafer Assembly \\
\hline 439043 & & 6 " Wafer Densitometer \\
\hline 439045 & & 5 " Wafer Densitometer \\
\hline 439044 & & 4 " Wafer Densitometer \\
\hline 442955 & & Pump Discharge Spool and Elbow Arrangement \\
\hline 442956 & & Pump Discharge Spools and Flange Details \\
\hline 442957 & & Pump Discharge Elbows \\
\hline
\end{tabular}


Table 5. Hydraulic Resistance Compensating Orifices for the SET Mod-TMPSD Configuration

Loop Isolation Valve Simulator:

Orifice ID

$13.84 \mathrm{~cm}$ (5.45 inches)

Part No.

$438926-10$

Geometry

Square Edged

Simulated Loop Isolation Valve

.1285

Full Open Loss Factor (K)

Calculated Orifice Loss Factor (K) 


\section{EXPERIMENTOPERATION}

This section provides the detailed operating requirements for the SET-TMP-PT tests. Included are prerequisites (pretest activities), test matrices (boundary and initial conditions), and required measured or computed parameters.

\subsection{Prerequisites}

Operations to be performed prior to initiating tests each day are listed in Table 6.

\section{Table 6. Pre-Testing Operational Checks}

1. Check liquid levels - drain conditions

2. Check densitometers - drain conditions

3. Leak check - liquid full conditions

4. Check liquid levels, densitometers - full conditions

5. Flow checks - well bled/vented liquid full condition

\section{Items To Be Checked}

$1 / 4$ scale pump suction piping. $1 / 4$ scale pump discharge piping.

Horizontal section of $1 / 4$ scale pump suction piping.

Second vertical section of $1 / 4$ scale pump suction piping.

First vertical section of $1 / 4$ scale pump discharge piping.

$1 / 4$ scale pump suction piping, $1 / 4$ scale pump discharge piping, liquid storage tank, liquid supply system and separator standpipe system.

Same items as checked in 1 and 2 above.

Turbine flowmeters, thermal mass flowmeters, differential pressures.

In addition to the daily pre-testing operational checks, water quality checks should be made periodically with a surface tensiometer and precision hydrometers to ascertain the surface tension and specific gravity, respectively for the water in the storage tank. As a minimum, the checks should be made whenever the liquid storage tank inventory is replaced or the storage tank liquid temperature is changed for a series of tests. 


\subsection{Initial and Boundary Conditions}

The initial and boundary conditions for the SET-TMP-PT tests are outlined in References 1 thru 4 and on the test matrix tables shown in Appendices B and C.

Appendix A contains the general guidance for single-phase and two-phase pump characterization tests which satisfy the key objectives stated in References 1 and 2 (including pump suction air injection counterparts to Phase II moderator tank assembly air injection and air aspiration tests) as well as the expanded objectives of providing complete characterization of the pump for all four quadrants as follows:

- The key variables for these tests will be pump speed, total volumetric flow rate, pump inlet volumetric flow quality $(\beta)$, and pump inlet pressure.

- Testing will be performed for a range of pump speeds such that normalized speeds $(\alpha)$ ranging from about 0.1 to about 1.2 are adequately characterized to ascertain pump speed sensitivities.

- Testing will also be performed for a range of pump inlet volumetric flow qualities $(\beta)$ ranging from 0 to about 0.9 to characterize pump degradation and pump resistance characteristics with the major emphasis on qualities in the region of rapid pump head degradation. The volumetric flow quality for the two-phase air injection tests is defined as $\beta=\left[Q_{\text {air }} /\left(Q_{\text {liquid }}+Q_{\text {air }}\right)\right]$ where the air density is based on pump inlet conditions $P_{-} 7$ and TF_7 for forward flow tests and P_8 and TF_8 for reverse flow tests).

- Pump inlet pressures ranging from about 125 to about $300 \mathrm{kPa}$ will be investigated to characterize pump inlet pressure sensitivity effects.

- Testing will be reviewed, modified and performed as necessary to provide adequate characterization of the $1 / 4$ scale Bingham pump for all modes of operation under single and two-phase conditions, including pump speed and pump inlet pressure sensitivity effects. Test results will be reviewed on a weekly basis to ascertain additional data needs to complete the characterization tests. The results of the review will provide a basis for testing performed in the following week.

- For tests requiring reverse pump rotation, pump motor wiring will be re-configured ( 2 of the 3 phases reversed) to drive the pump in reverse rotation. 
- For tests requiring turbining mode operation of the pump, the purap motor will be removed and the pump will be connected to a speed control device.

- For tests investigating pump locked rotor characteristics, rotation is prevented by attaching a lever arm which locks the pump shaft thereby preventing rotation of the pump impeller. The position of the rotor shaft will be noted.

Appendix B (Tables B-3 and B-5) contains single-phase pump tests identified in Tables 3 and 5 of Reference 3 which were originally specified as part of Phase II testing but had to be delayed until Phase III due to limitations in achieving the specified conditions in the Phase II configuration. Forward and reverse flow locked rotor resistance and zero head and torque tests identified in Reference 3 will be performed as part of the single-phase pump characterization testing. Tests which address the conditions and objectives specified in Reference 3, Tables 4 and 6 will be performed under a different nomenclature which will be identified in posttest reports.

Pump discharge break studies originally identified in Reference 4 as part of Phase II testing were also delayed until Phase III due to Phase II configuration limitations on achieving specified conditions. These tests are identified in Appendix C (Tables $\mathbf{C}-1$ thru C-5) for inclusion in Phase III testing.

The ranges of variables identified for tests identified as additional characterization tests in Reference 2 (Tables 1 thru 5) will be adequately covered as part of the two-phase pump characterization testing. Tests which address the conditions and objectives specified in the reference tables will be performed under a different nomenclature which will be identified in posttest reports.

\subsection{Measurements Requirements}

This section contains the overall requirements for experimental measurements for the SETTMP-PT Phase III pump characterization tests. Tables 7, 8 and 9 contain the desired instruments, grouped by subsystem, for tests using the tank/muff/pump short discharge (ModTMPSD, Figures 1 and 4), tank bypass short discharge (Mod-TBSD, Figures 2 and 5) and the Bingham pump reverse flow (Mod-BPRF, Figures 3 and 6) geometries, respectively. Information given includes the measurement type and location, measurement range, and the manufacturer specified accuracies. These manufacturer specified accuracies should not be considered the measurement uncertainty. Actual measurement uncertainties will be included in the 


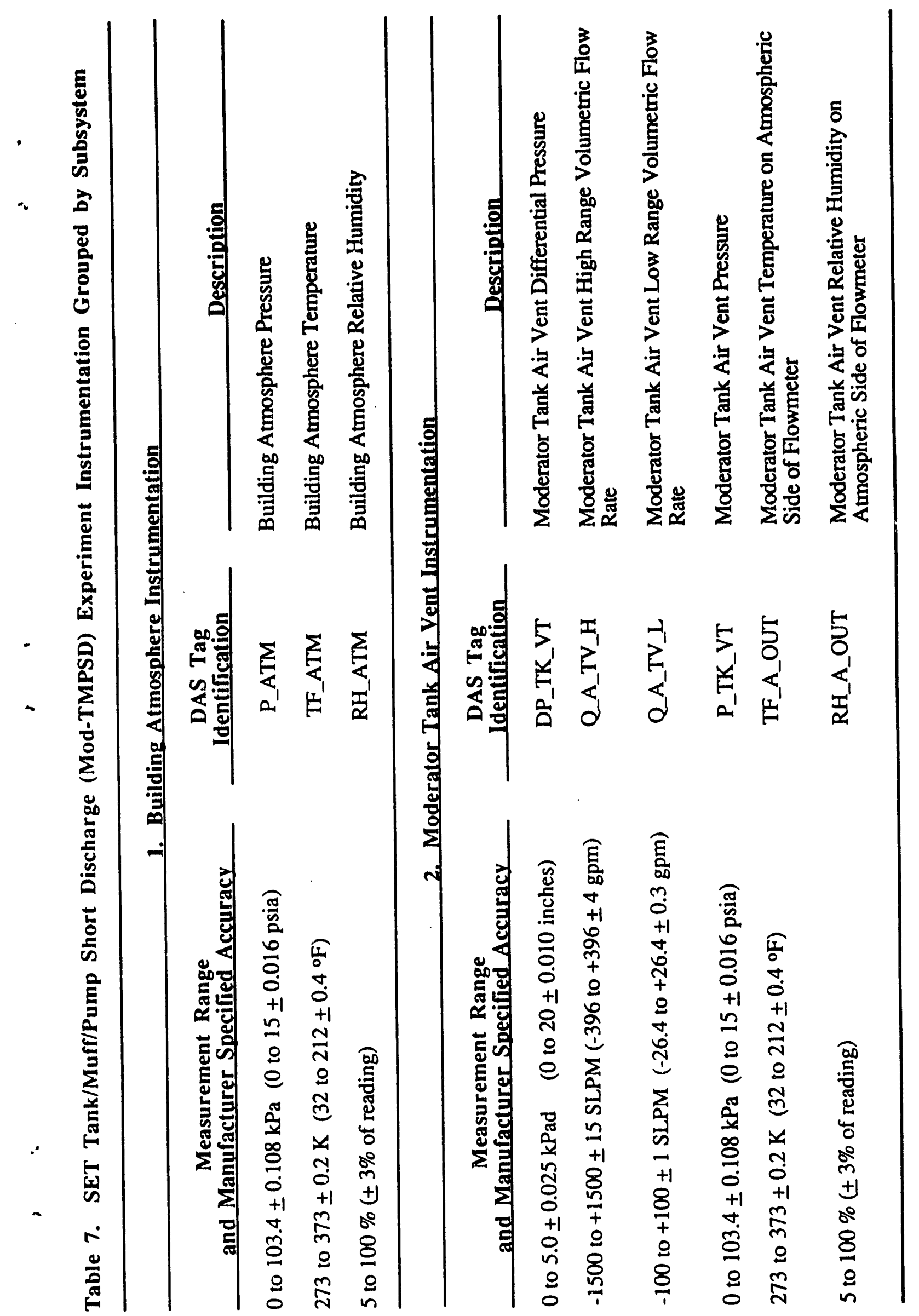




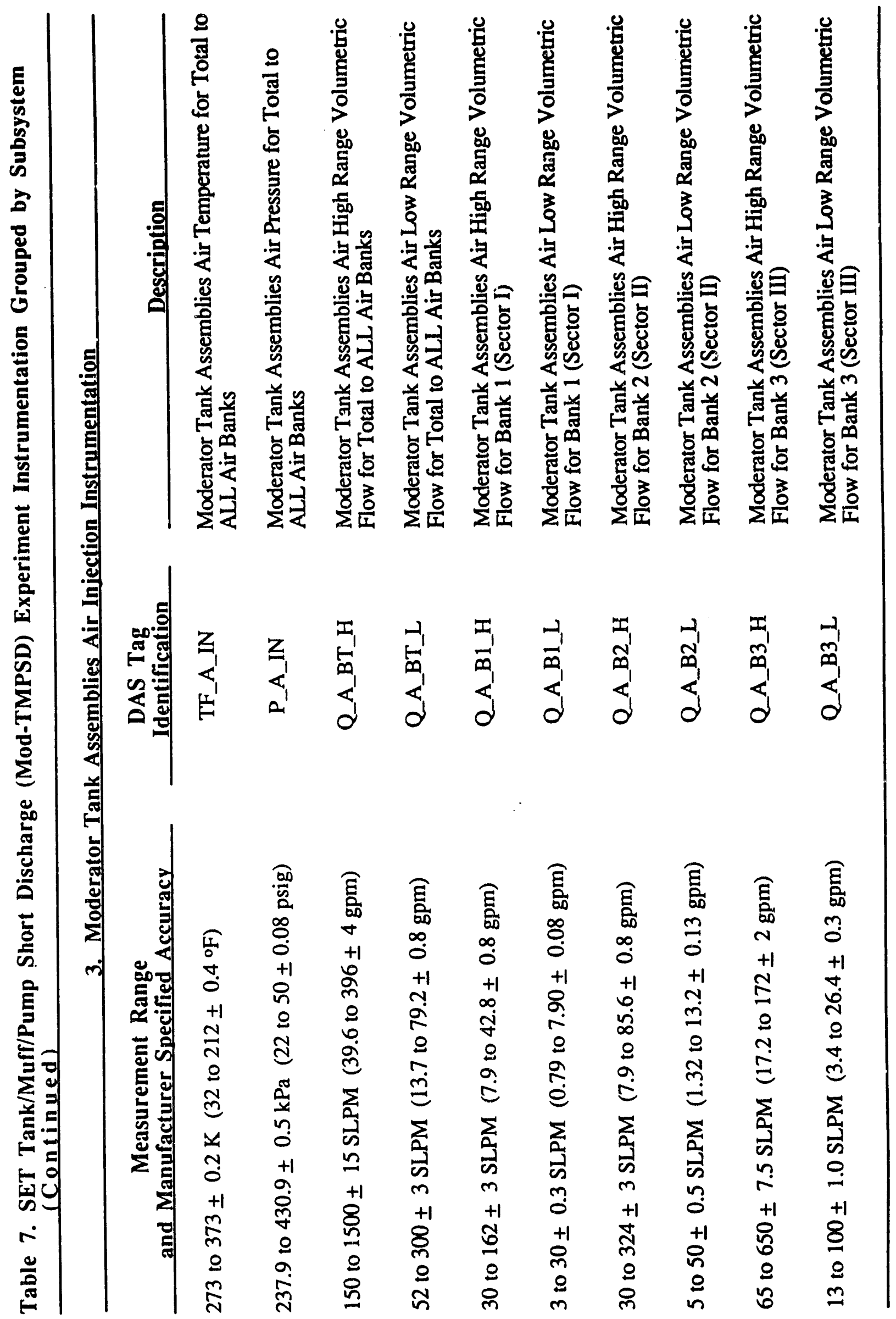




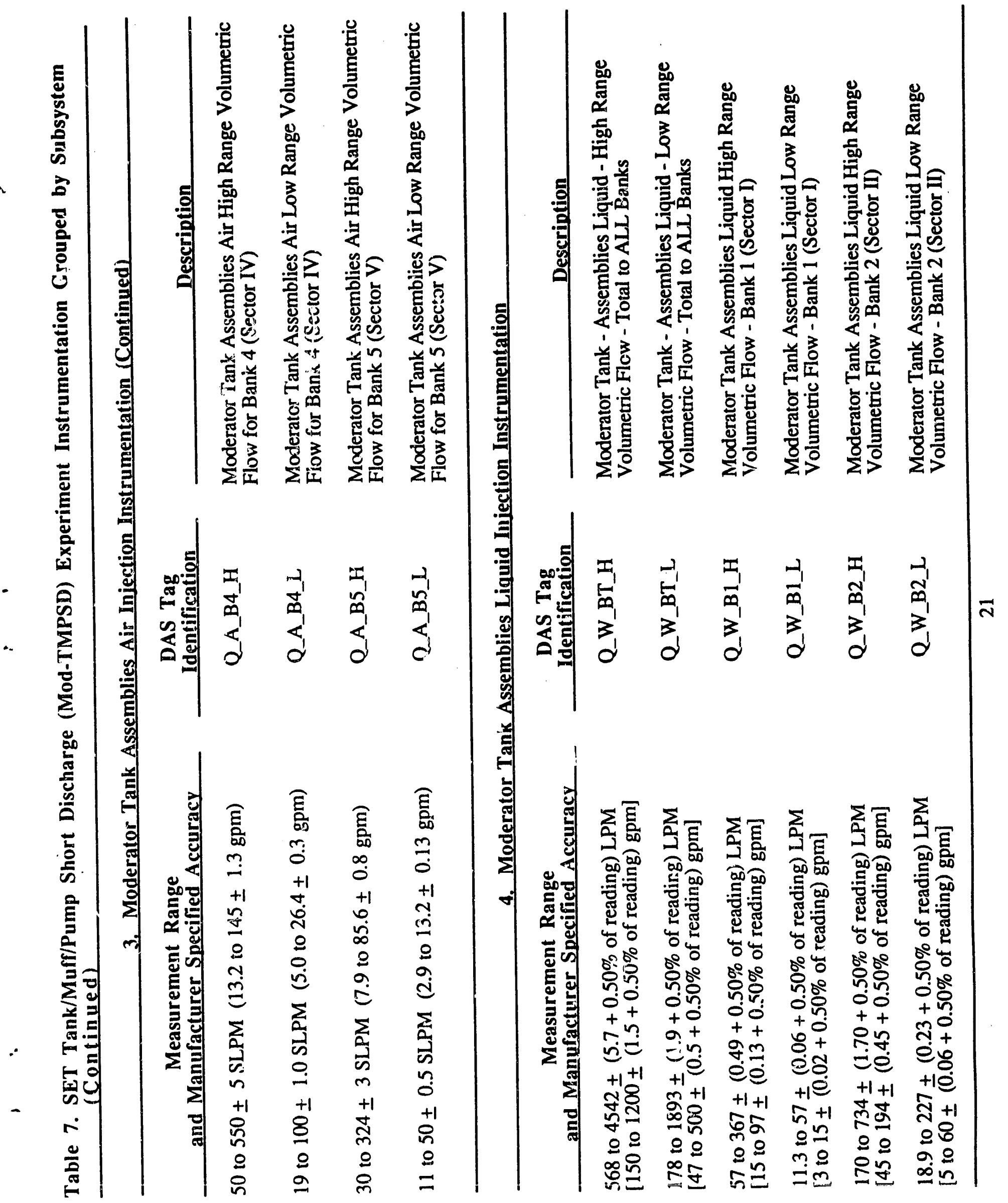




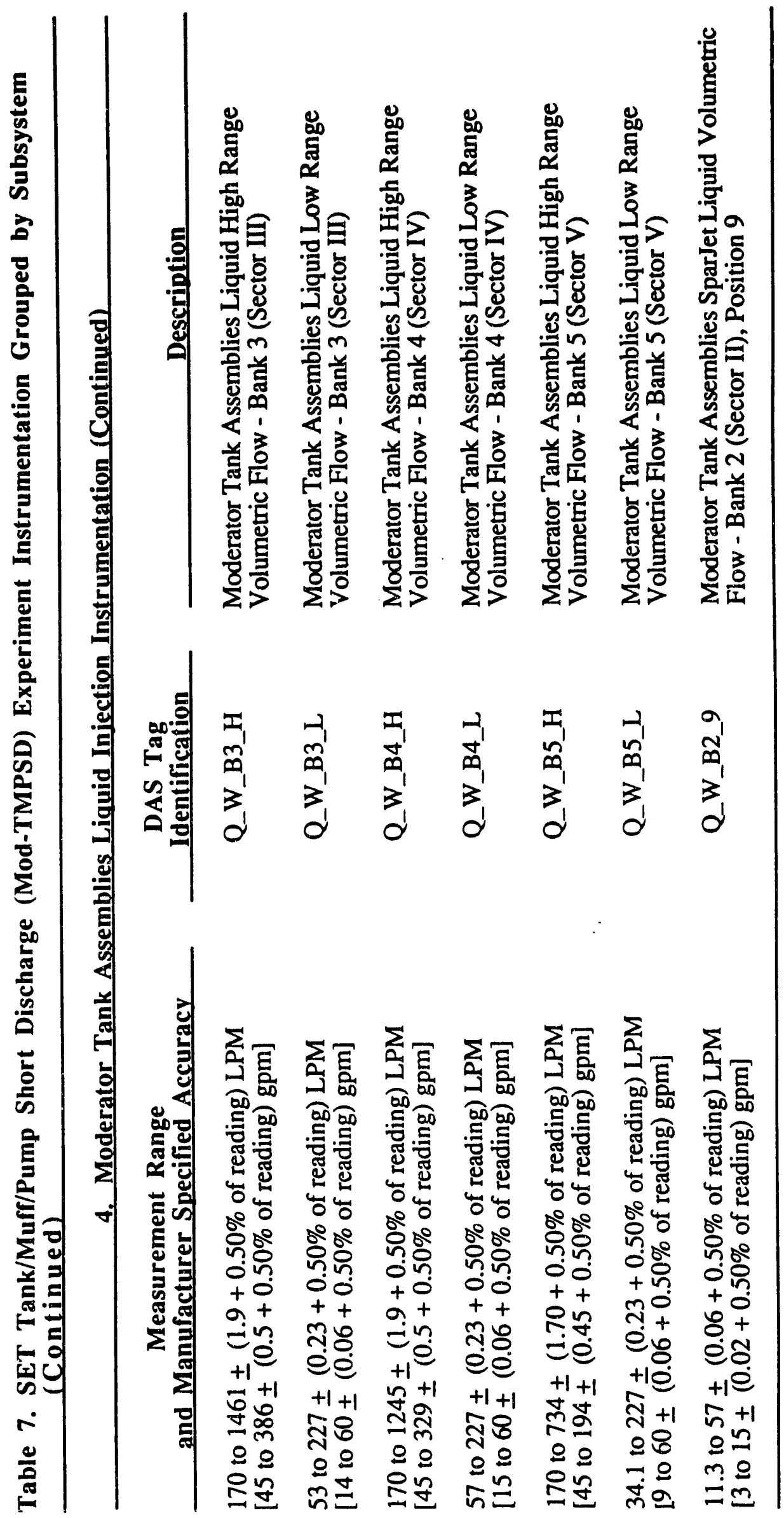




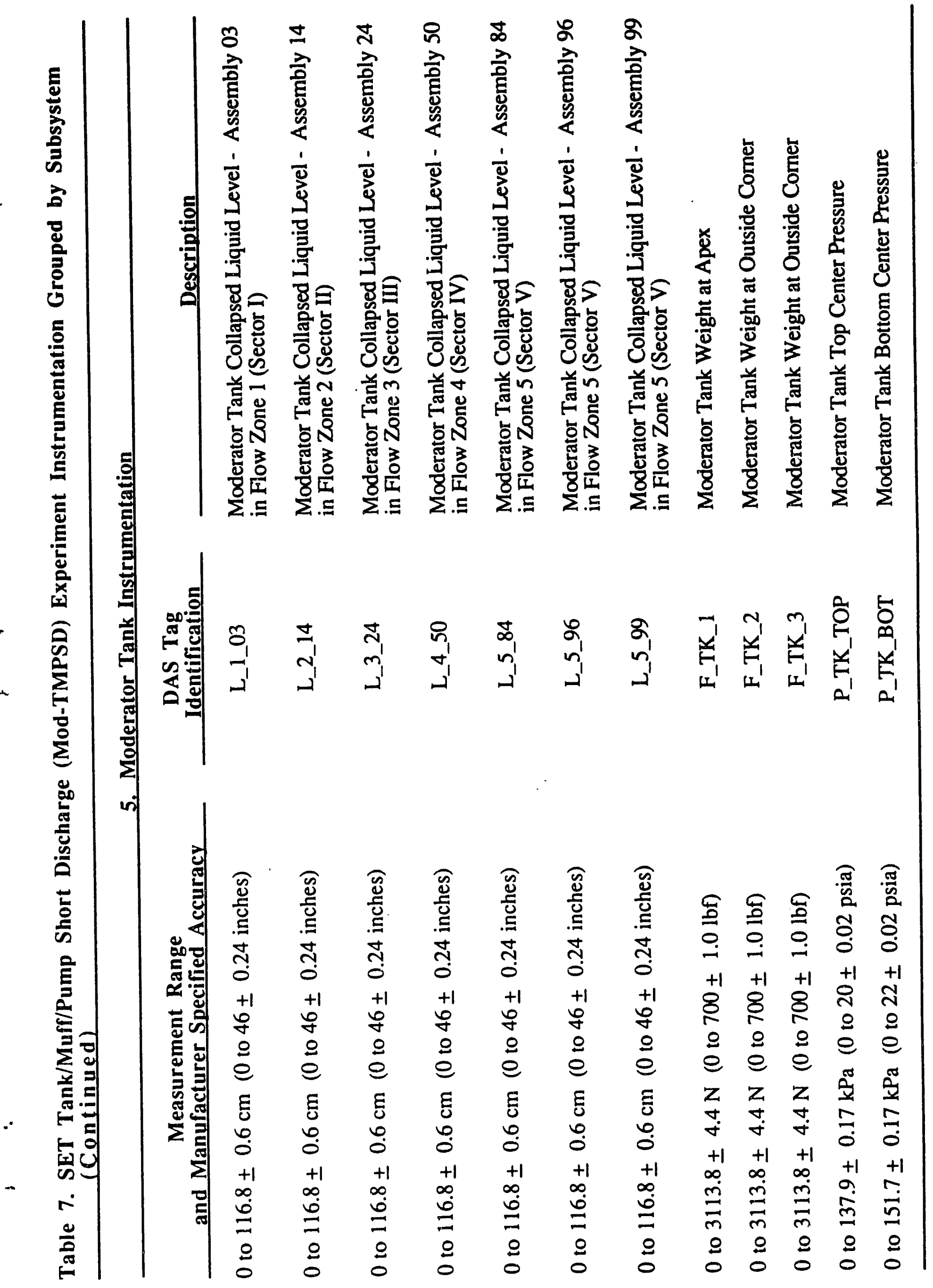




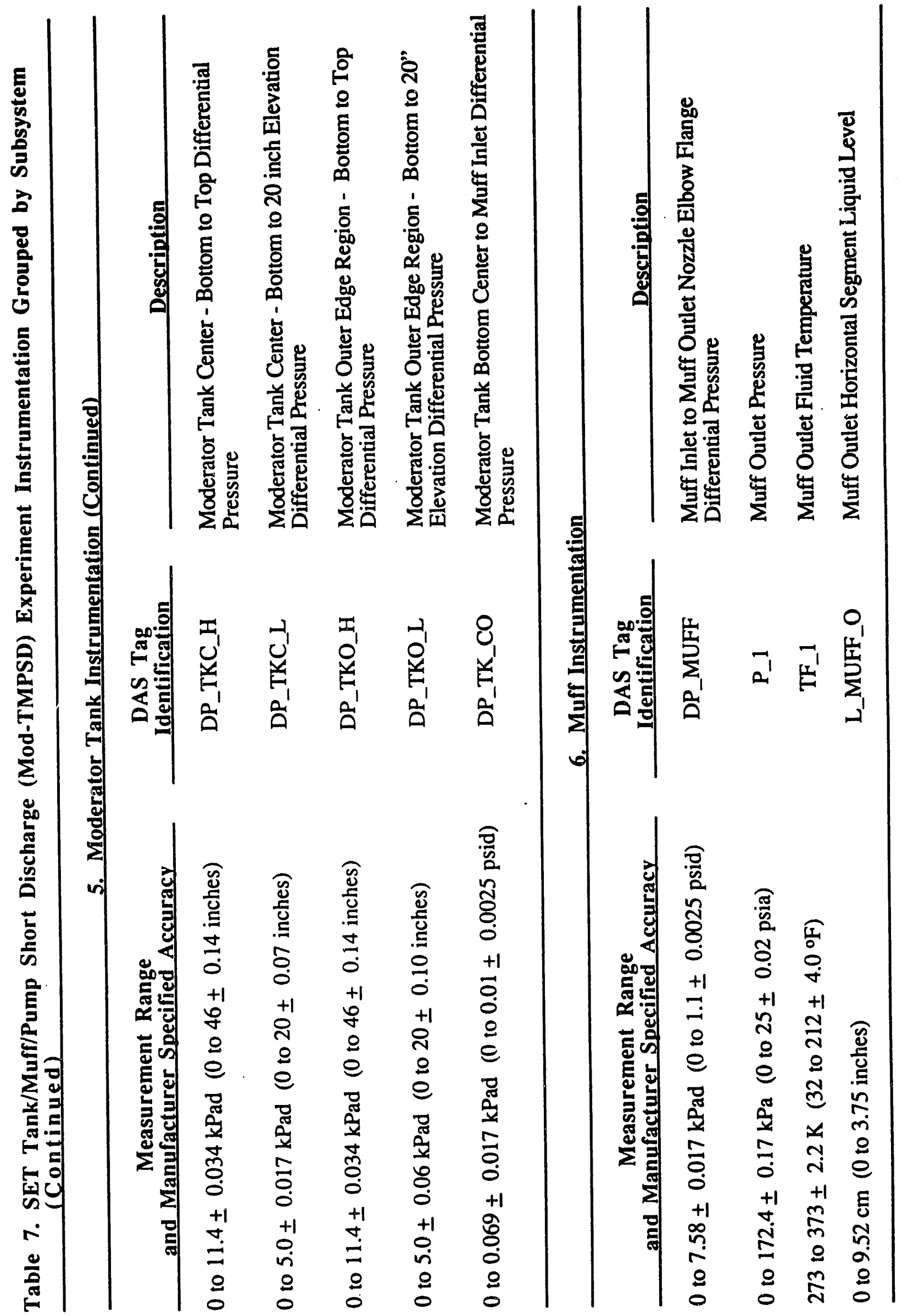




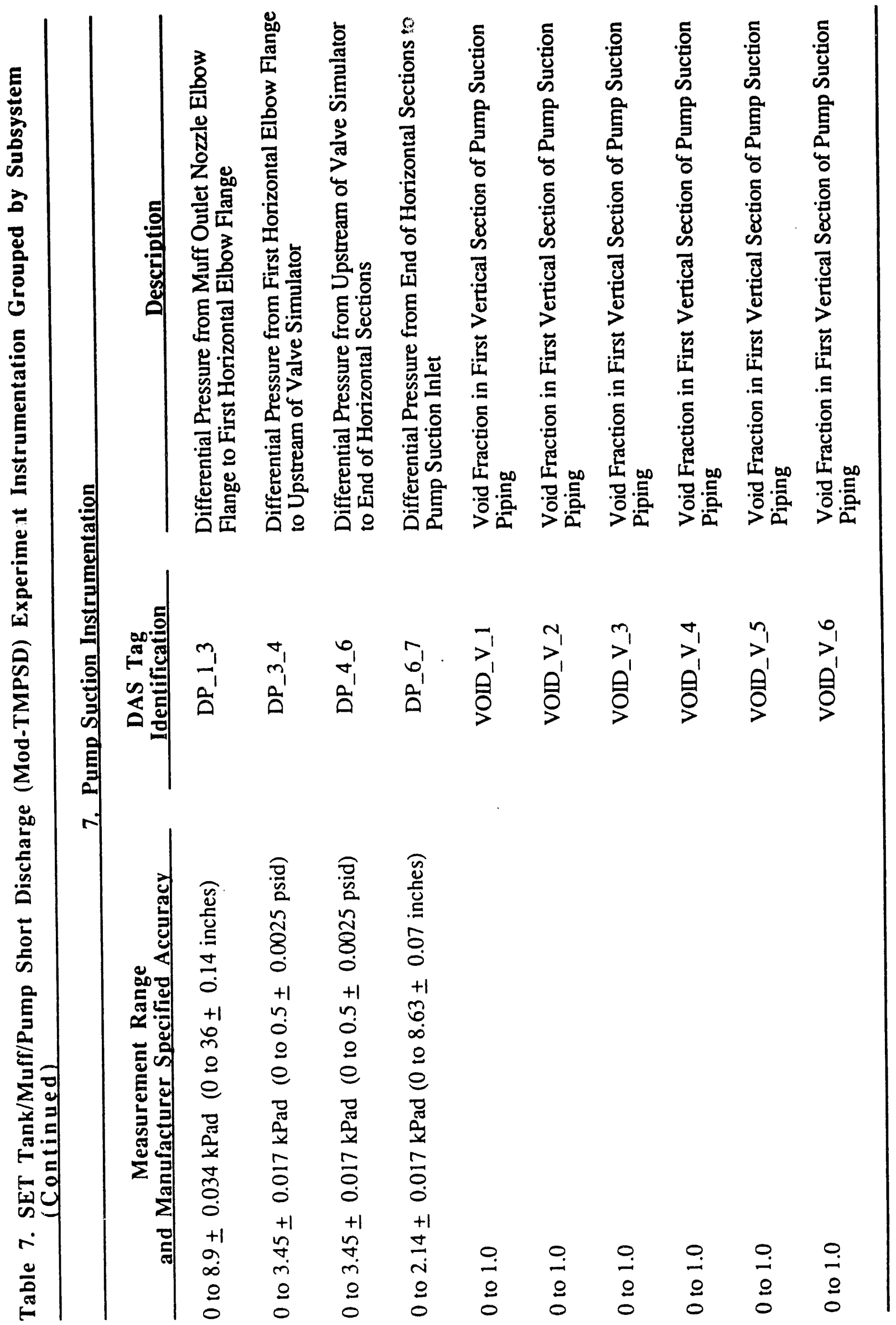




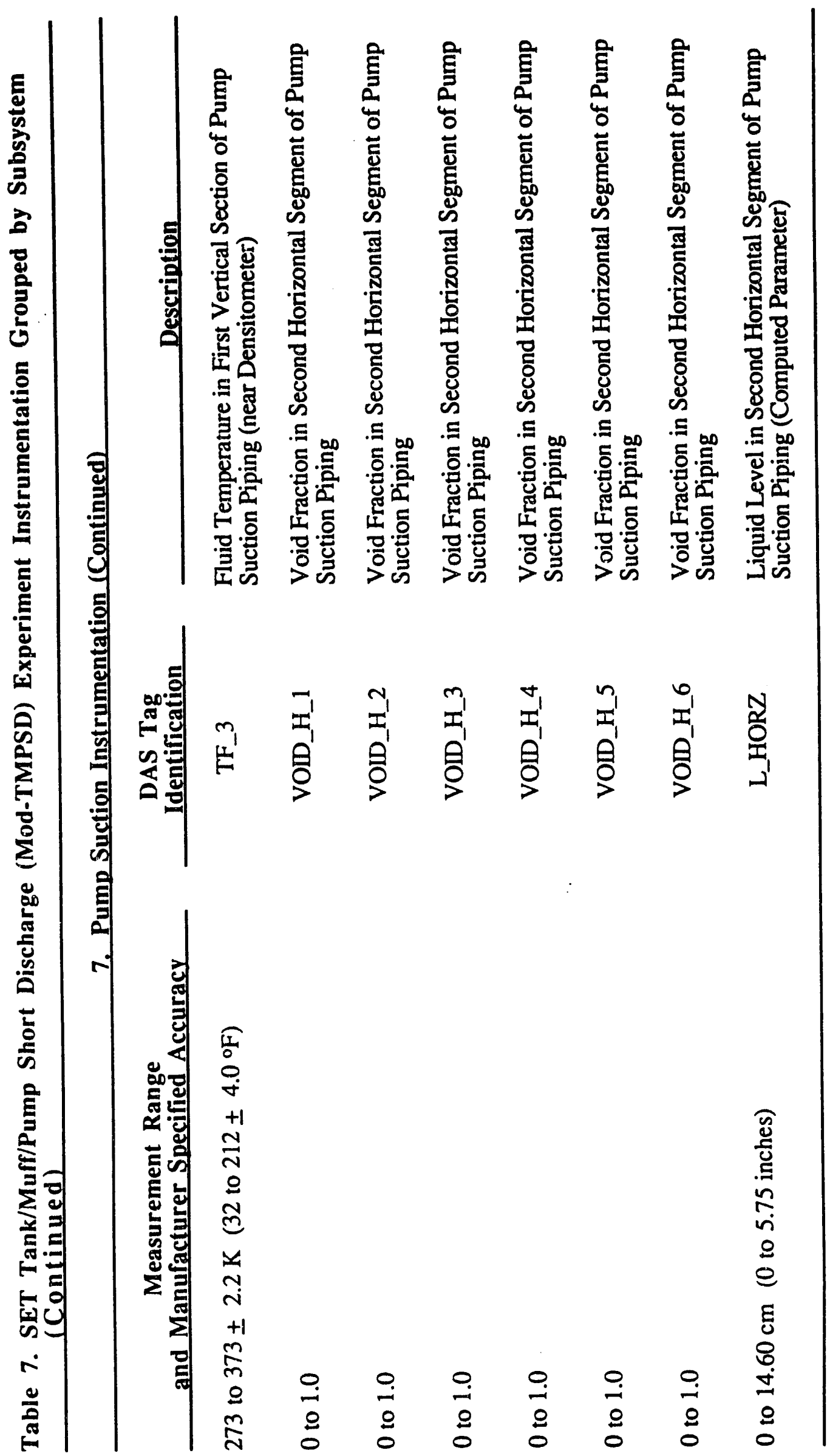




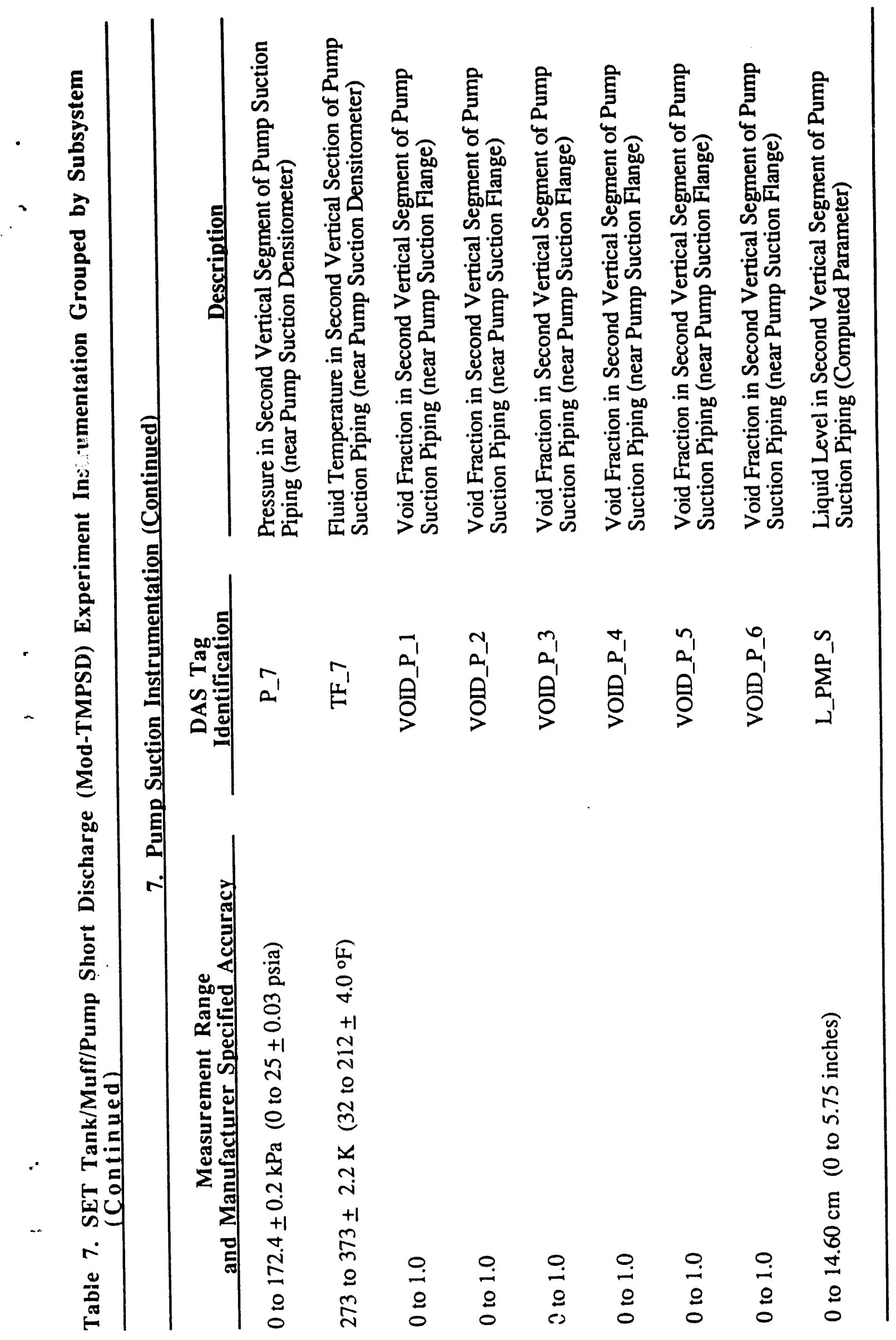




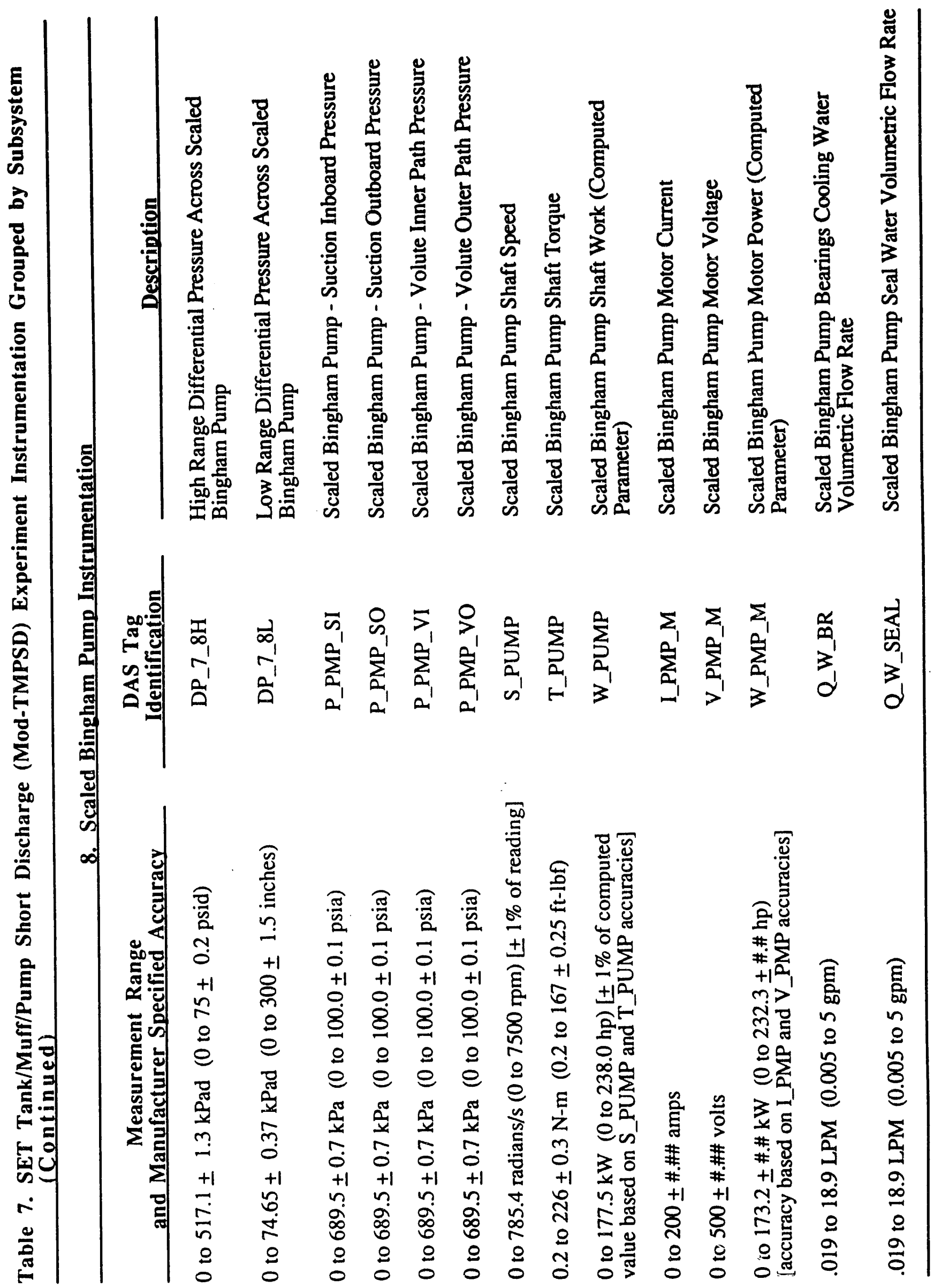




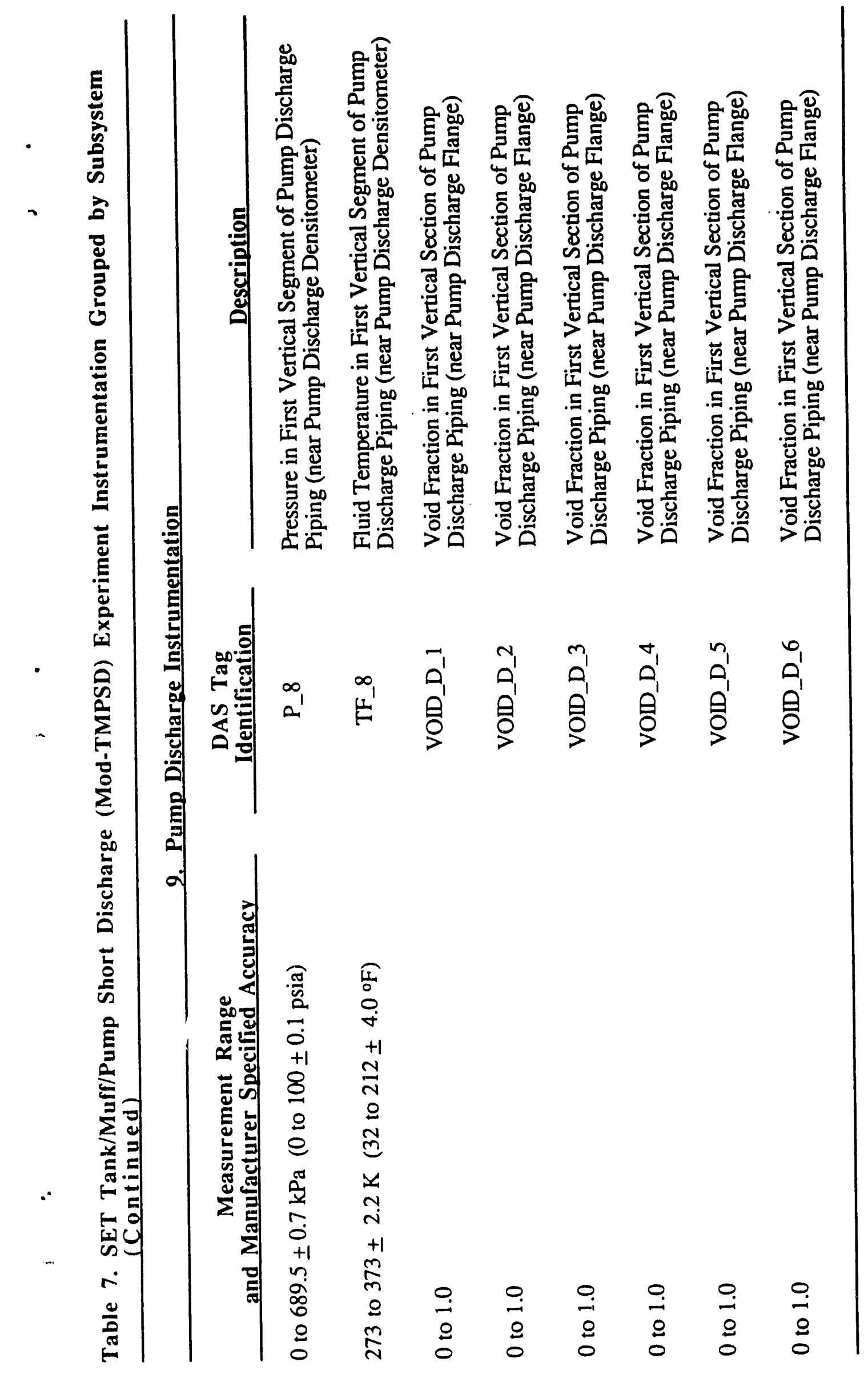



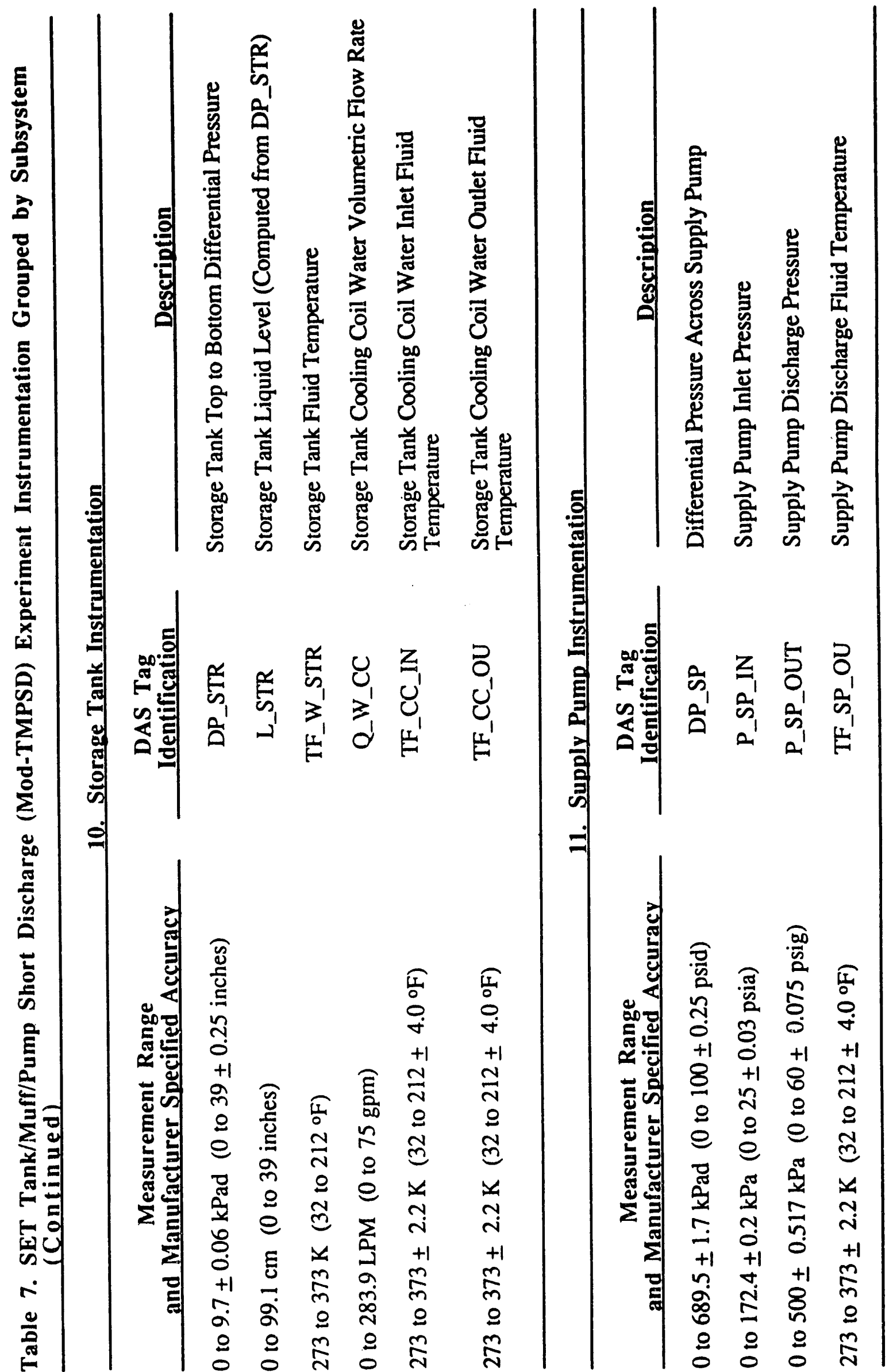


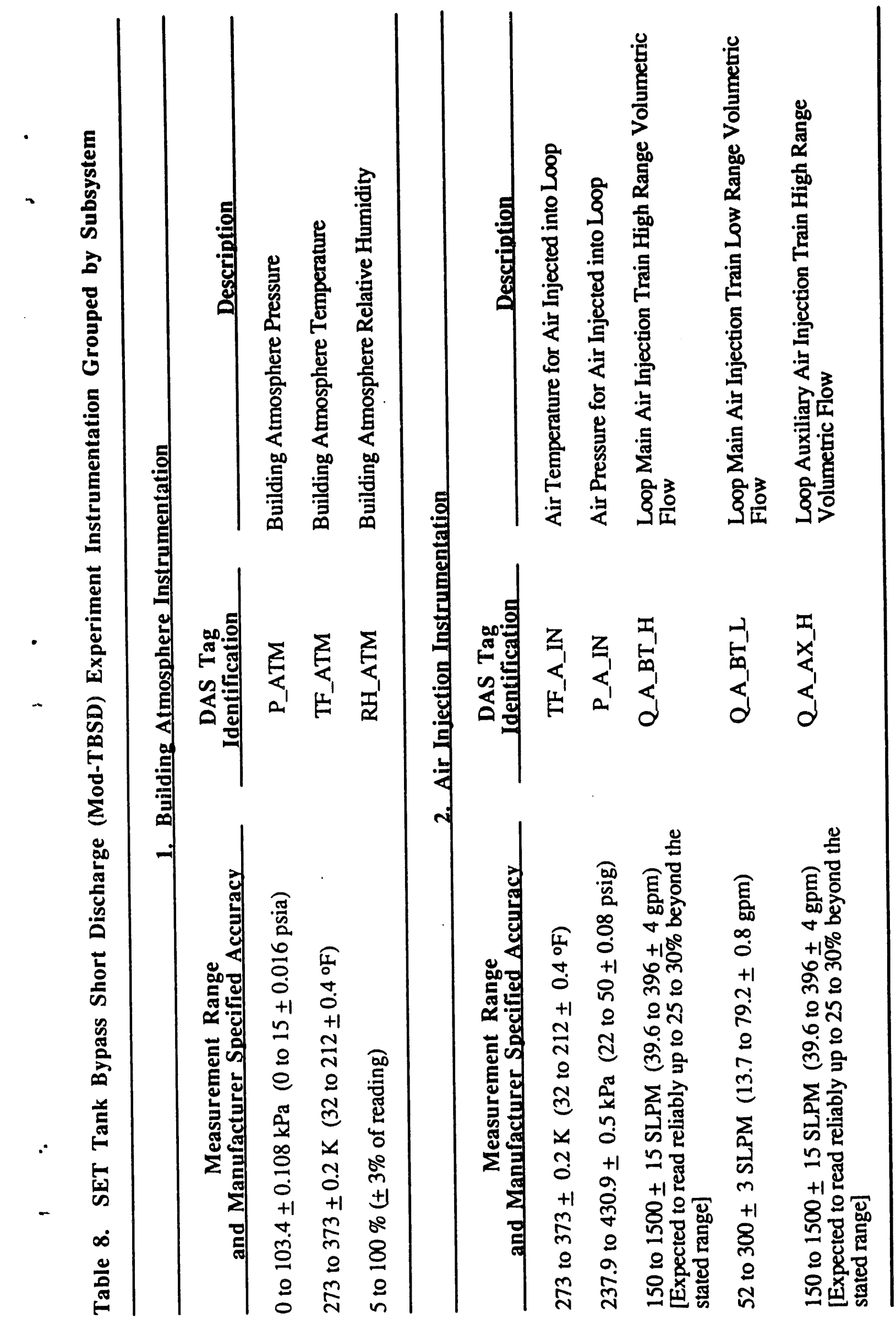




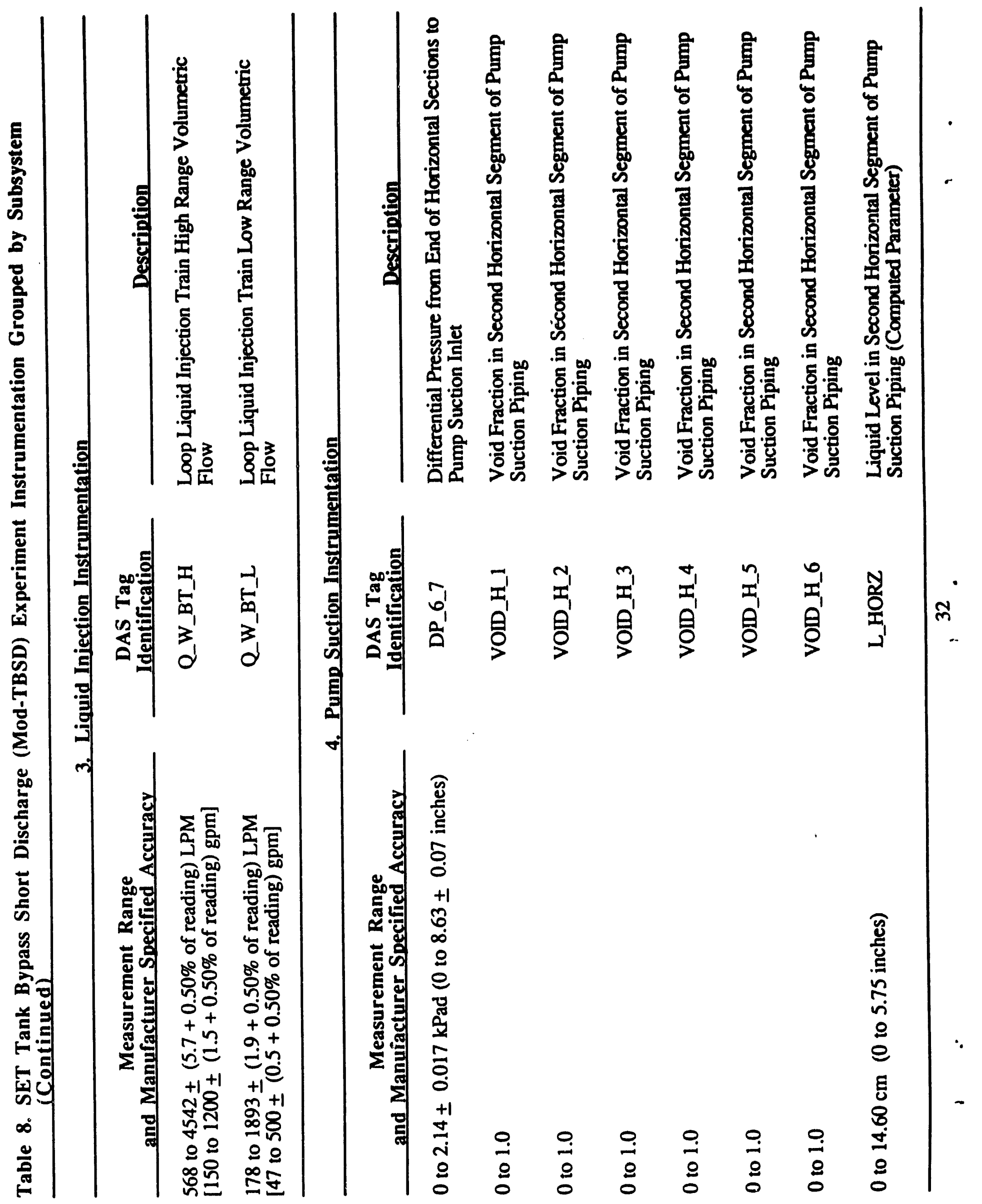




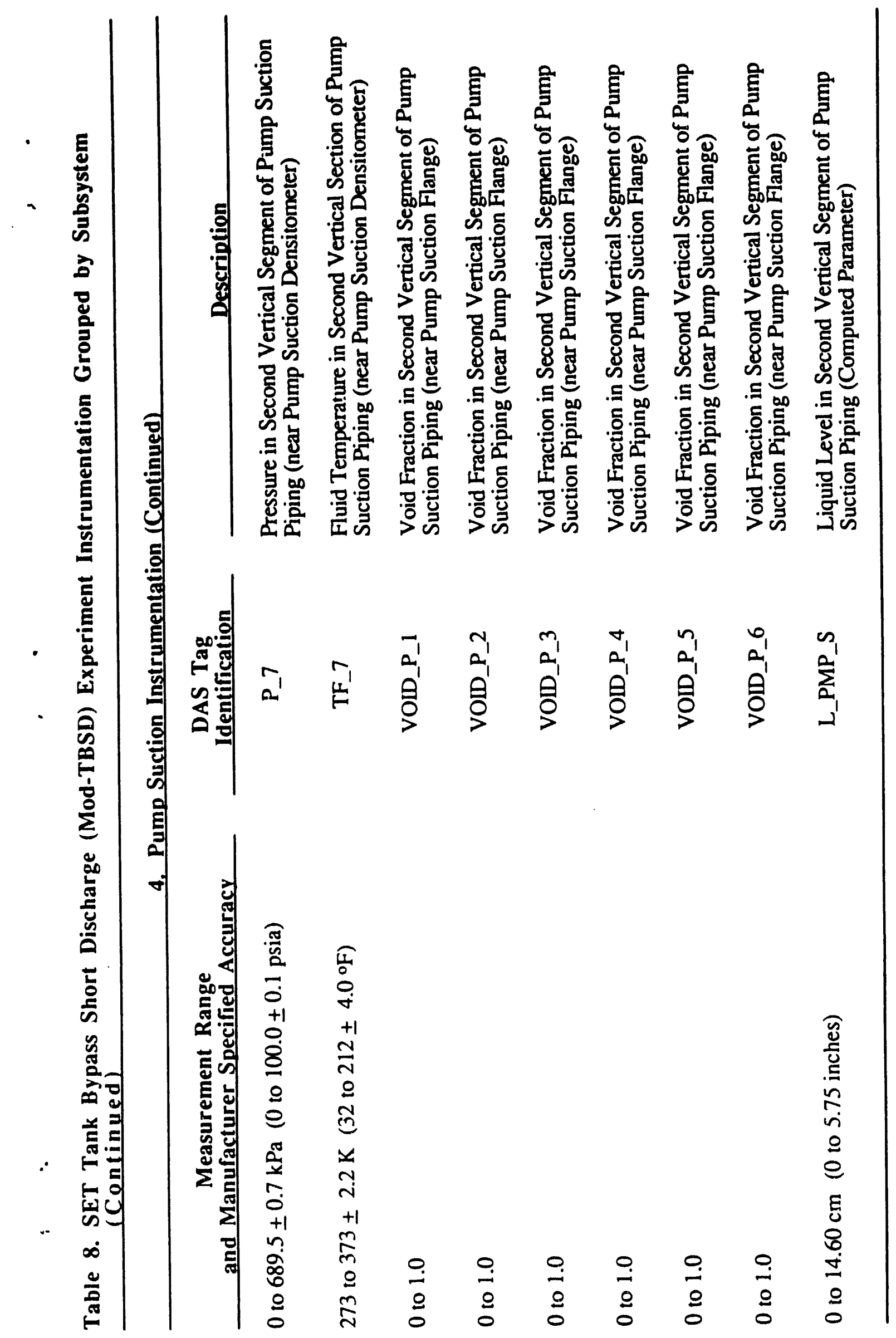




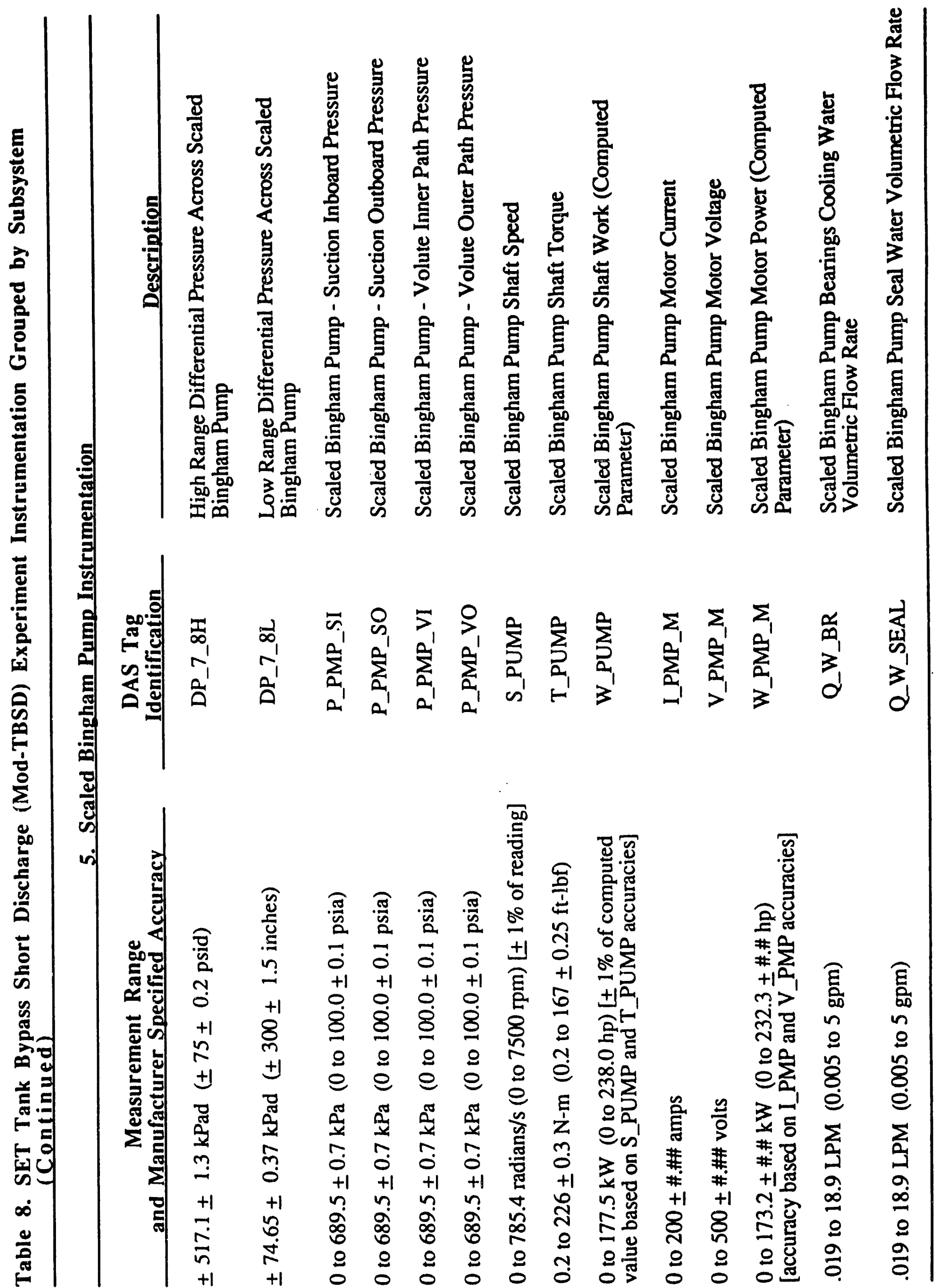




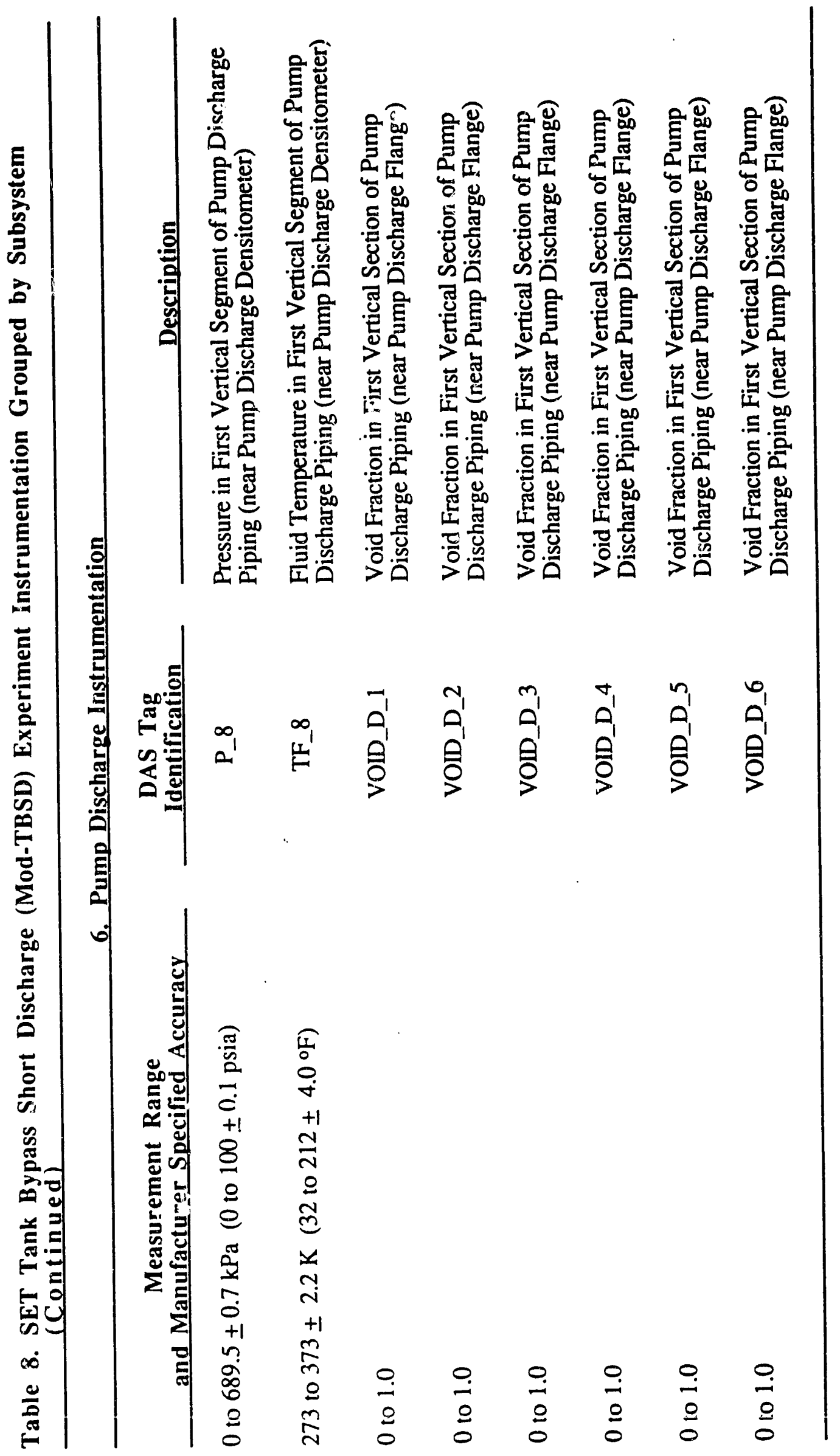




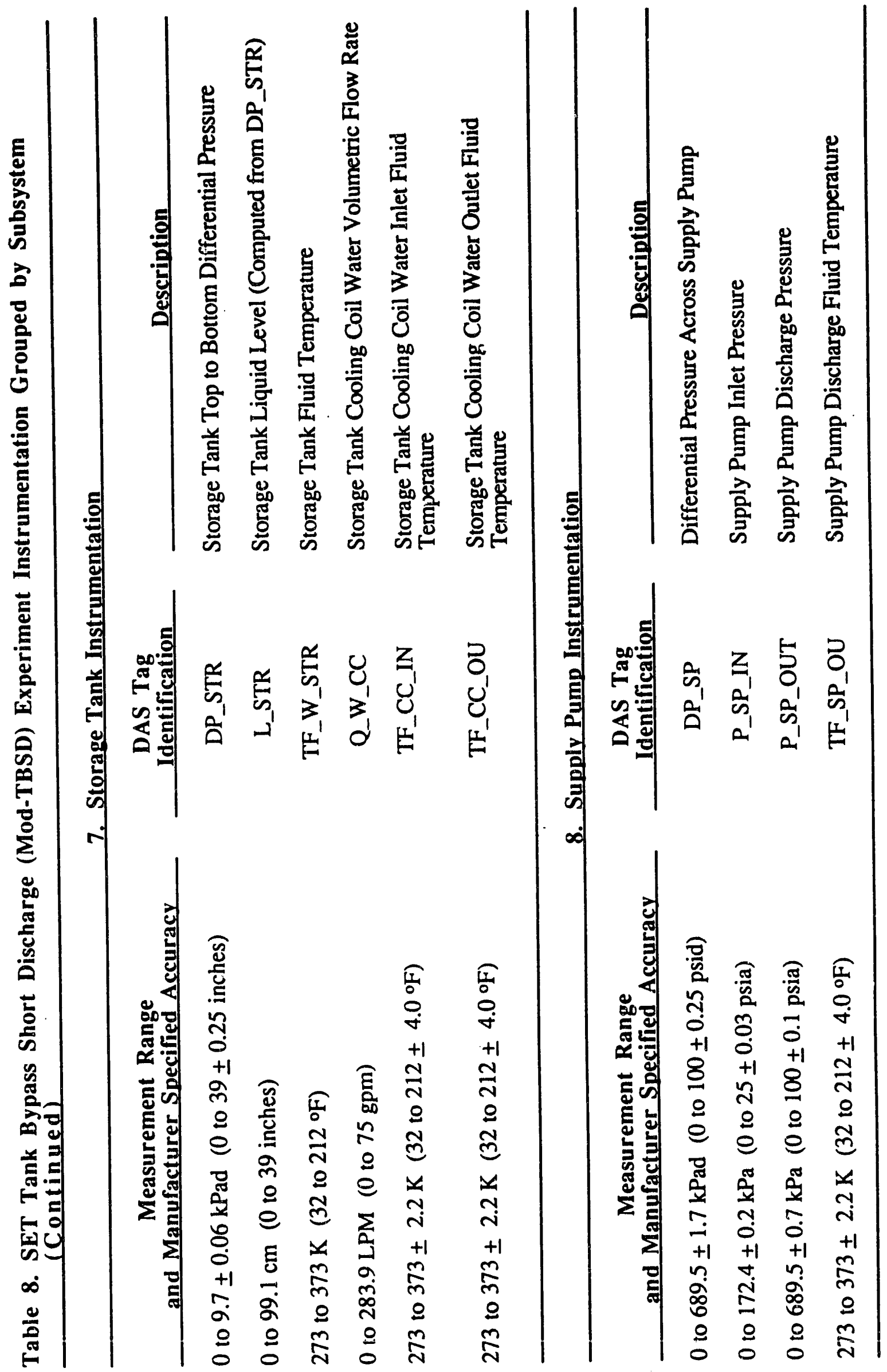




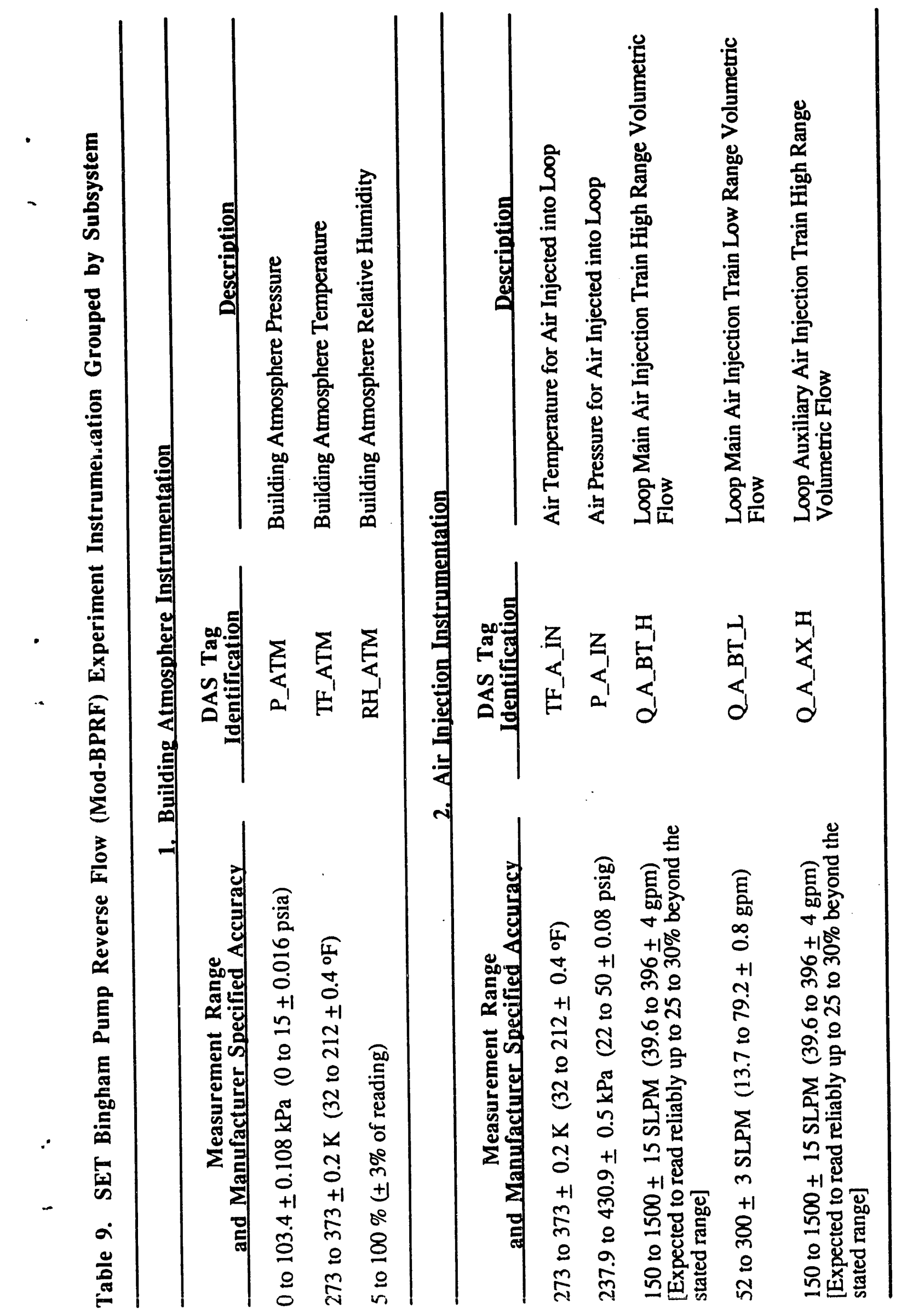

n 


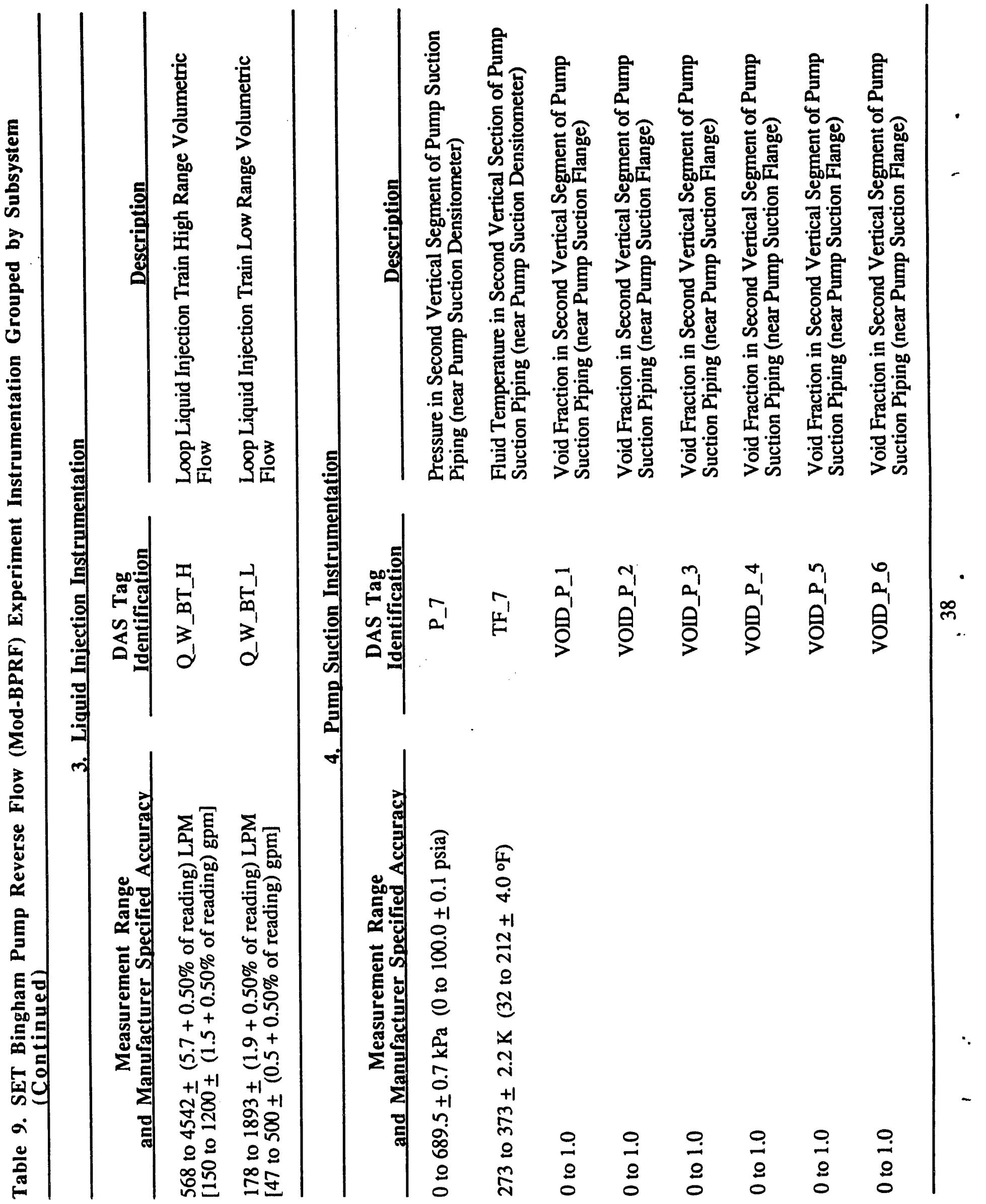




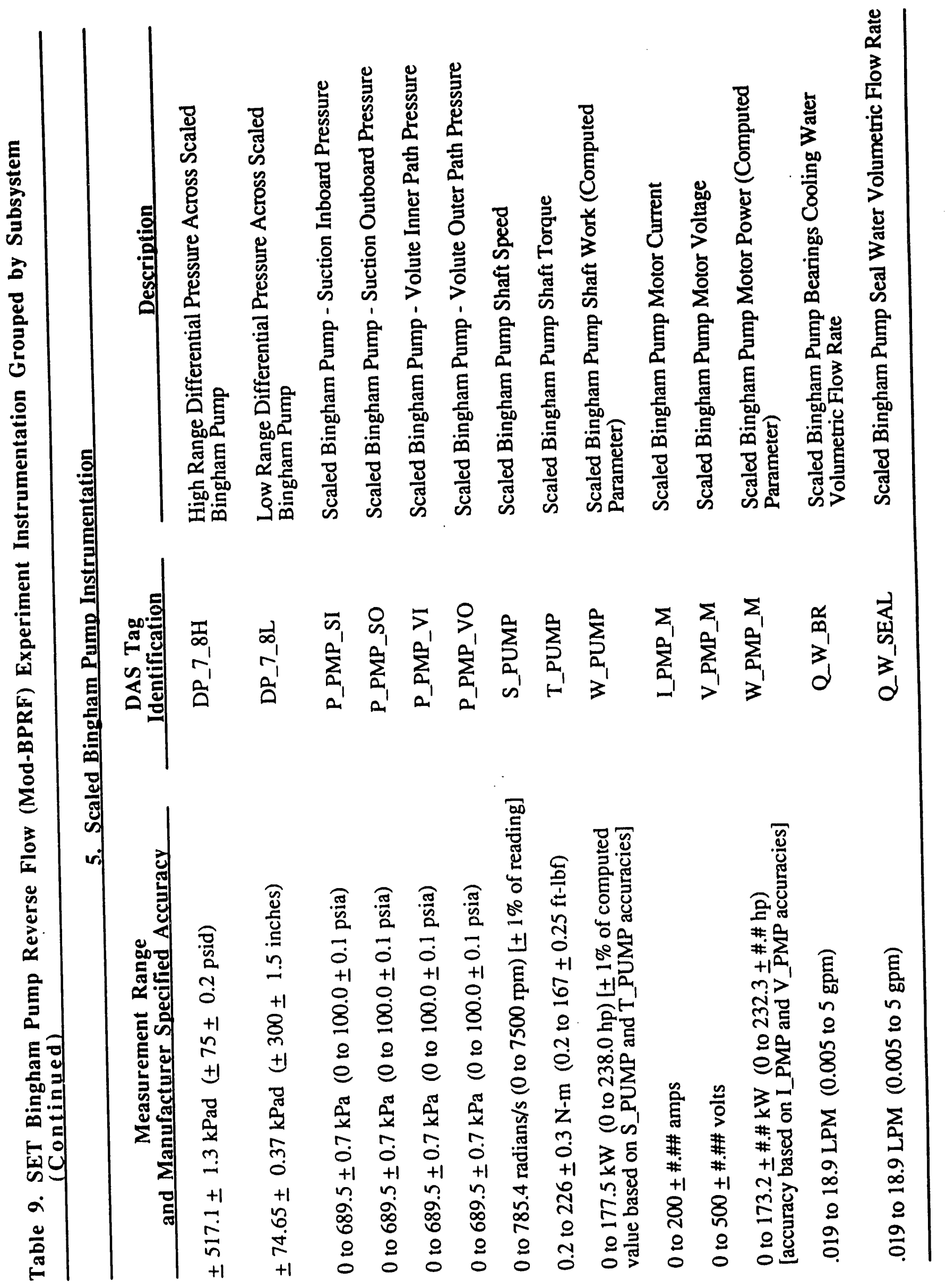




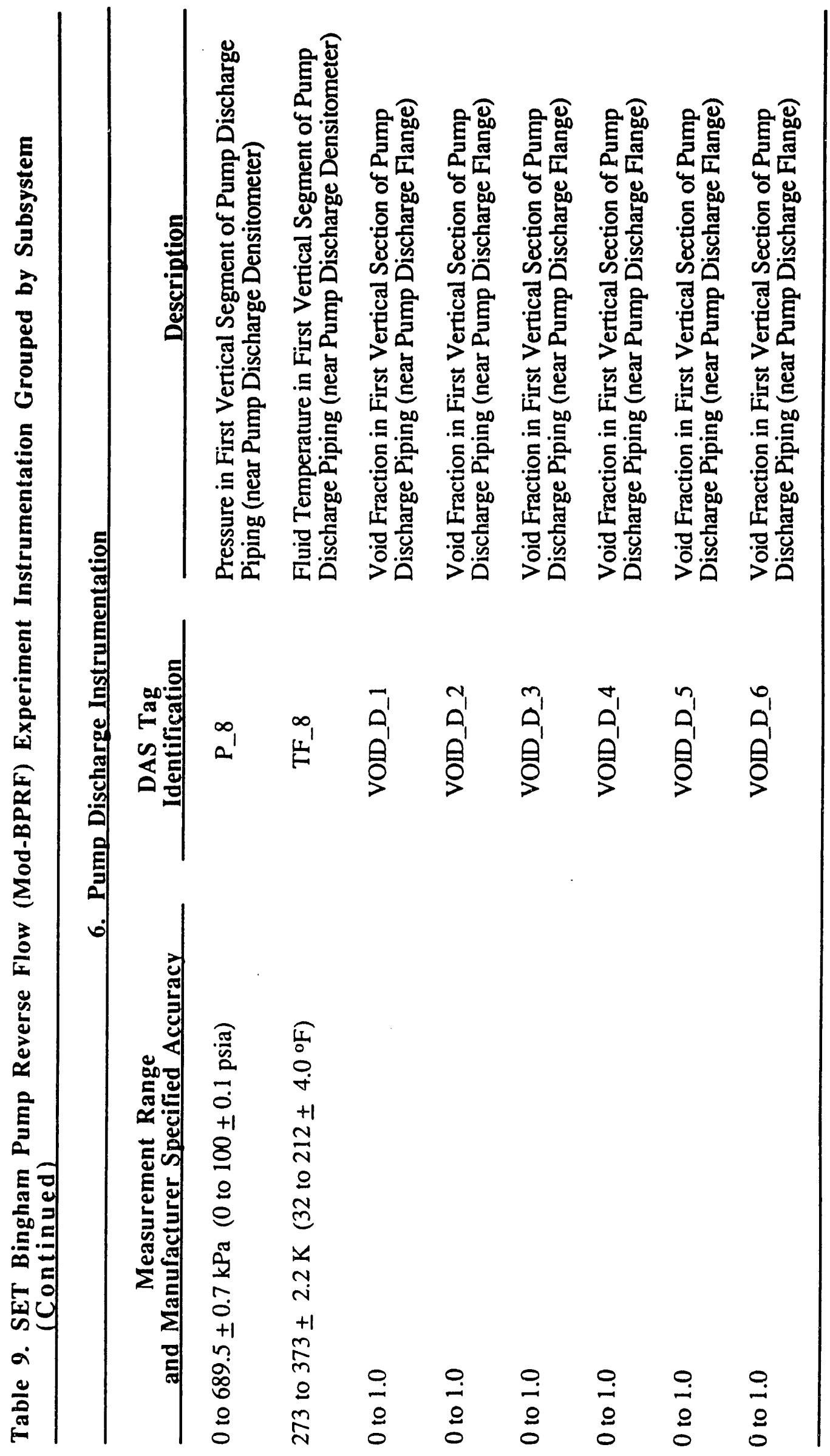




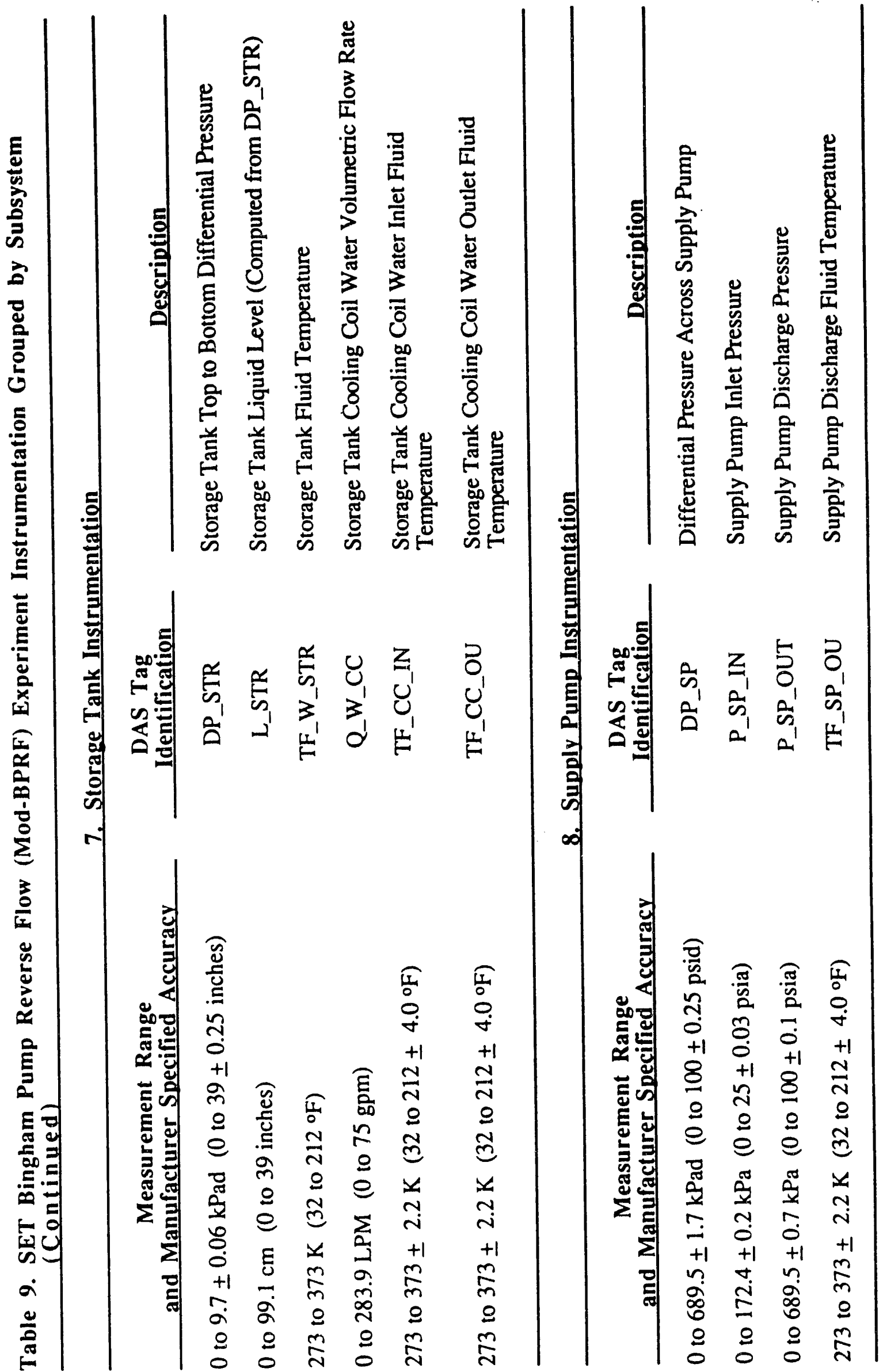


data report for the tests. The manufacturer specified accuracies have only been included to give an indication of the best potential measurement uncertainty. In most instances the actual measurement uncertainty will be on the order of 2 to 3 times greater than the manufacturer specified accuracy. Although the DAS tag identification shown for void fraction measurements is "VOID_\#\#", the actual measured parameter is the densitometer beam detector count rate from which the void fraction is computed. Hence, the actual DAS tag identification for void fraction measurements is "CNT_\#_\#" which has units of counts/second while the actual void fraction is a computed parameter designated by "VOID_\#_\#".

The SET test loop is intended to provide flow visualization information in conjunction with the standard data acquisition activities. Provisions for recording flow visualization are provided by several means. Several process video cameras are available for observing and recording general flow phenomena in the test loop and liquid storage tank. Several high speed video cameras are also available for observing and recording high speed images of flow phenomena in the test loop. Finally, a variable shutter speed camera is also available for capturing still images of flow phenomena.

\subsection{Measured or Computed Parameter Requirements}

Those parameters (measured or computed) essential to satisfying the test objectives specified in References 1 through 4 have been identified as critical parameters. The critical parameters for single-phase Bingham pump tests are shown on Table 10 while those for two-phase Bingham pump tests are shown on Table 11. As noted in the tables, a number of the parameters may be obtained by several methods. Tests should not be performed without at least one method of obtaining the critical parameters. If the primary critical parameter is unavailable for a test, a redundant critical parameter may be substituted and testing continued provided that both cognizant EG\&G and WSRC personnel agree that the redundant critical parameter provides sufficient accuracy. If cognizant WSRC personnel are not available for consultation, testing can be continued and data will be reviewed to assess the potential need to re-perform the test.

The possible methods of obtaining critical parameters are shown on Table 12. The primary method of obtaining critical parameters will vary between tests depending upon the nature of the test. 
Table 10. Critical Parameters for SET-TMP-PT Single-Phase Bingham Pump Tests Grouped by Subsystem

I. Pump Suction Liquid Injection Parameters:

1. Temperature of injected water.

2. Total volumetric flow rate of injected water.

II. Pump Suction Piping Parameters:

1. Absolute pressure.

III. Scaled Bingham Pump Parameters:

1. Pump suction inboard and outboard pressures.

2. Pump volute inner and outer path pressures.

3. Pressure drop across pump.

4. Pump shaft speed.

5. Pump shaft torque.

6. Pump shaft work.

7. Pump motor current.

8. Pump motor power.

IV. Pump Discharge Piping Parameters:

1. Absolute pressure.

Note: Parameters may be either computed or directly measured. A number of the parameters may be obtained by several methods. Tests should not be performed without at least one method of obtaining the critical parameters. 


\section{Table 11. Critical Parameters for SET-TMP-PT Two-Phase Bingham Pump Tests Grouped by Subsystem}

I. Pump Liquid and Air Injection Parameters:

(Pump suction for forward flow, pump discharge for reverse flow)

1. Temperature of injected liquid.

2. Total volumetric flow rate of injected liquid.

3. Density of injected air.

4. Mass flow rate of injected air.

II. Pump Suction Piping Parameters:

1. Absolute pressure.

2. Fluid temperature.

3. Pressure drop across last $90^{\circ}$ elbow and last vertical section - (Only for forward flow).

4. Void fraction in last horizontal section of pipe - (Only for forward flow).

5. Void fraction in last vertical section of pipe (vertical section connected to pump).

III. Scaled Bingham Pump Parameters:

1. Pump suction inboard and outboard pressures.

2. Pump volute inner and outer path pressures.

3. Pressure drop across pump.

4. Pump shaft speed.

5. Pump shaft torque.

6. Pump shaft work.

7. Pump motor current.

8. Pump motor power.

IV. Pump Discharge Piping Parameters:

1. Absolute pressure.

2. Fluid temperature.

3. Void fraction in first vertical section pipe (vertical section connected to pump).

Note: Parameters may be either computed or directly measured. A number of the parameters may be obtained by several methods. Tests should not be performed without at least one method of obtaining the critical parameters. 
Table 12. Possible Methods of Obtaining Critical Parameters

\begin{tabular}{|c|c|c|c|}
\hline $\begin{array}{c}\text { Critical } \\
\text { Parameter }\end{array}$ & Primary Method & Alternate Method 1 & Alternate Method 2 \\
\hline $\begin{array}{l}\text { Pump suction } \\
\text { injected air mass } \\
\text { flowrate }\end{array}$ & Q_A_BT_F or L & & \\
\hline $\begin{array}{l}\text { Pump suction } \\
\text { injected water } \\
\text { temperature }\end{array}$ & TF_SP_OU & TF_7 or TF_8 & TF_8 or TF_7 \\
\hline $\begin{array}{l}\text { Pump suction } \\
\text { injected water } \\
\text { volumetric } \\
\text { flowrate }\end{array}$ & Q_W_BT_Hor L & & \\
\hline $\begin{array}{l}\text { Pump suction air } \\
\text { injection } \\
\text { volumetric flow } \\
\text { rate }\end{array}$ & $\begin{array}{l}\text { Q_A_BT_H or L, } \\
\text { Q_A_AX_H, } \\
\text { P_7 and TF_7 }\end{array}$ & & \\
\hline $\begin{array}{l}\text { Pump suction } \\
\text { absolute pressure }\end{array}$ & P_7 & P_8 and DP_7_8H or L & \\
\hline $\begin{array}{l}\text { Pump suction } \\
\text { fluid temperature }\end{array}$ & TF_7 & & \\
\hline $\begin{array}{l}\text { Pump suction } \\
\text { last } 90^{\circ} \text { elbow } \\
\text { and last vertical } \\
\text { section } \Delta P\end{array}$ & DP_6_7 & & \\
\hline $\begin{array}{l}\text { Pump suction } \\
\text { horizontal } \\
\text { section void } \\
\text { fraction }\end{array}$ & VOID_H_1 through 6 & & \\
\hline $\begin{array}{l}\text { Pump suction } \\
\text { vertical section } \\
\text { void fraction }\end{array}$ & VOD_P_l through 6 & DP_6_7, P_7 and TF_7 & \\
\hline
\end{tabular}




\begin{tabular}{|c|c|c|c|}
\hline $\begin{array}{l}\text { Critical } \\
\text { Parameter }\end{array}$ & Primary Method & Alternate Method 1 & Alternate Method 2 \\
\hline $\begin{array}{l}\text { Pump suction } \\
\text { inboard and } \\
\text { outboard } \\
\text { pressures }\end{array}$ & $\begin{array}{l}\text { P_PMP_SI and } \\
\text { P_PMP_SO }\end{array}$ & & \\
\hline $\begin{array}{l}\text { Pump volute } \\
\text { inner and outer } \\
\text { path pressures }\end{array}$ & $\begin{array}{l}\text { P_PMP_VI and } \\
\text { P_PMP_VO }\end{array}$ & & \\
\hline Pump $\triangle \mathrm{P}$ & DP_7_8H or L & $P_{-} 7$ and $P_{-} 8$ & $\begin{array}{l}\text { P_PMP_SI or } \\
\text { P_PMP_SO and } \\
\text { P_PMP_VI or } \\
\text { P_PMP_VO }\end{array}$ \\
\hline $\begin{array}{l}\text { Pump shaft } \\
\text { speed }\end{array}$ & S_PUMP & & \\
\hline $\begin{array}{l}\text { Pump shaft } \\
\text { torque }\end{array}$ & T_PUMP & & \\
\hline Pump shaft work & W_PUMP & & \\
\hline $\begin{array}{l}\text { Pump motor } \\
\text { current }\end{array}$ & I_PMP_M & & \\
\hline $\begin{array}{l}\text { Pump motor } \\
\text { power }\end{array}$ & W_PMP_M & & \\
\hline $\begin{array}{l}\text { Pump discharge } \\
\text { absolute pressure }\end{array}$ & P_8 & P_7 and DP_7_8H or L & \\
\hline $\begin{array}{l}\text { Pump discharge } \\
\text { fluid temperature }\end{array}$ & TF_8 & & \\
\hline $\begin{array}{l}\text { Pump discharge } \\
\text { vertical section } \\
\text { void fraction }\end{array}$ & VOID_D_1 through 6 & & \\
\hline
\end{tabular}




\subsection{Experiment Termination Criteria}

Experiment termination prior to completion of test objectives may be necessary under abnormal conditions. The test will be terminated under unusual, emergency or safety-related conditions. Otherwise, the experiments can be stopped when the conditions specified in the test matrix table have been satisfied.

\subsection{Post Testing Operational Checks}

Following completion of daily testing activities, the operations listed in Table 13 should be performed. These operations will provide valuable information for posttest analysis and system operability considerations.

\section{Table 13. Post-Testing Operational Checks}

1. Status

Test day testing has been completed.

2. Perform post testing operational checks and take post testing data.

1. Prepare the data acquisition system as necessary to obtain the post testing data.

2. Fill the test loop. Obtain liquid level and densitometer data.

3. Drain and vent the test loop. Obtain liquid level and densitometer data.

4. Inspect the facility for and record all leakage points or unusual configuration/operation conditions.

3. Secure the facility

1. Secure the fluid systems.

2. Start or continue data processing operations. 


\subsection{ExperimentAcceptance Criteria}

After completion of the experiment, an evaluation will be performed to determine the acceptability of the experiment based on satisfaction of objectives. The following criteria will be applied to determine if all of the experiment objectives were met:

1. Initial values and parameters critical to meeting experimental objectives are within the tolerances specified.

2. Proper performance of experimental instrumentation and recording of data to insure that the experimental results can be analyzed and the experiment objectives met. 


\section{REFERENCES}

1. J. S. Bollinger and J. D. Sterrett ltr. to C. A. Nash, Phase 3 Tank/Muff/Pump (TMP) 1/4Scale Formal Bingham Pump Test Matrix, Savannah River Site, NES-CDG-930006, January 18, 1993.

2. J. S. Bollinger ltr. to C. A. Nash, Summary of Phase 3 Pump Testing at the 1/4-Scale Separate Effects Test Facility (SET) and Description of Additional Characterization Tests, Savannah River Site, NES-CDG-930053, March 10, 1993.

3. J. S. Bollinger ltr. to C. A. Nash, Tank/Muff/Pump (TMP) Integral Single-Phase Pump Test Matrix, Savannah River Site, NES-CDG-920181, October 9, 1992.

4. J. S. Bollinger ltr. to C. A. Nash, Pump Discharge Break Studies - Second Tank/Muff/Pump (TMP) Testing Phase, Savannah River Site, NES-CDG-920241, Rev. 1, January 15, 1992.

5. T. J. Boucher and J. S. Bollinger, "Appendix SC-TMPS-IT of the Experiment Operating Specification for the Savannah River One-Fourth Linear Scale, One-Sixth Sector Tank/Muff/Pump (TMP) Separate Effects Tests (SET) Experiment Series," EGG-NE-10379, WSRC-TR-92-383, Revision 0, September 1992.

5. T. J. Boucher and T. K. Larson, "Quick Look Report for Phase II of the Savannah River One-Fourth Linear Scale, One-Sixth Sector Tank/Muff/Pump (TMP) Separate Effects Tests (SET) Experim. nt Series," EGG-NRE-10721, Revision 0, March 1993.

7. A. J. Stepanof., Centrifugal and Axial Flow Pumps, Second Edition, John Wiley \& Sons, Inc., 1957.

8. R. W. Winks, One-Third-Scale Air-Water Pump Program, Test Program and Pump Performance, EPRI NP-135, Electric Power Research Institute, Palo Alto, CA, July, 1977.

9. W. G. Kennedy, et. al., Pump Two-Phase Performance Program, Volume 2: Steady-State Tests, NP-1556, Volume 2, Electric Power Research Institute, Palo Alto, CA, September, 1980.

10. P. S. Karmath and W. L. Smith, Two-Phase Performance of Scale Models of a Primary Coolant P.ump, EPRI NP-2578, Electric Power Research Institute, Palo Alto, CA, September, 1982.

11. J. S. Bollinger and T. J. Boucher, "Experiment Operating Specification for the Savannah River One-Fourth Linear Scale, One-Sixth Sector Tank/Muff/Pump (TMP) Separate Effects Tests (SET) Experiment Series," WSRC-TR-92-91, Revision 0, February 1992. 


\section{Appendix A}

General Guidance for SET 1/4 Linear Scale Bingham Pump Single-Phase and Two-Phase, Two-Component Complete Characterization Tests 
The performance of a pump can be characterized in several manners. As described in Stepanoff[7], complete pump characteristics can be presented by constant head and torque contours as a function of normalized speed and normalized flow (Figure A-1). As shown on the figure, compilation of pump characteristics in this manner allows for clear definition of operating conditions based on the zero head and zero torque lines as well as the direction of pump rotation and pump flow (the four axes). Using these lines, Stepanoff defined eight different zones of pump operation designated by the letters $A$ thru $H$ (Figure A-1). These eight zones may be described as follows:

- Zone A - Forward rotation, forward flow, normal pump (positive head and torque)

- Zone B - Forward rotation, reverse flow, energy dissipation (positive head and torque)

- Zone C - Reverse rotation, reverse flow, normal turbine (positive head and torque)

- Zone D - Reverse rotation, reverse flow, energy dissipation (positive head and negative torque)

- Zone E - Reverse rotation, forward flow, reverse rotation pump (positive head and negative torque)

- Zone F - Reverse rotation, forward flow, energy dissipation (negative head and negative torque)

- Zone G - Forward rotation, forward flow, reverse flow turbine (negative head and negative torque)

- Zone $\mathrm{H}$ - Forward rotation, forward flow, energy dissipation (negative head and positive torque)

Complete characterization of the $1 / 4$ linear scale Bingham pump will therefore require testing for all eight of these operating zones.

Another widely accepted method of presenting complete pump characterization curves is based upon pump affinity laws which collapse the constant normalized head $(h)$ and torque $(\beta)$ versus normalized speed $(\alpha)$ and normalized flow $(v)$ contours of Figure A-1 down to two sets of eight curves (one set for the head and one set for the torque). This is accomplished using homologous parameters which further normalize the head $(h)$ and torque $(\beta)$ by dividing by $\alpha^{2}$ or $v^{2}$ and plotting against $v / \alpha$ or $\alpha / v$. Figure A-2 shows the relationship between the Stepanoff curve (Figure A-1) zones and the homologous normalizing parameters for the pump characteristic curves while Figures A-3 and A-4 show the relationships between the Stepanoff curve (Figure A-1) zones and the pump homologous head and homologous torque parameters. As shown on the figures, the criteria for selection of the normalizing parameter ( $\alpha$ or $v)$ is as 


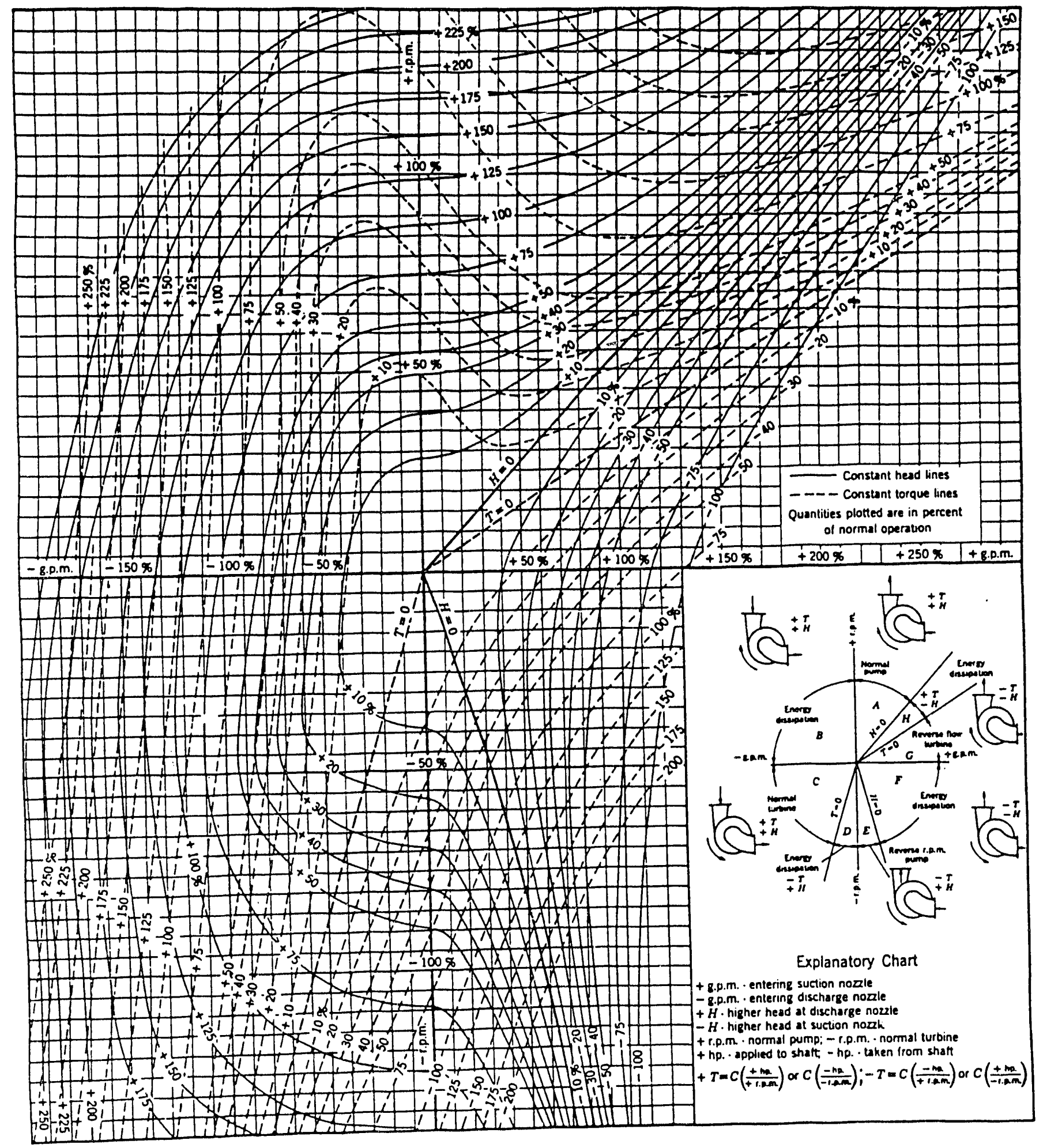

Figure A-1. Complete Pump Characteristics for a Typical Double-Suction Centrifugal Pump as Reported by A. J. Stepanoff. 


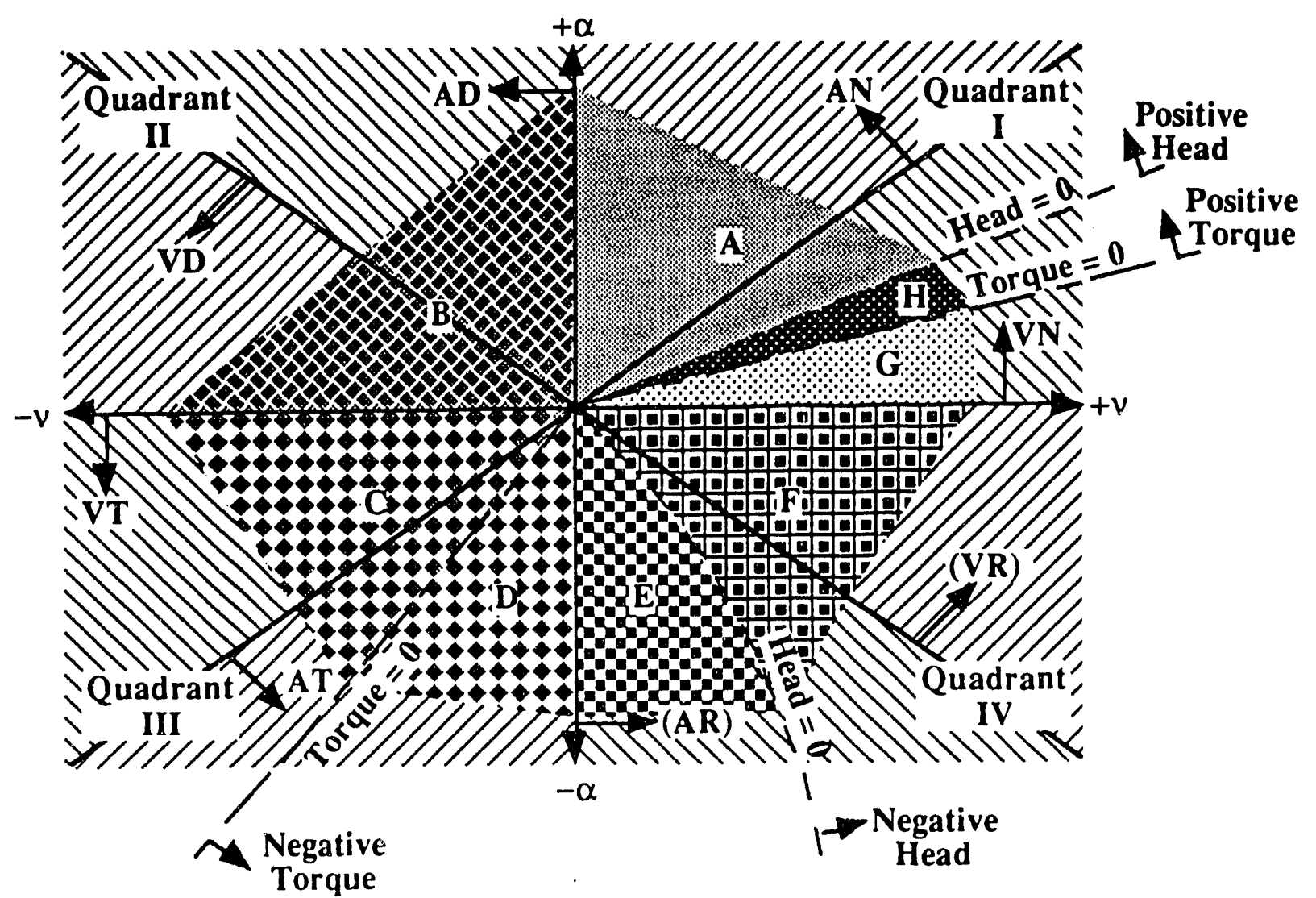

Key to labels HAN, HVN, BAN, BVN, etc. on homologous head and torque curves:

$\mathrm{H}->$ Head function (function with $\mathrm{h}$ in the numerator)

$B \rightarrow$ Hydraulic torque function (function with $\beta$ in the numerator)

A $\rightarrow$ Function with $\alpha$ in denominator

$\mathrm{V} \rightarrow>$ Function with $v$ in denominator, used when $|v / \alpha|>1$

$\mathrm{N} \rightarrow$ Normal pumping quadrant with forward flow and speed

D $\rightarrow$ Dissipation quadrant with reverse flow and forward speed

$\mathrm{T} \rightarrow>$ Normal turbine quadrant with reverse flow and speed

$\mathrm{R} \rightarrow \mathrm{Reverse}$ pumping quadrant with forward flow and reverse speed

where;

$\mathrm{h}=$ pump total dynamic head / rated pump total dynamic head $=\mathrm{TDH} / \mathrm{TDH} \mathrm{H}_{\text {Rated }}$

$\beta=$ pump hydraulic torque $/$ rated pump hydraulic torque $=T / T_{\text {Rated }}$

$\alpha=$ pump speed $/$ rated pump speed $=\omega / \omega_{\text {Rated }}$

$v=$ pump volumetric flow / rated pump volumetric flow $=Q / Q_{\text {Rated }}$

Examples:

HAN $->h / \alpha^{2}$ vs. $v / \alpha$ for forward flow and speed

BVD $\rightarrow \beta / v^{2}$ vs. $\alpha / v$ for reverse flow and forward speed

Figure A-2. Example Pump Characteristic Curves Showing Relationship Between Homologous Parameters and Stepanoff Curve (Figure A-1) Zones. 


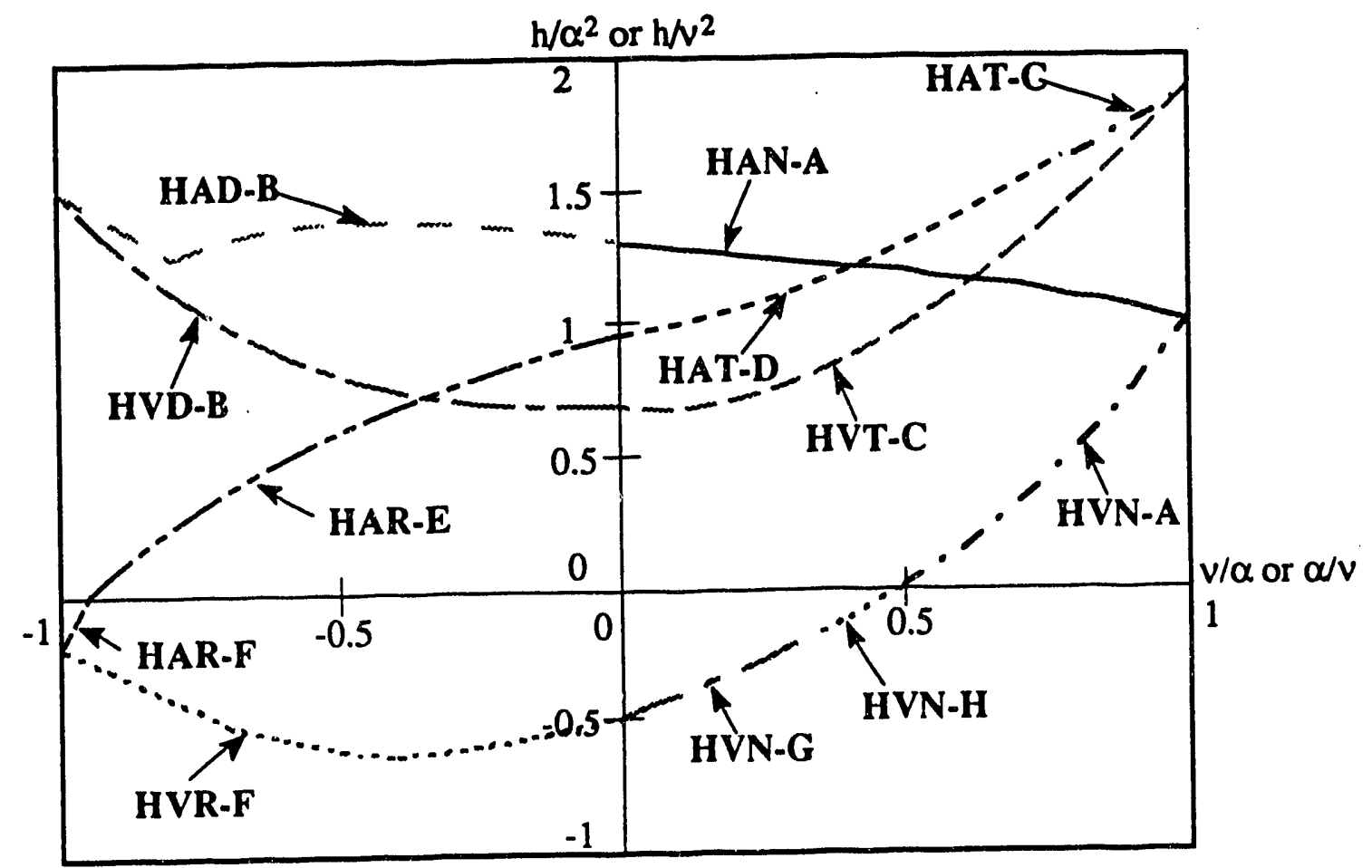

Key to labels HVN-A, HVN-H, HVN-G, etc. on homologous head curves:

The nomenclature for the homologous head regions on this figure is:

Homologous head parameter region-Stepanoff curve zone

For example, HVN-A signifies either a portion or all of the homologous head HVN curve and either a portion or all of the Stepanoff curve zone A.

Hence, the entire homologous head HVN curve is represented by the curves HVN-A, HVN-H and HVN-G while on the Stepanoff curve the homologous head HVN curve would represent a portion of zone $A$ and all of zones $\mathrm{H}$ and $\mathrm{G}$.

Figure A-3. Example Pump Homologous Head Curves Showing Relationship Between Homologous Head Parameters and Stepanoff Curve (Figure A-1) Zones. 


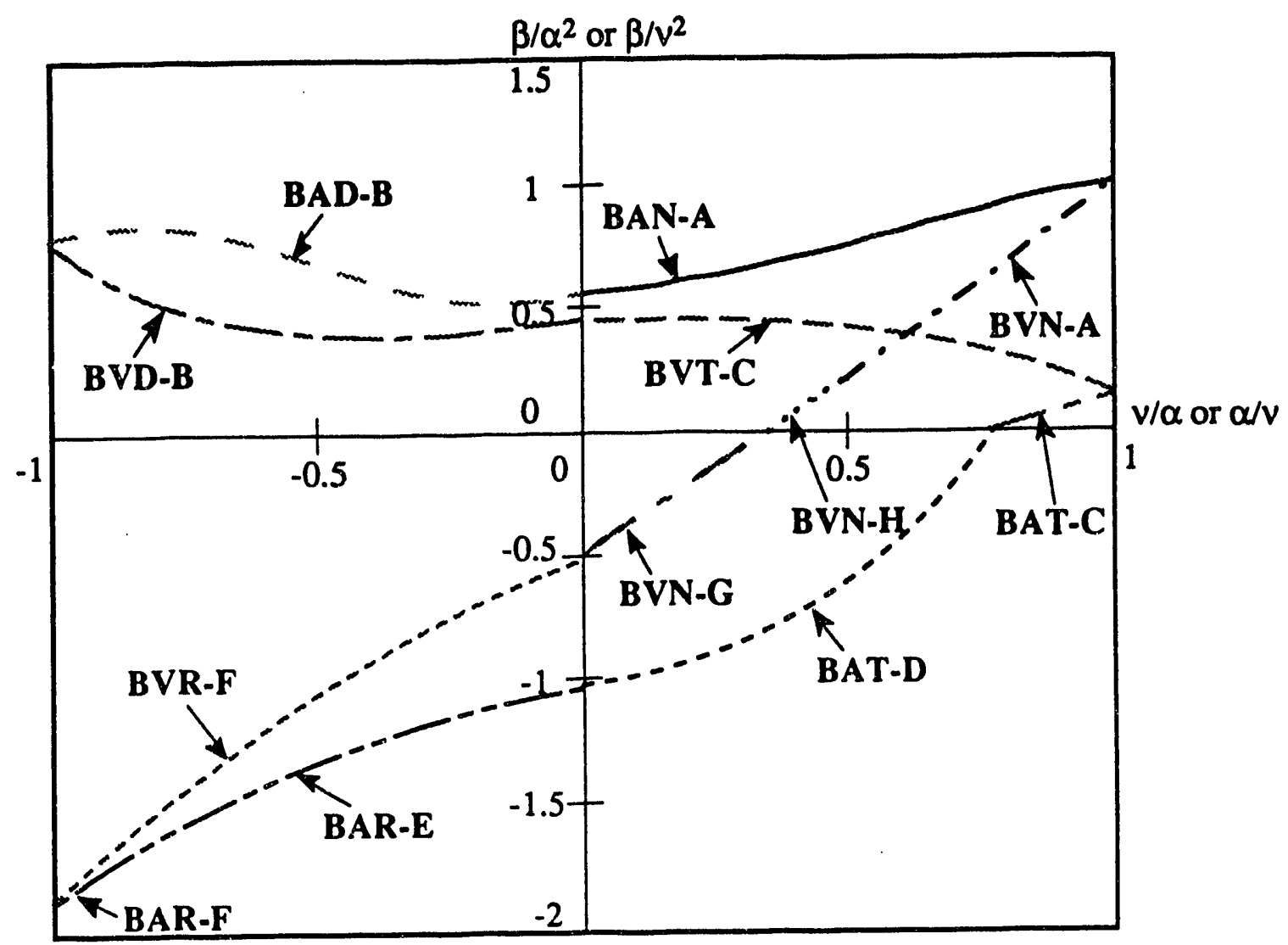

Key to labels BVN-A, BVN-H, BVN-G, etc. on homologous torque curves:

The nomenclature for the homologous torque regions on this figure is:

Homologous torque parameter region-Stepanoff curve zone

For example, BVN-A signifies either a portion or all of the homologous torque BVN curve and either a portion or all of the Stepanoff curve zone A.

Hence, the entire homologous torque BVN curve is represented by the curves BVN-A, BVN-H and BVN-G while on the Stepanoff curve the homologous torque BVN curve would represent a portion of zone $A$ and all of zones $\mathrm{H}$ and $\mathrm{G}$.

Figure A-4. Example Pump Homologous Torque Curves Showing Relationship Between Homologous Torque Parameters and Stepanoff Curve (Figure A-1) Zones. 
follows: for flow-to-speed ratio absolute values $(|v / \alpha|) \leq 1$, the speed ratio squared $\left(\alpha^{2}\right)$ is used as the normalizing parameter and the flow-to-speed ratio $(v / \alpha)$ is used as the abscissa; for flow-tospeed ratio absolute values $(|v / \alpha|)>1$, the flow ratio squared $\left(v^{2}\right)$ is used as the normalizing parameter and the speed-to-flow ratio $(\alpha / v)$ is used as the abscissa. Using this technique, the points on the Stepanoff curve (Figure A-1) which represent the intersection of the head ( $h$ ) and torque $(\beta)$ contours and a line of constant $v / \alpha$ or $\alpha / v$ become single points on the homologous head and torque curves, respectively. Thus, the homologous head and torque curves provide a much simpler method of representing the complete pump characteristics and predicting singlephase pump performance.

Further understanding of the relationship between the Stepanoff curve (Figure A-1) zones and the pump homologous curve regions may be gained by examining Table A-1 which provides an explanation of the Stepanoff curve zones in terms of the normalized pump homologous parameters. The overlap of the homologous curves and the Stepanoff curve zones shown in Figures A-2 thru A-4 are also evident in the table.

\begin{tabular}{|c|c|c|c|c|c|c|c|c|c|c|}
\hline $\begin{array}{l}\text { Fig. } \\
\text { A-1 } \\
\text { Zone }\end{array}$ & $\begin{array}{l}\text { Speed } \\
\text { Ratio } \\
\alpha\end{array}$ & $\begin{array}{c}\text { Flow } \\
\text { Ratio } \\
V\end{array}$ & $\begin{array}{c}\text { Head } \\
\text { Ratio } \\
\text { h }\end{array}$ & $\begin{array}{c}\text { Torque } \\
\text { Ratio } \\
\beta\end{array}$ & $\begin{array}{l}\alpha / v \\
\text { or } \\
v / \alpha\end{array}$ & $\begin{array}{c}h / \alpha^{2} \\
\text { or } \\
h / v^{2}\end{array}$ & $\begin{array}{c}\beta / \alpha^{2} \\
\text { or } \\
\beta / v^{2}\end{array}$ & $\begin{array}{l}\text { Charac. } \\
\text { Curves } \\
\text { ( } \alpha \text { vs. v) } \\
\text { Quadrant }\end{array}$ & $\begin{array}{l}\text { Homol. } \\
\text { Head } \\
\text { Curve } \\
\text { Regions }\end{array}$ & $\begin{array}{c}\text { Homol. } \\
\text { Torque } \\
\text { Curve } \\
\text { Regions }\end{array}$ \\
\hline $\bar{A}$ & $t$ & + & t & + & + & T & + & 1 & $\begin{array}{l}\text { HAN } \\
\text { HVN }\end{array}$ & $\begin{array}{l}\text { BAN } \\
\text { BVN }\end{array}$ \\
\hline $\bar{B}$ & $t$ & - & $t$ & T & - & $t$ & + & II & $\begin{array}{l}\text { HAD } \\
\text { HVD }\end{array}$ & $\begin{array}{l}\text { BAD } \\
\text { BVD }\end{array}$ \\
\hline $\bar{C}$ & - & - & $t$ & + & + & $t$ & + & III & $\begin{array}{l}\text { HVT } \\
\text { HAT }\end{array}$ & $\begin{array}{l}\text { BVT } \\
\text { BAT }\end{array}$ \\
\hline $\bar{D}$ & - & - & + & - & $t$ & $t$ & - & III & HAT & $\overline{B A T}$ \\
\hline$E$ & - & $t$ & $t$ & $\overline{-}$ & - & $t$ & - & IV & HAR & $\overline{\mathrm{BAR}}$ \\
\hline $\bar{F}$ & - & + & - & - & $=$ & - & - & IV & $\begin{array}{l}\text { HAR } \\
\text { HVR }\end{array}$ & $\begin{array}{l}\text { BAR } \\
\text { BVR }\end{array}$ \\
\hline$G$ & $t$ & + & - & - & + & - & - & I & HVN & $\mathrm{BVN}$ \\
\hline$\overline{\mathrm{H}}$ & + & $t$ & - & + & + & - & + & $\mathrm{I}$ & HVN & BVN \\
\hline
\end{tabular}

Previous works on two-phase pump characterization [8 thru 11] have presented and/or correlated results using the pump homologous head and torque curves. The above discussion has shown the direct relationship between these homologous curves and the Stepanoff curves for single-phase conditions. However, for two-phase conditions other variables such as pump void fraction or volumetric flow quality may prevent the Stepanoff curves from collapsing to the homologous head and torque curves as neatly as for single-phase conditions. Hence, it would 
seem prudent to outline a testing scheme which establishes the two-phase head and torque conditions on pump characteristic curves (similar to the Stepanoff curve) with the emphasis on constant flow-to-speed ratio $(v / \alpha)$ or constant speed-to-flow ratio $(\alpha / v)$ lines. This should allow for evaluation of the appropriateness of collapsing the two-phase curves in a manner similar to the single-phase curves.

The objective for the Phase III pump characterization tests is to provide complete characterization of the 1/4 linear scale Bingham pump for two-phase, two-component conditions in all four pump characteristic curve quadrants. The existing data base on pump two-phase performance is not adequate to allow for apriori determination of sensitivities to the various boundary conditions (flow-to-speed or speed-to-flow ratios, pump speeds, pump inlet pressures, and void fractions or volumetric flow qualities). Hence, the skeleton test matrix shown in Figure A-5 has been developed for these tests. It is intended to provide general guidance on the range of flow-to-speed or speed-to-flow ratios and pump speeds to be examined for the four pump characteristic curve quadrants.

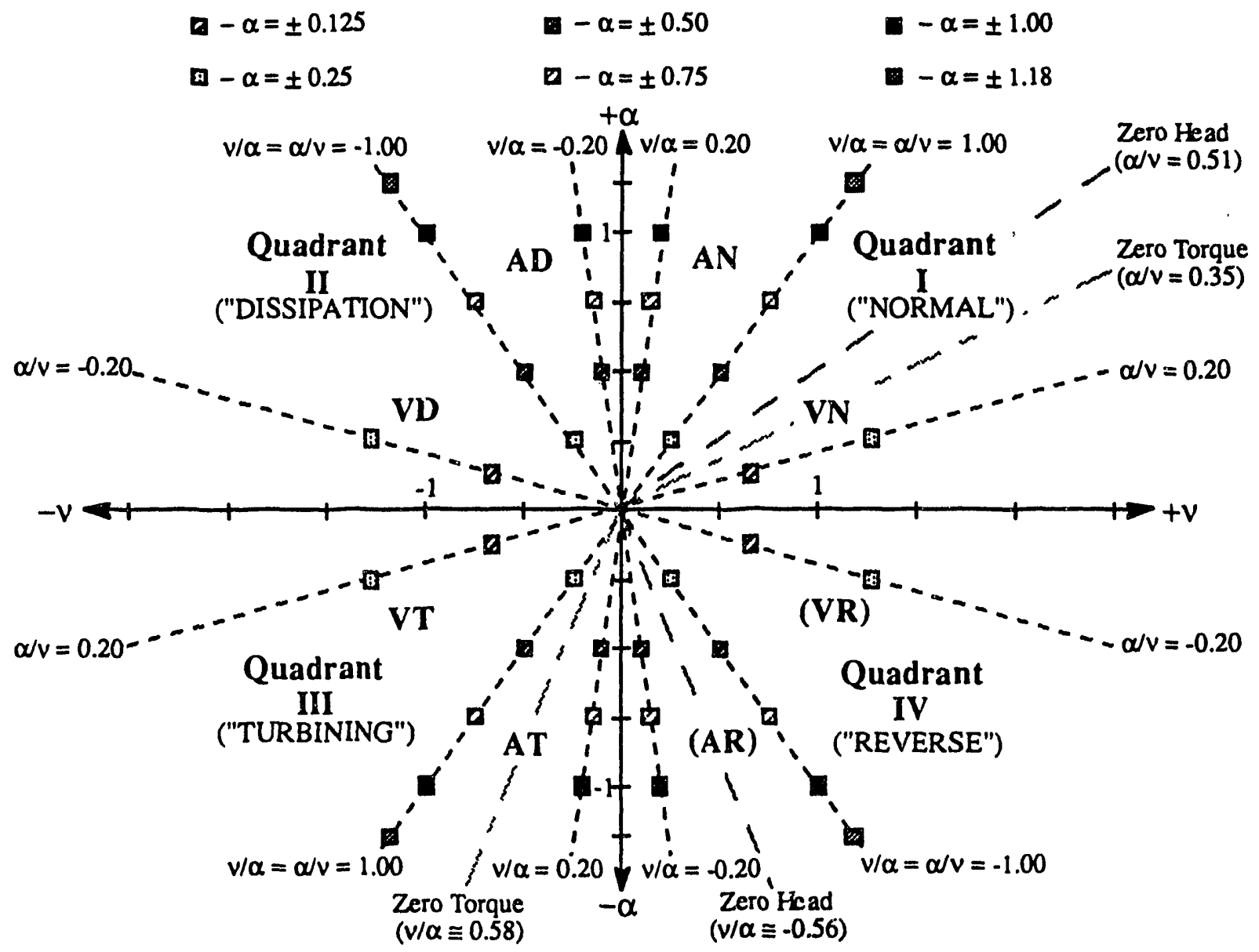

Figure A-5. Skeleton Test Matrix for the Four Pump Characteristic Curve Quadrants. 
The points identified in Figure A-5 provide a skeleton test matrix which will be filled in based upon the results of the experiments. As testing progresses, the sensitivities to the various boundary conditions will be examined and further test points will be specified (within the limitations of the test rig and support equipment capabilities) which provide for adequate characterization of the complete pump curves.

At each point a range of volumetric flow qualities between 0 and $90 \%$ (within the limits of the support equipment capabilities) will be investigated. Since the greatest sensitivity to volumetric flow quality is anticipated to occur at lower flow qualities, a smaller increment (2.5\%) will be used between 0 and $20 \%$. A volumetric flow quality of $25 \%$ will also be investigated and for volumetric flow qualities between 30 and $90 \%$, a larger increment (10\%) will be used. This forms the general guidance for the volumetric flow qualities to be investigated. However, for all regions of significant sensitivity such as the steep pump head degradation region in the normal pump operation quadrant, additional volumetric flow qualities will be investigated as necessary.

For certain points a range of pump inlet pressures between 125 and $400 \mathrm{kPa}(18.1$ and 58.0 psia) will be examined. Since the major concern for pump inlet pressure effects relates to air compressibility effects, more emphasis will be placed upon characterizing the pressure sensitivity effects in the normal pump quadrant than the other quadrants. Further, the initial testing will focus on pressure sensitivity effects closer to the pump normal operating conditions $(v / \alpha=1)$. Pressure sensitivities at other first quadrant points will be investigated until adequately characterized. For the other pump homologous quadrants a similar approach will be taken. However, it is anticipated that pressure sensitivity effects will either be less significant or unimportant for the other three quadrants and will therefore require fewer multiple pressure test points.

The following general notes are applicable for all of these test points:

For all forward flow tests, the tank bypass, short discharge geometry (Mod-TBSD, Figures 2 and 5) will be used.

For all reverse flow tests, the Bingham pump reverse flow geometry (Mod-BPRF, Figures 3 and 6) will be used.

For all reverse pump rotation tests, the pump motor wiring will be re-configured ( 2 of the 3 phases reversed) to drive the pump in reverse rotation.

For all turbining operation tests, the pump motor will be replaced by a pump speed control device. 
For all locked rotor tests, a lever arm will be attached to the shaft to prevent rotation of the pump rotor. The position of the rotor shaft will also be noted.

For all tests data are to be sampled for a minimum of $1 / 2$ minute or one complete cycle of oscillatory behavior.

For all tests, the pump inlet conditions should be set to achieve the desired pressure, total volumetric flow rate and volumetric flow quality after the pump speed is set.

The objectives for all of these tests is to provide complete characterization of the 1/4 linear scale Bingham pump for single-phase and two-phase, two-component conditions for all four pump homologous curve quadrants.

An additional concern for pump response sensitivity relates to effects of pump discharge geometries and methods of air introduction. Hence, ten integral system tests performed as part of Phase II testing were selected to be repeated in the Phase III tests. The objectives of these tests (Table A-2) are to verify that two-phase, air-water pump performance with air injected directly into the pump suction pipe and not quite prototypic pump suction and discharge geometries is the same as pump performance with air introduced via the moderator tank assemblies or ingestion at the tank exit muff and prototypic suction and discharge geometries. The latter of the two being more prototypic of actual conditions in a Savannah River Site production reactor. 


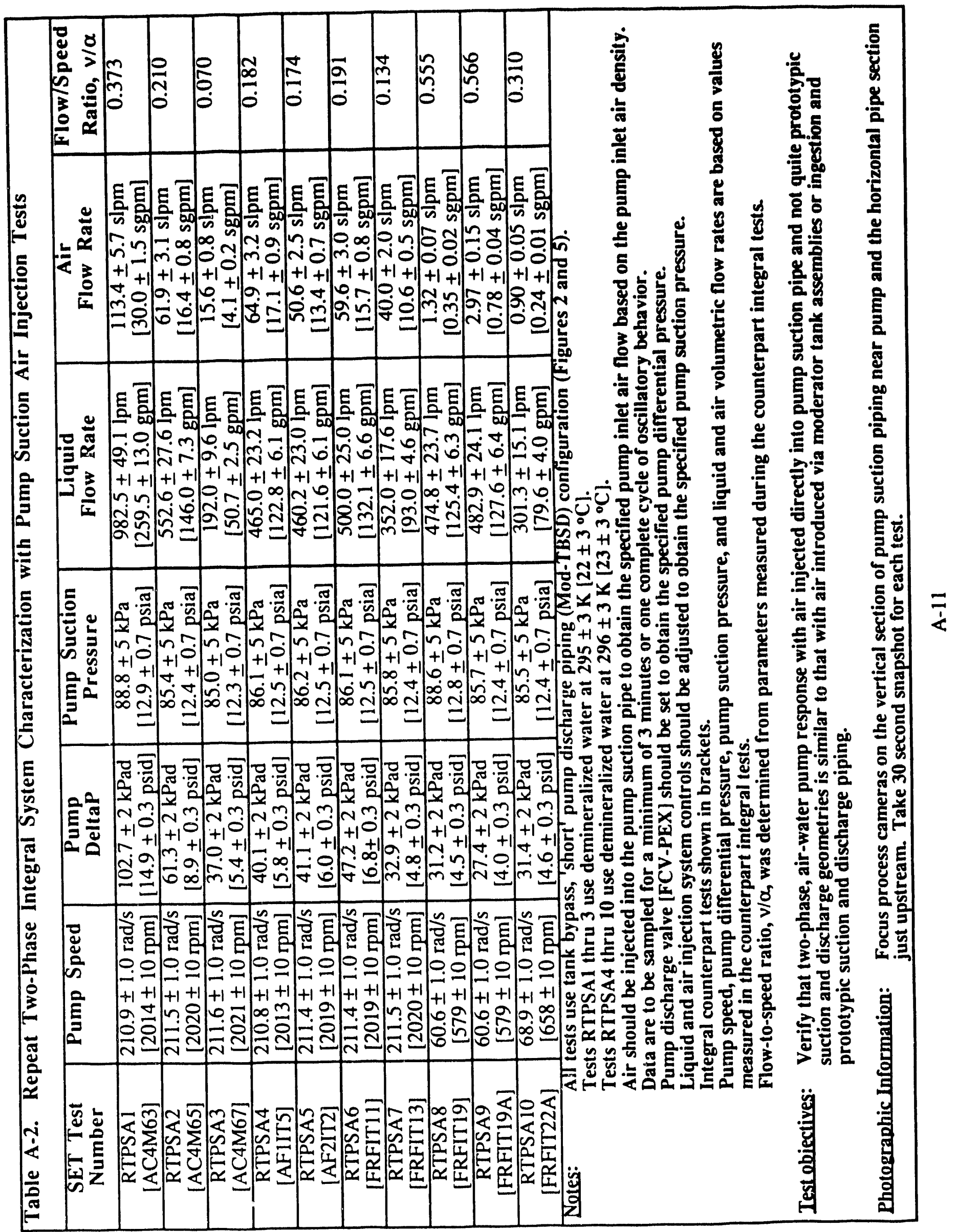


Appendix B

Test Matrix Tables for SET Phase III Tests

From NES-CDG-920181

B-1 


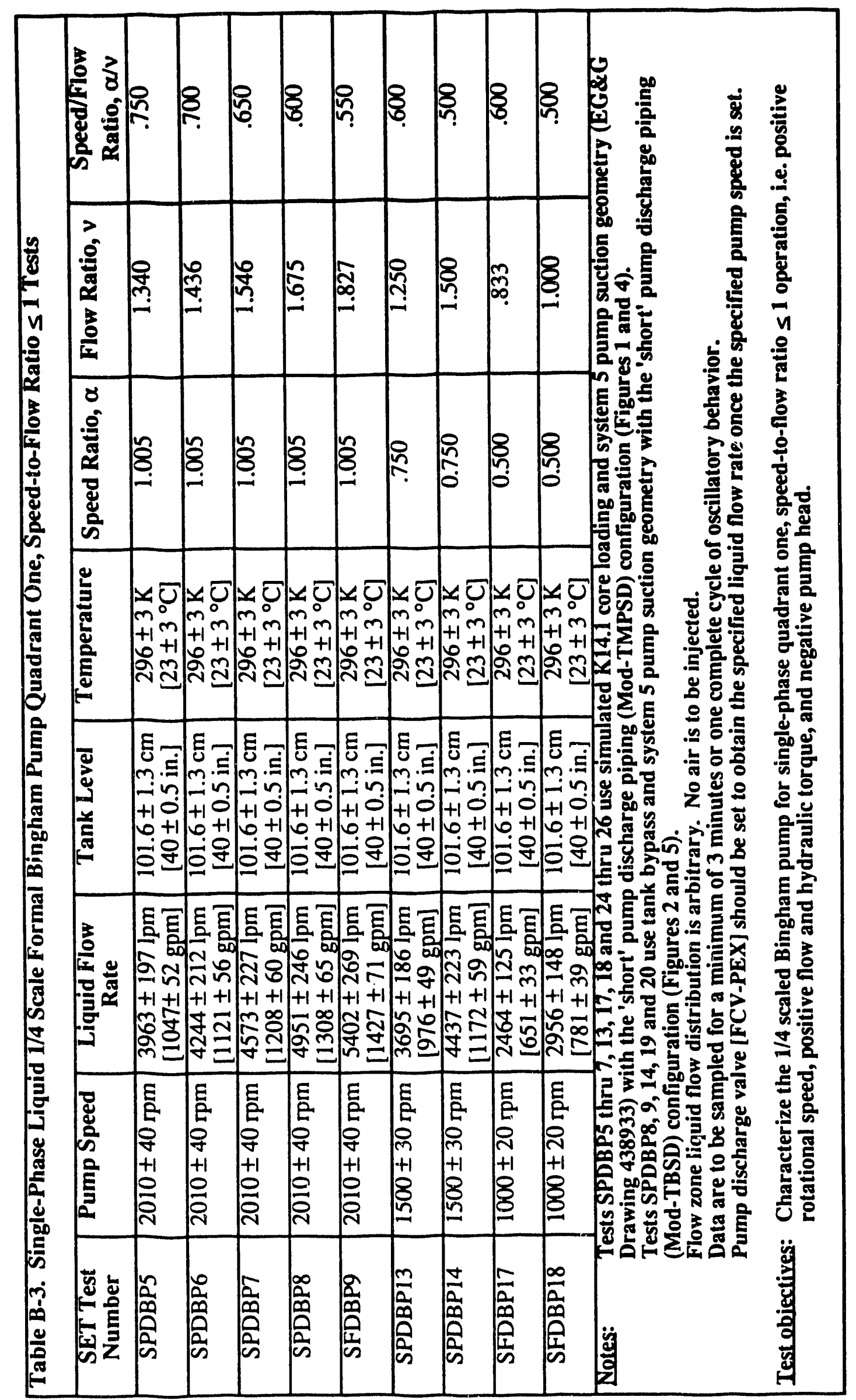




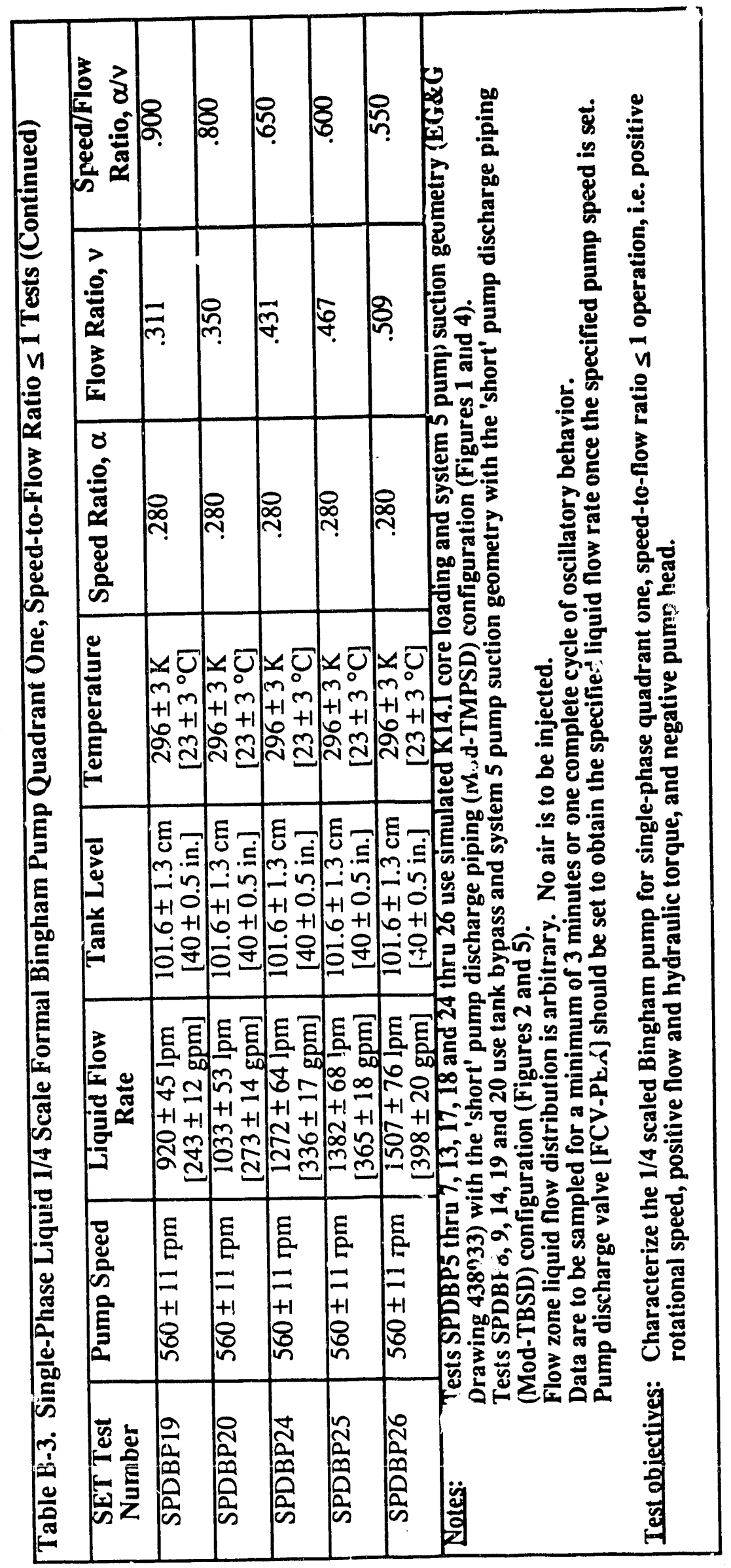

$\cong$ 


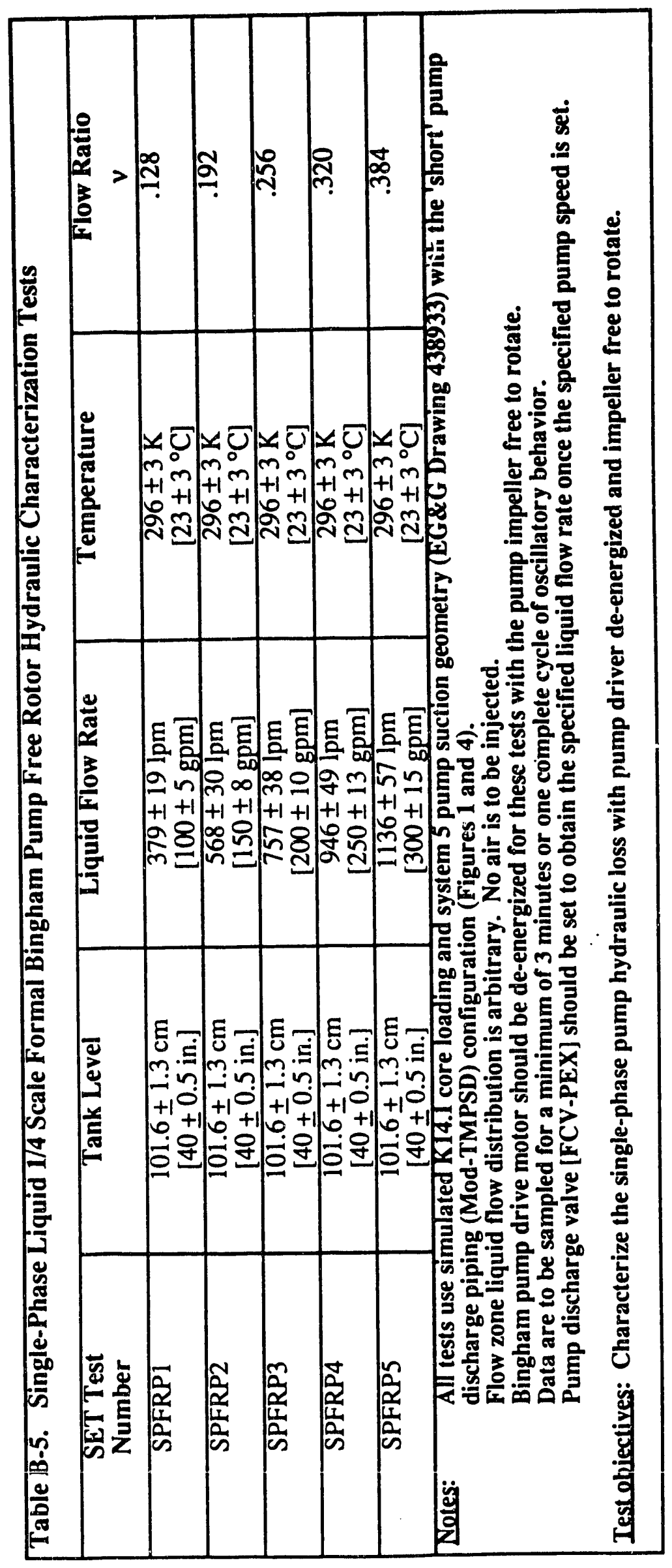


Appendix C

Test Matrix Tables for SET Phase III Tests

From NES-CDG-920241, Revision 1

C-1 


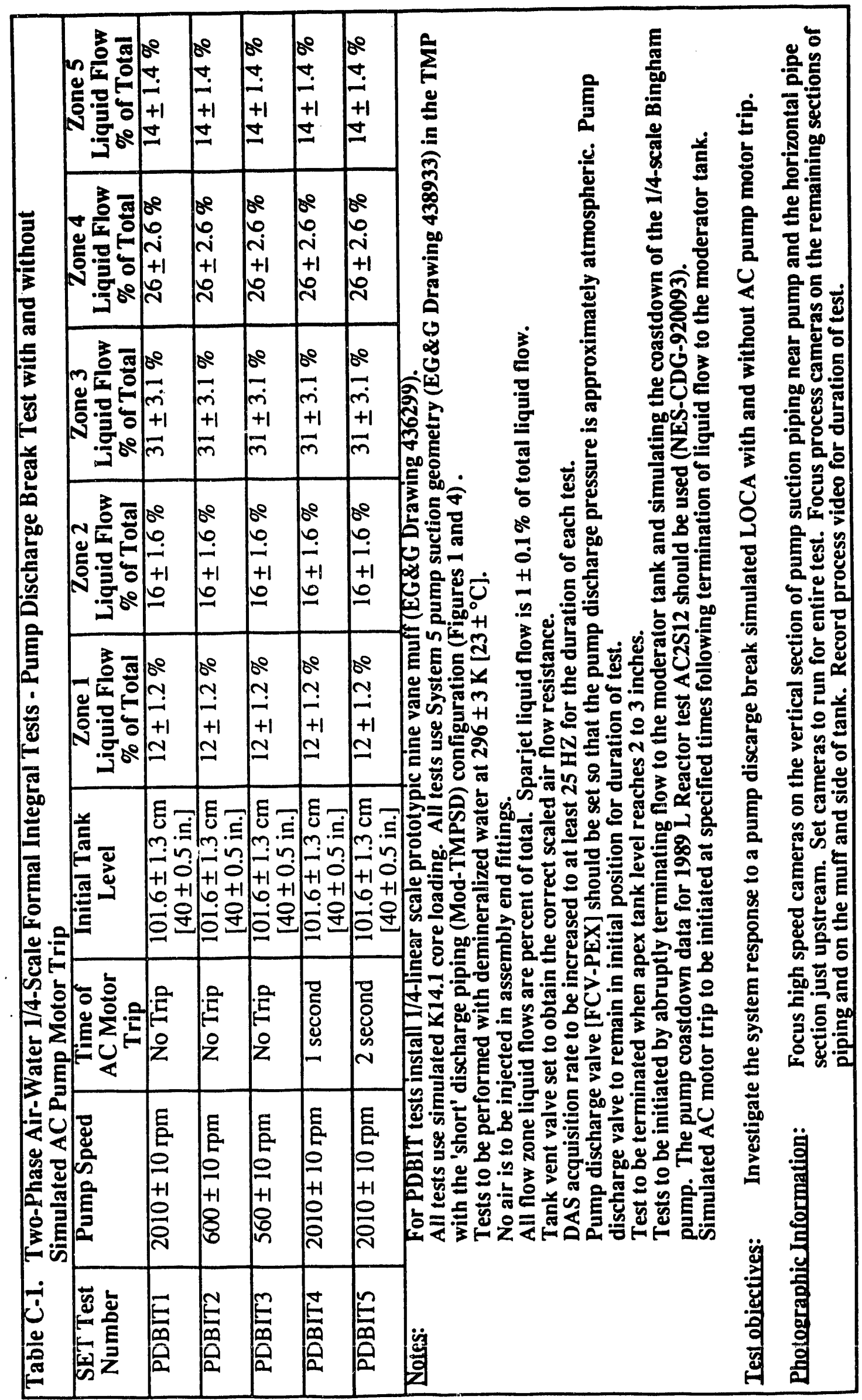




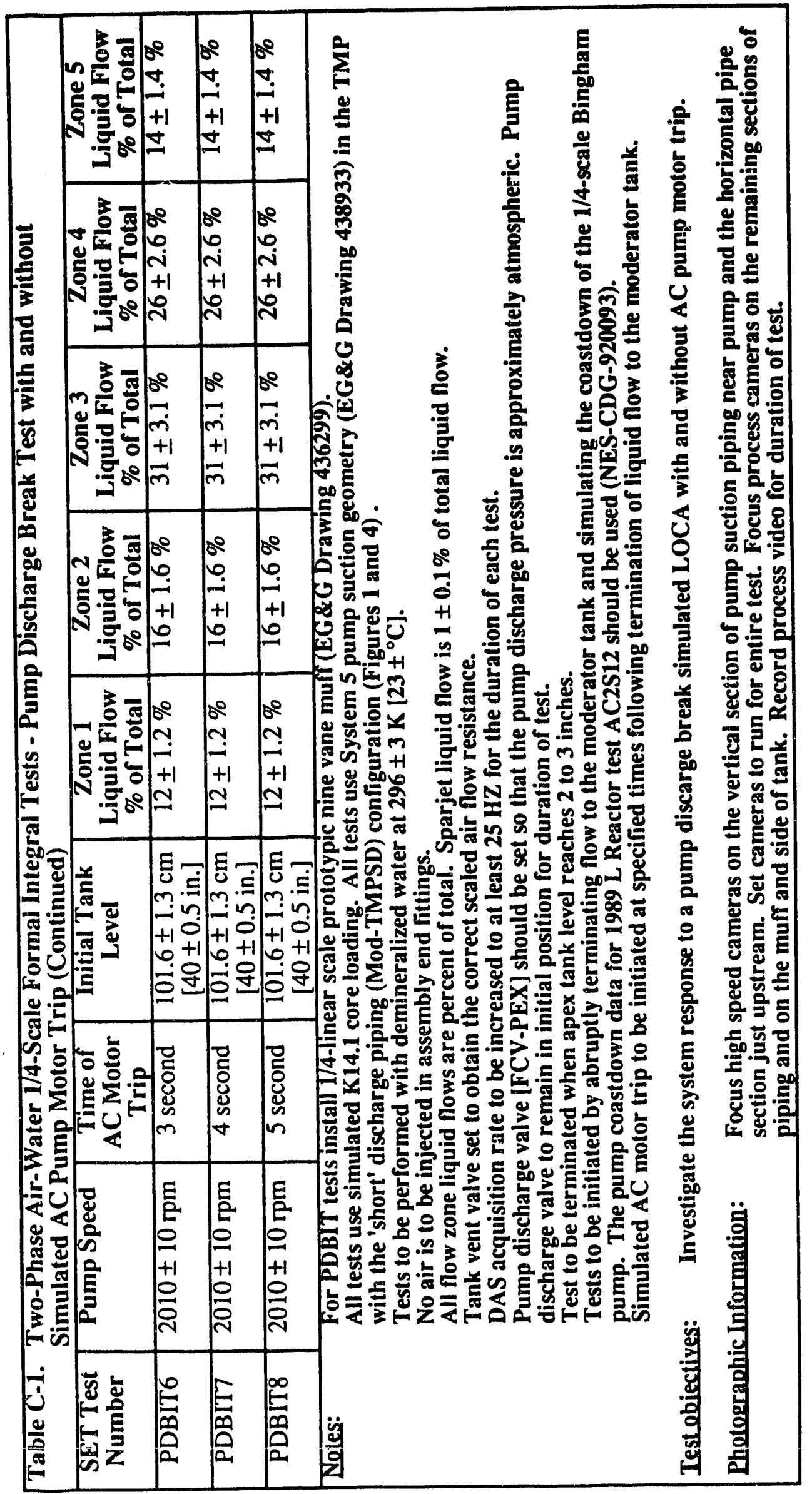




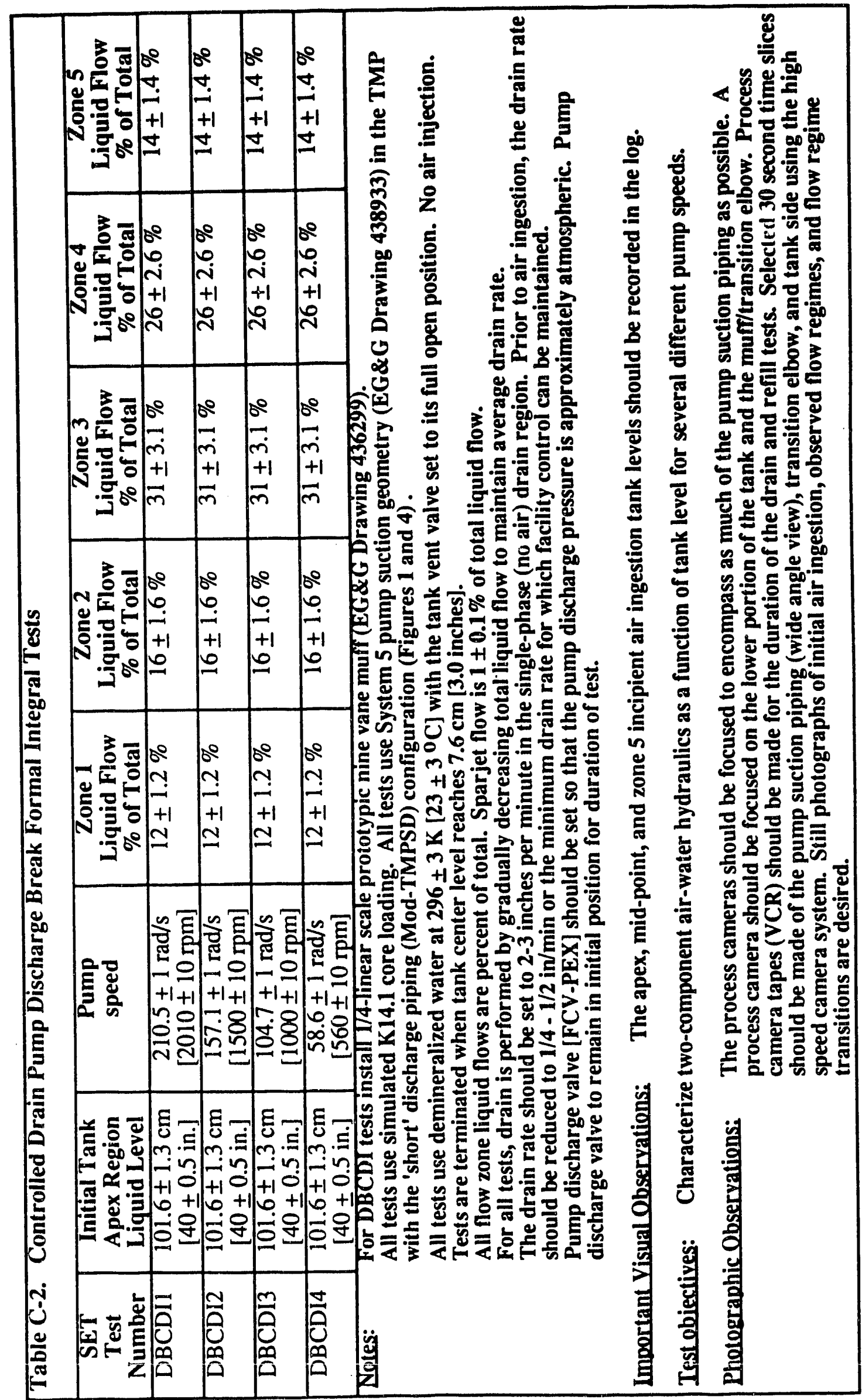




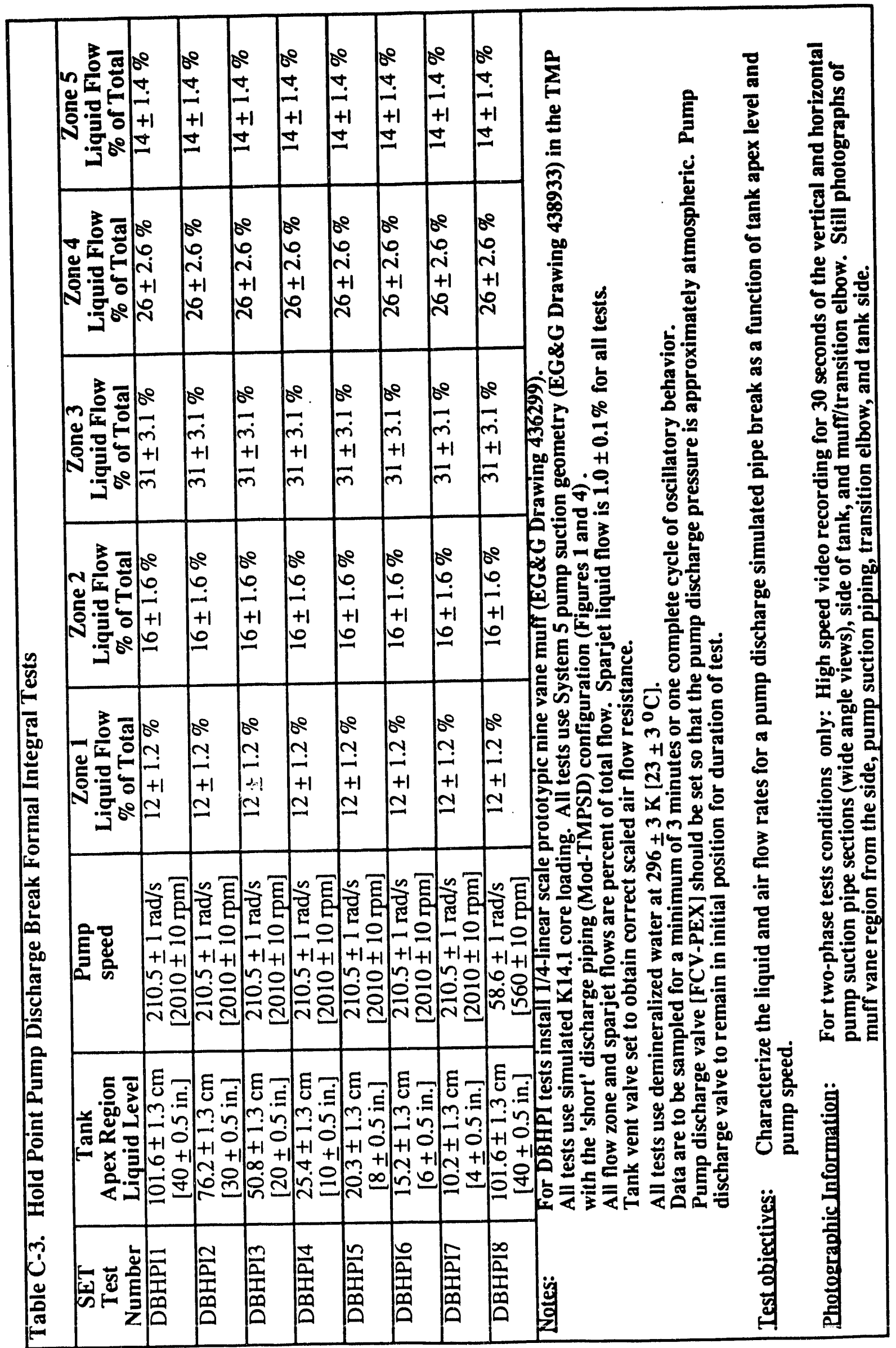




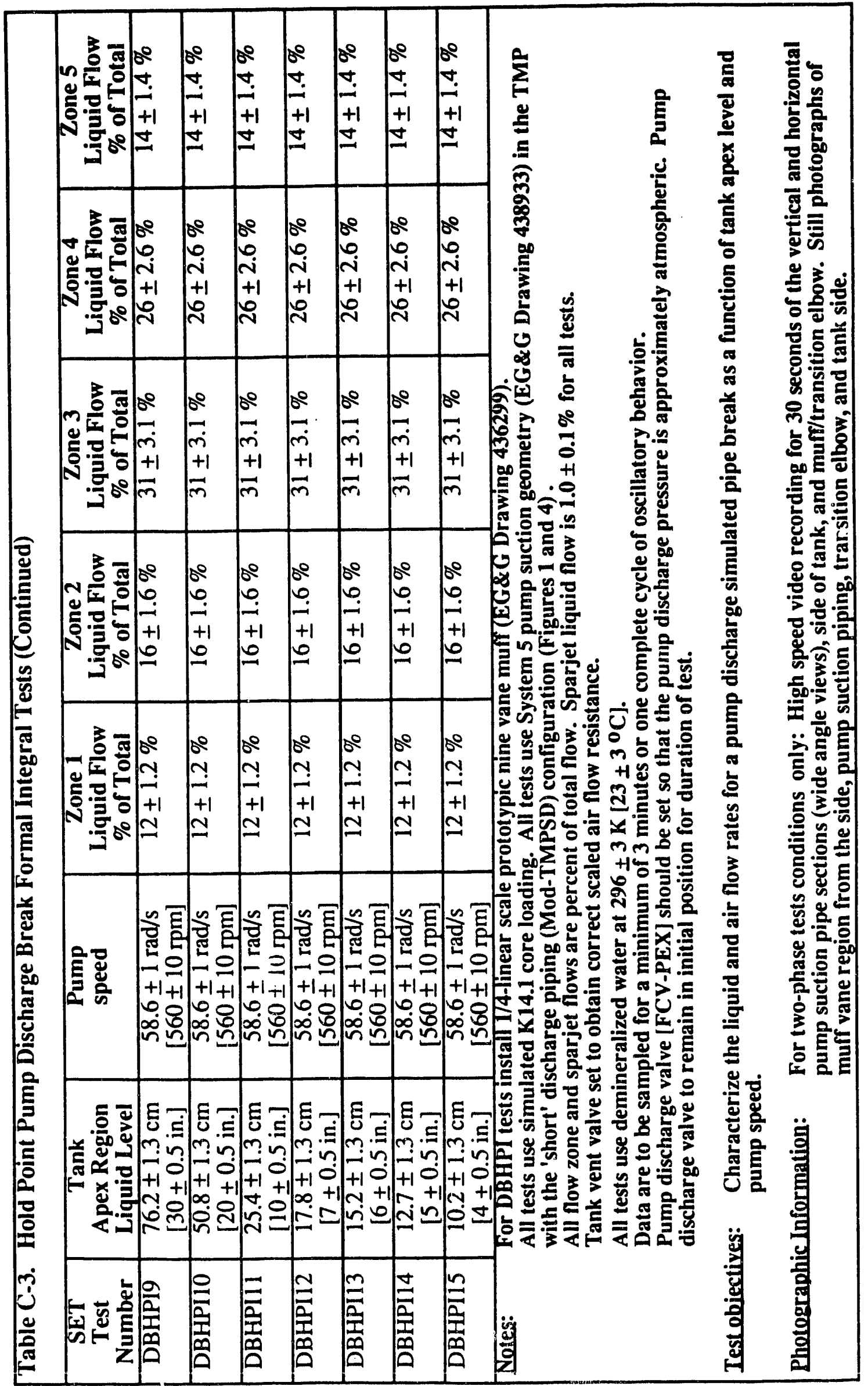




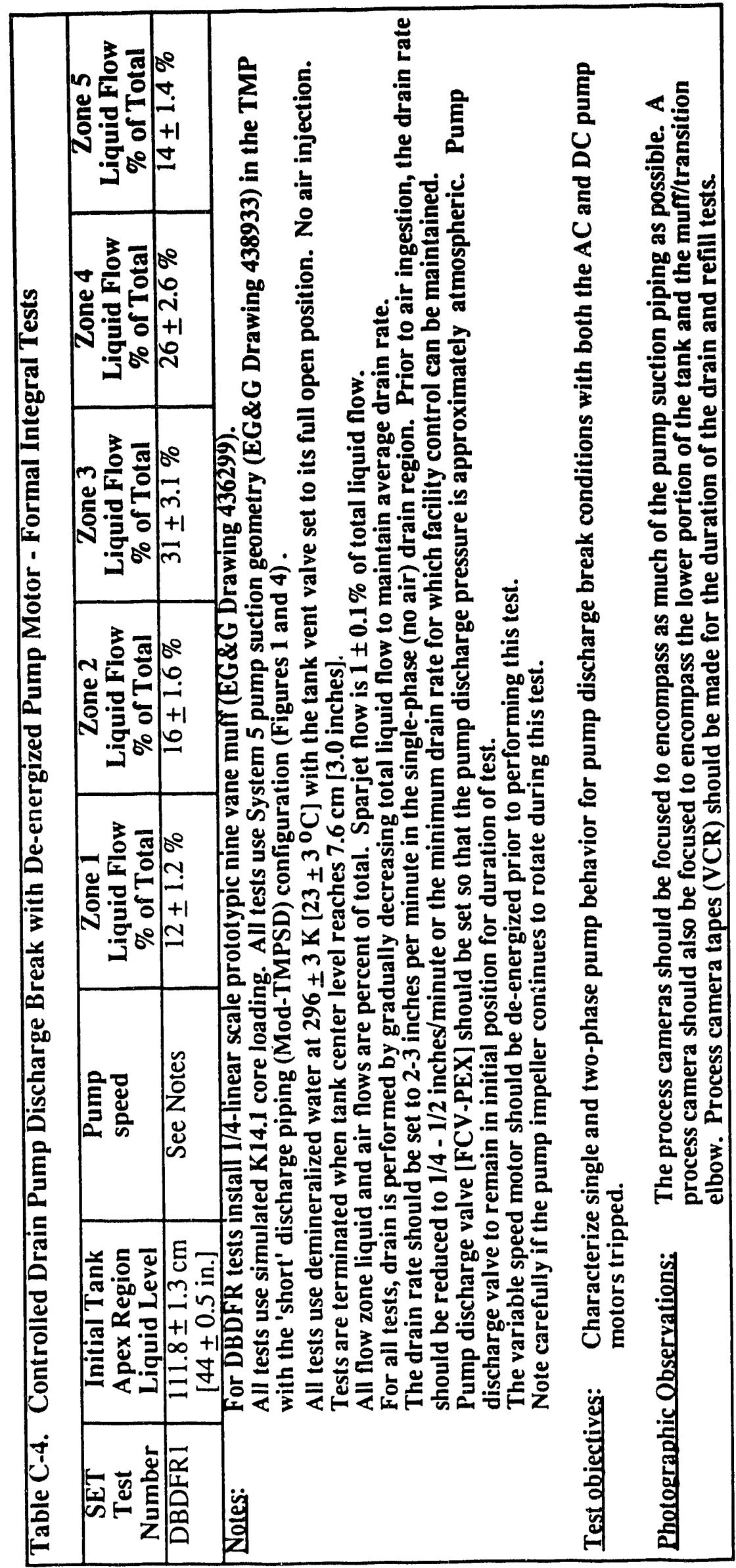




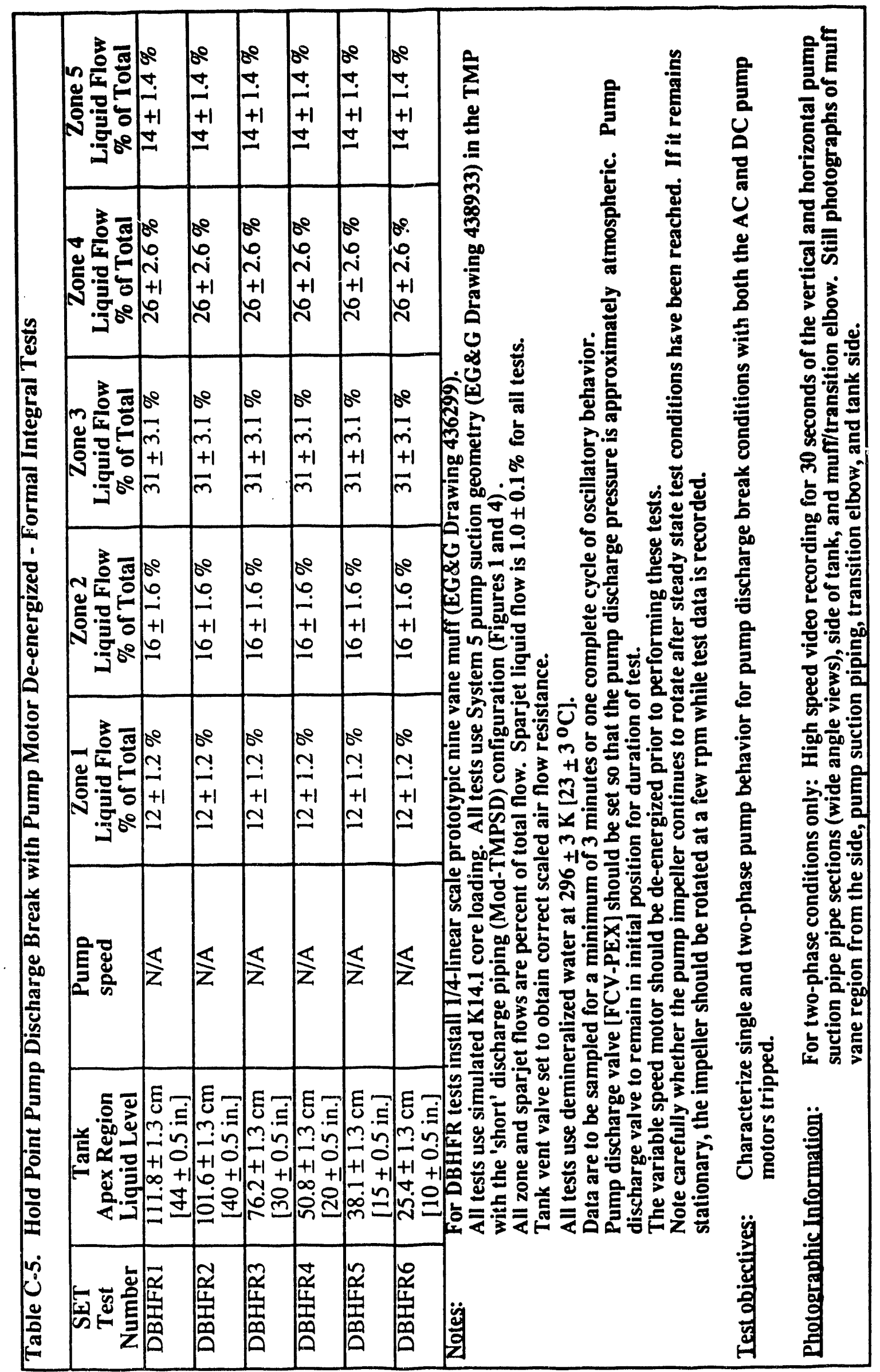




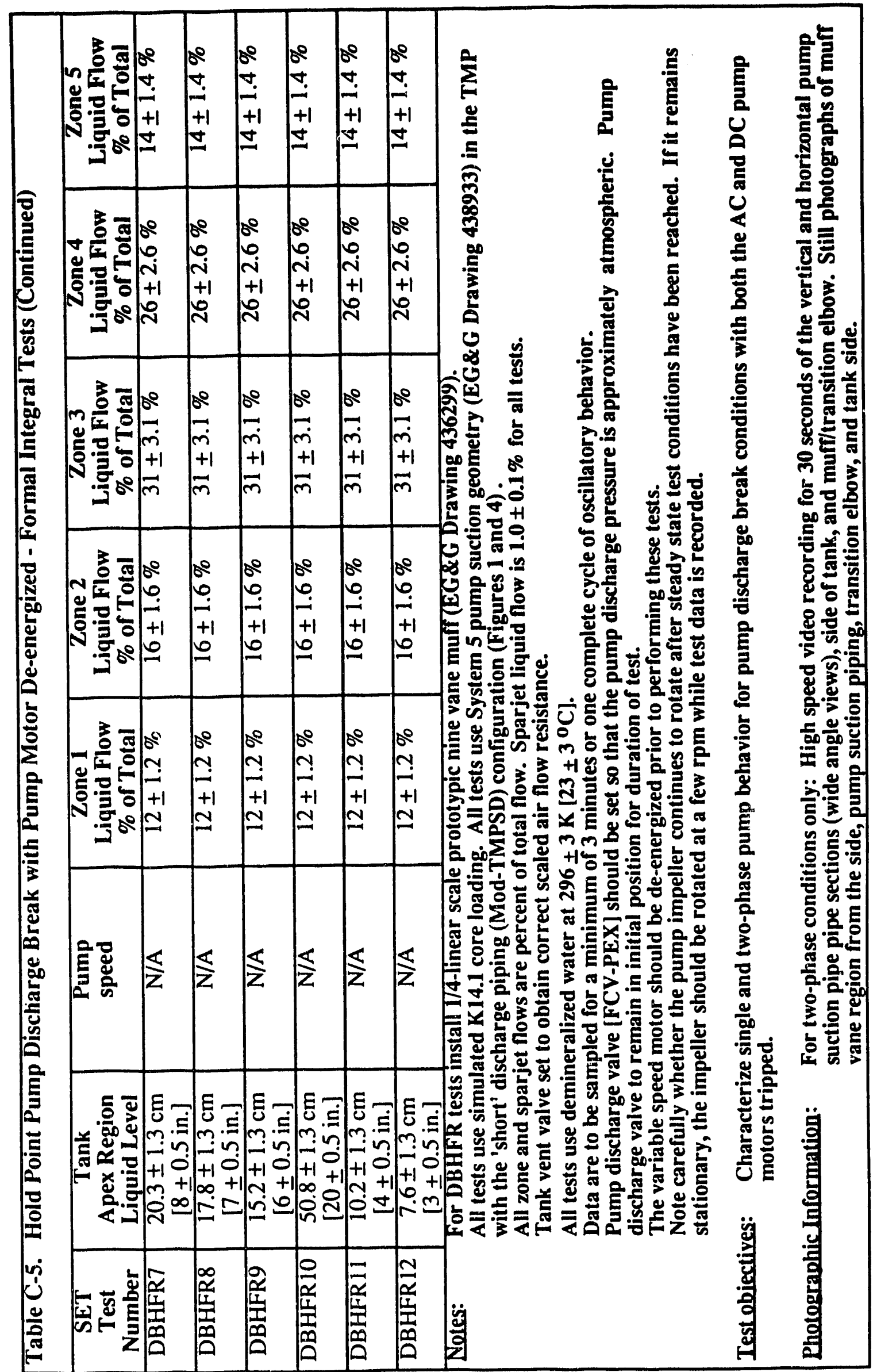



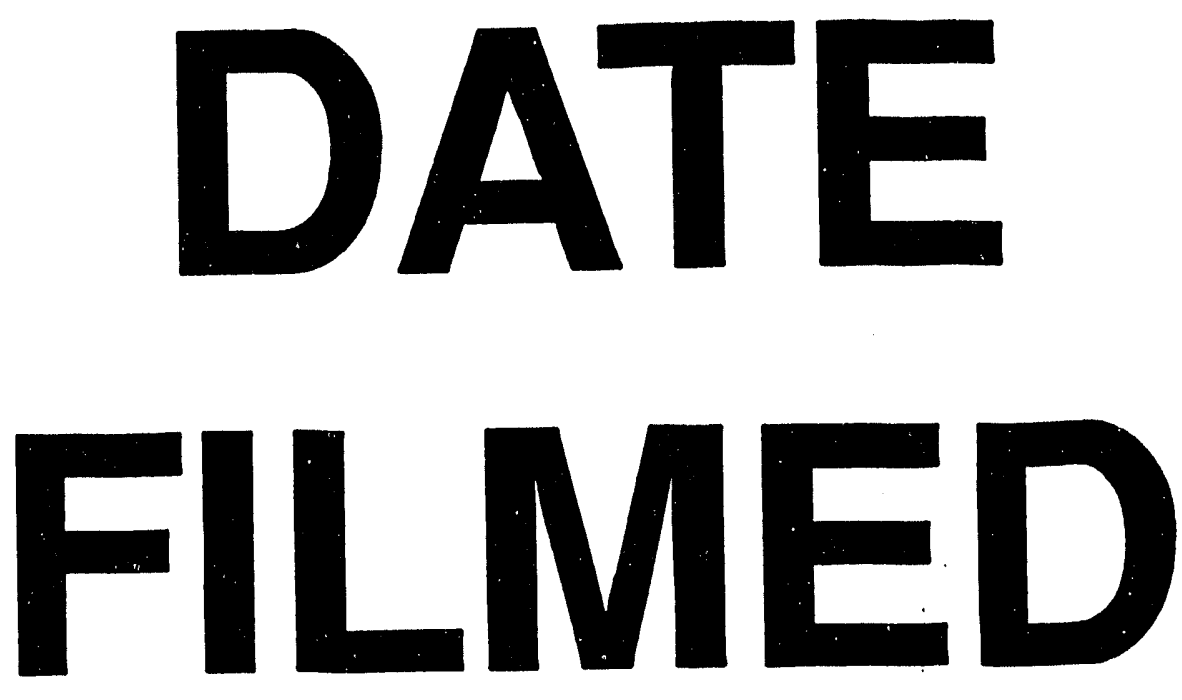

$9 / 20 / 93$
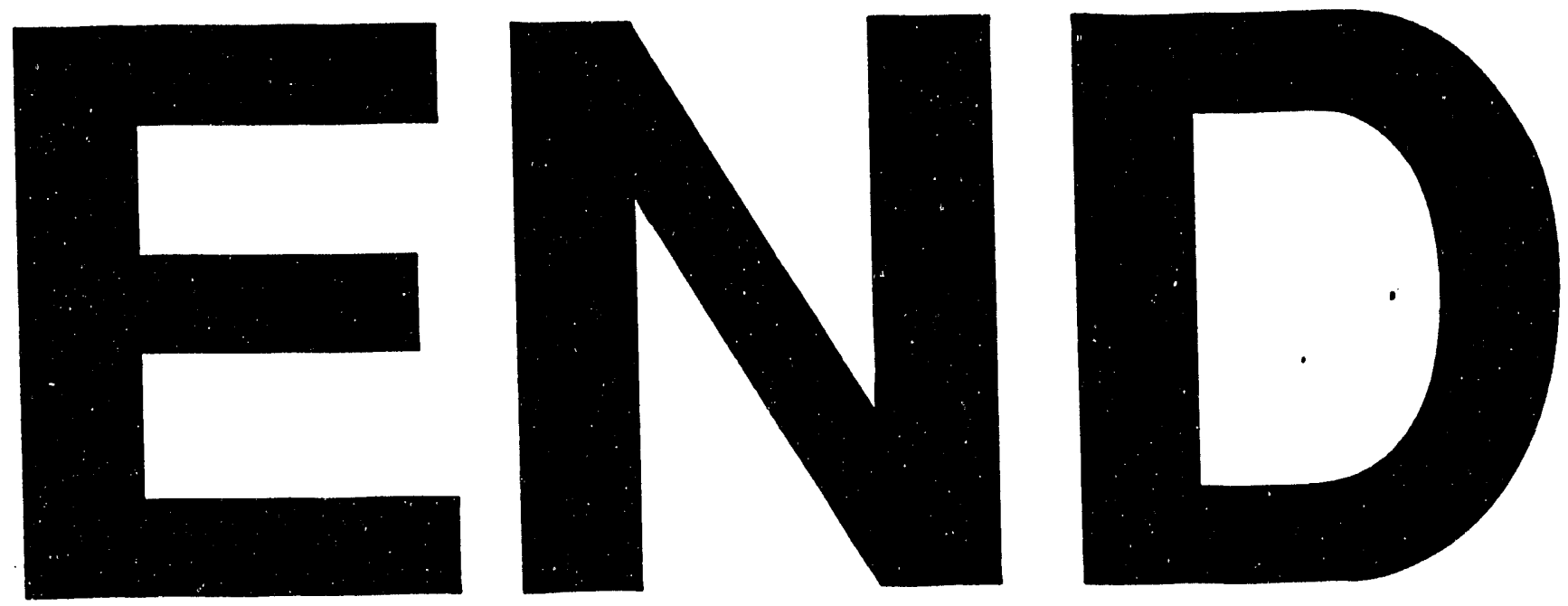
